\title{
Um Sistema de Injeção de Defeitos de Software Baseado em Operadores de Mutaçẳo
}

\author{
Elisa Yumi Nakagawa \\ Orientador: Prof. Dr. José Carlos Maldonado
}

Dissertação apresentada ao Instituto de Ciências Matemáticas e de Computação - Universidade de São Paulo, como parte dos requisitos para a obtenção do título de Mestre em Ciências - Área: Ciências de Computação e Matemática Computacional.

USP - São Carlos

Maio/1998 


\section{Agradecimentos}

Agradeço ao meu orientador, Prof. Dr. José Carlos Maldonado pelos ensinamentos e principalmente pela amizade durante o desenvolvimento deste trabalho.

Ao Fabrício e a Camilinha pelo amor e paciência.

À FAPESP pelo suporte financeiro. 


\section{Resumo}

A Injeção de Defeitos é uma técnica que tem sido empregada amplamente para a construção de sistemas que precisam ser altamente confiáveis. Dentre as atividades de Injeção de Defeitos, existem estudos que englobam a injeção de defeitos de hardware e de software. Observa-se que existem poucos trabalhos relacionados à injeção de defeitos de software na literatura, assim como modelos de defeitos e métodos de injeção relacionados. Desse modo, o objetivo deste trabalho é estudar modelos de defeitos de software e investigar métodos de injeção, baseado nos conceitos e princípios oriundos do critério Análise de Mutantes.

Dada a crescente complexidade dos sistemas computacionais, o projeto e a implementação de uma ferramenta de suporte à atividade de injeção tornam-se necessários.

Dessa forma, neste trabalho é apresentada uma ferramenta de injeção de defeitos de software, denominada ITool, baseada em um esquema de injeção de defeitos. Esse esquema caracteriza o mapeamento de uma taxonomia de defeitos de software (Taxonomia de DeMillo) para os operadores de mutação do critério de teste Análise de Mutantes para a linguagem $C$.

Para ilustrar a relevância e a factibilidade das idéias exploradas neste trabalho, conduziu-se um experimento piloto utilizando-se o programa Space, um sistema real desenvolvido pela ESA (European Space Agency). 


\section{Abstract}

Fault Injection is a technique that has been widely used in the development of computer systems that need to be very reliable. In this area, there are studies related with hardware and software fault injection. It should be pointed out that there are few works related to software fault injection in the literature as well as software fault model and injection methods. The objective of this work is to study software fault models and investigate injection methods based on concepts and principles taken from Mutation Analysis Criterion.

Considering the increasing complexity of computer systems, the project and implementation of supporting tools to fault injection become necessary.

In this perspective, in this work a software fault injection tool, named ITool, is presented. This tool is based on a fault injection scheme that defines the mapping of a software fault taxonomy (DeMillo's Taxonomy) to the mutation operators of the Mutation Analysis criterion for $\mathrm{C}$ language.

To illustrate the relevance and feasibility of the ideas presented in this work, a pilot experience was carried out using the Space program, a real system developed by ESA (European Space Agency). 


\section{Sumário}

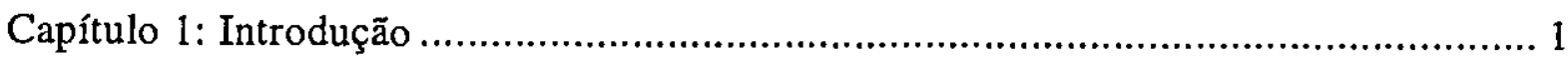

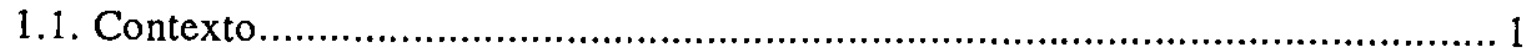

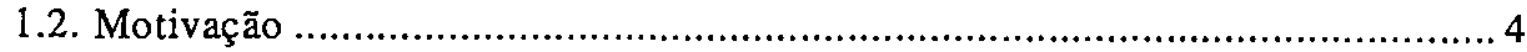

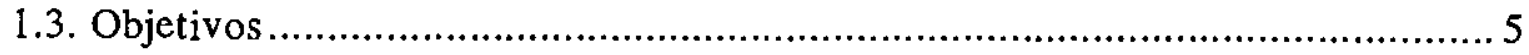

1.4. Organização do Trabalho .......................................................................... 5

Capítulo 2: Injeção de Defeitos ............................................................................. 7

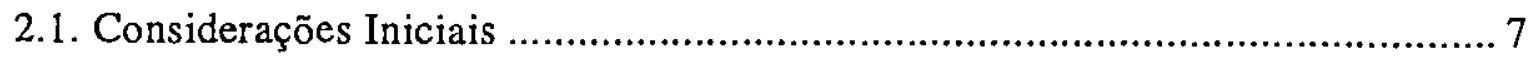

2.2. Modelos de Defeitos e Métodos de Injeção................................................ 12

2.3. Automatização da Atividade de Injeção de Defeitos .................................... 16

2.3.1. Ferramenta FINE ..................................................................... 17

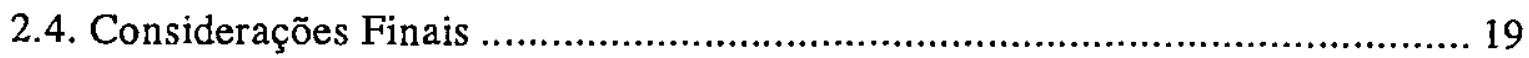

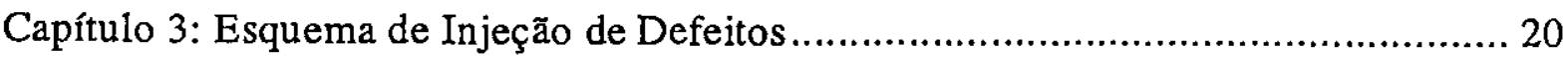

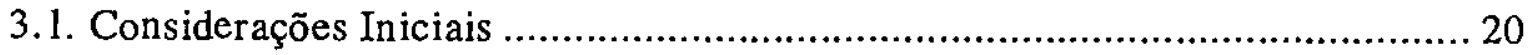

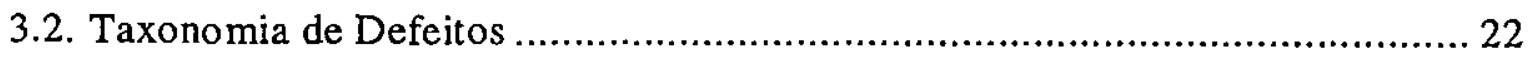

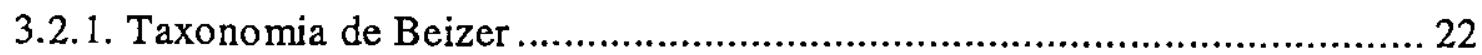

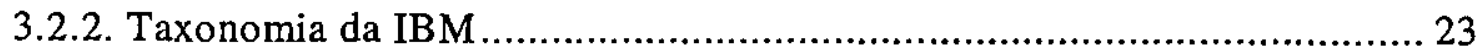

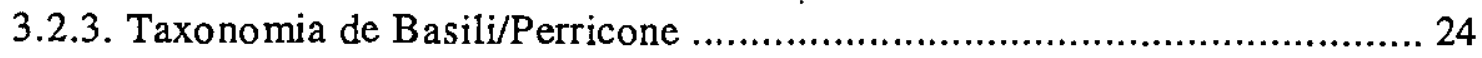

3.2.4. Taxonomia de DeMillo/Mathur ........................................................... 25

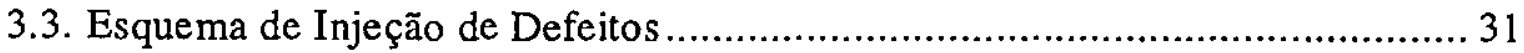

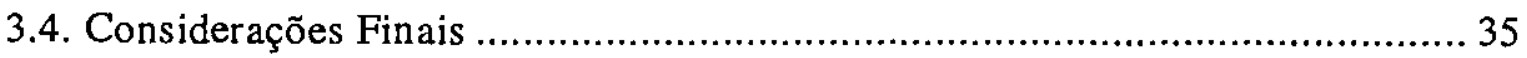

Capítulo 4: Projeto e Implementação da Ferramenta .............................................. 36

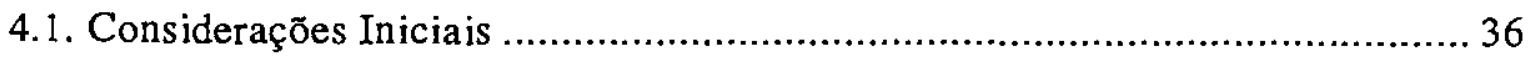

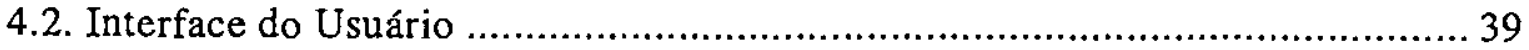

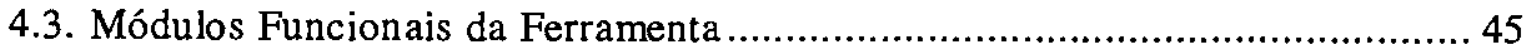

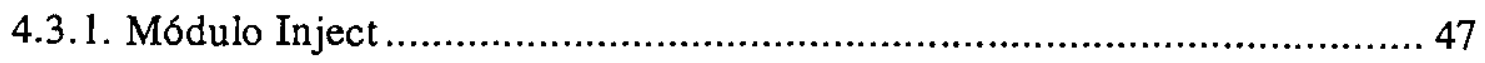

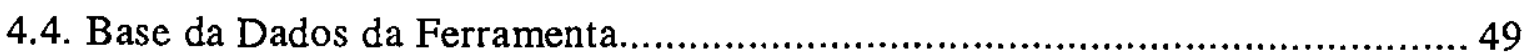

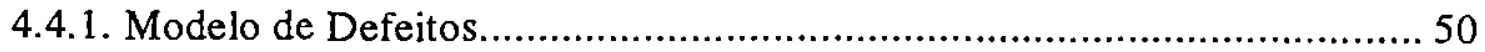

4.4.1.1. Seleção dos Operadores de Mutação .............................................. 50

4.4.1.2. Formato do Arquivo de Modelo de Defeitos ................................... 54 
4.4.1.3. Exemplo de Seleção de Defeitos Baseado no Modelo de Defeitos .... 56

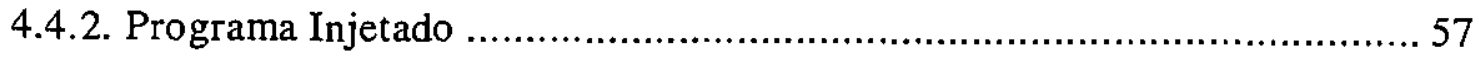

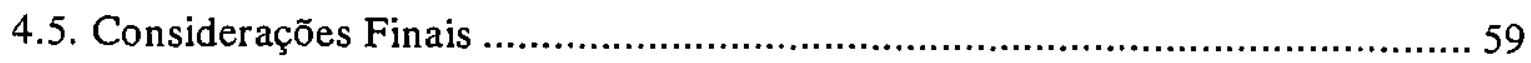

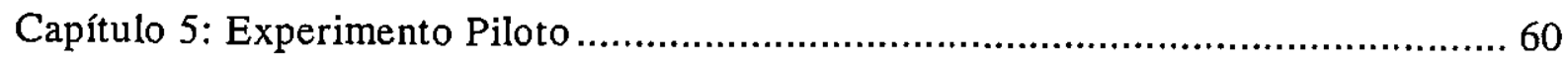

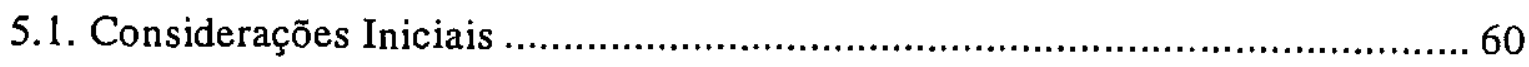

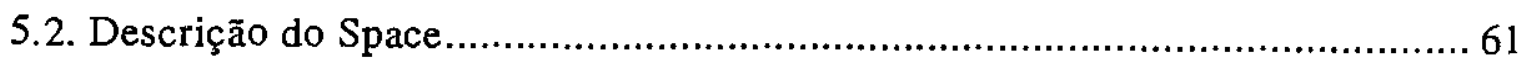

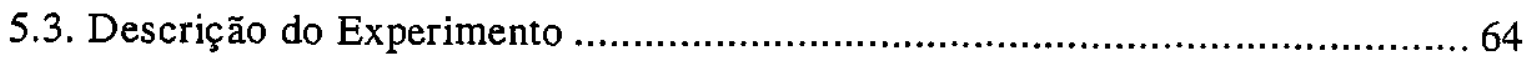

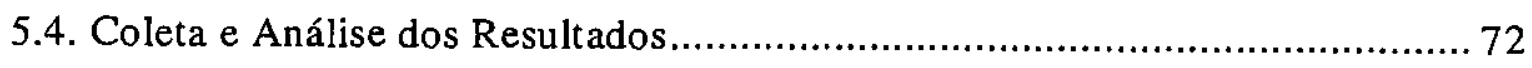

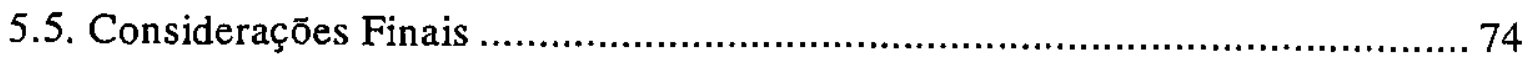

Capítulo 6: Conclusões e Desdobramentos ............................................................ 75

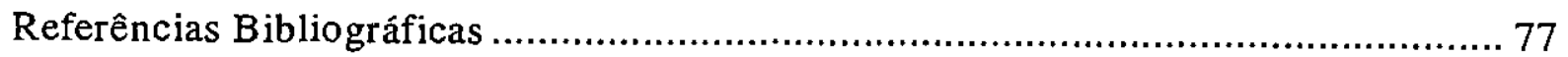

Apêndice A: Operadores de Mutação do Critério Análise de Mutantes...................... 84

Apêndice B: Operadores de Mutação do Critério Mutação de Interface ..................... 87

Apêndice C: Um Exemplo Utilizando a Ferramenta............................................. 89

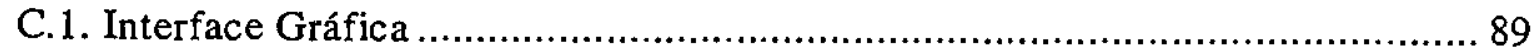

C.1.1. Criando uma Sessão de Teste ......................................................... 90

C. 1.2. Manipulando um Modelo de Defeitos .................................................. 92

C. 1.3. Adicionando Casos de Teste........................................................... 95

C.1.4. Injetando Defeitos .................................................................... 98

C.1.5. Visualizando Resultados ................................................................. 102

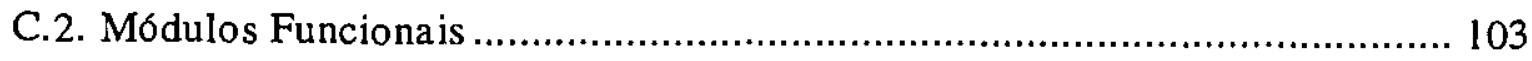

C.2.1. Criando uma Sessão de Teste ...................................................... 103

C.2.2. Manipulando um Modelo de Defeitos ............................................... 104

C.2.3. Adicionando Casos de Teste............................................................... 104

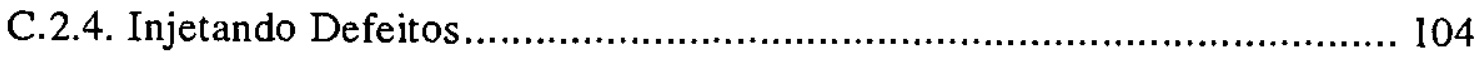

C.2.5. Visualizando Resultados ............................................................. 105

Apêndice D: Defeitos do Programa Space ............................................................ 106 


\section{Lista de Figuras}

Figura 1: Relação entre Defeito, Erro e Falha [CLA95] .......................................... 9

Figura 2: Transformação Genérica - Classe Entidade Simples Incorreta ..................... 27

Figura 3: Transformação Genérica - Classe Falta de Entidade .................................. 28

Figura 4: Transformação Genérica - Classe Entidade Espúria ................................. 28

Figura 5: Transformação Genérica - Classe Entidade Mal Empregada...................... 29

Figura 6: Exemplo de Transformação - Entidade Simples Incorreta ........................... 34

Figura 7: Exemplo de Transformação - Entidade Espúria......................................... 35

Figura 8: Esquema Geral da Ferramenta ITool................................................... 38

Figura 9: Janela Principal da Ferramenta ITool..................................................... 41

Figura 10: Selecionando um Modelo de Defeitos................................................ 42

Figura 11: Visualizando um Modelo de Defeitos ................................................. 42

Figura 12: Ativando/Desativando Classes de Defeitos e Operadores de Mutação....... 43

Figura 13: Aplicando o Modelo de Defeitos ......................................................... 43

Figura 14: Visualizando o Programa com Defeitos Injetados ................................ 44

Figura 15: Ativando/Desativando Defeitos Injetados ............................................. 45

Figura 16: Descritor de Defeito de um Defeito Gerado pelo Operador SWDD........... 52

Figura 17: Descritor de Defeito de um Defeito Gerado pelo Operador Cccr.............. 52

Figura 18: Conflito na Aplicação de Operadores de Mutação ................................... 54

Figura 19: Exemplo de um Arquivo de Modelo de Defeitos .................................... 56

Figura 20: Exemplo de Arquivo de Defeitos Injetados ......................................... 58

Figura 21: Níveis de de Injeção de Defeitos ...................................................... 59

Figura 22: Arquivo de Entrada do Programa Space (arquivo com extensão .adl)....... 61

Figura 23: Arquivo de Saída do Programa Space (arquivo com extensão .dat)...........6 62

Figura 24: Saída para a Tela Fornecida pelo Programa Space...................................62 62

Figura 25: Modelo de Defeitos Utilizado no Experimento.....................................6 67

Figura 26: Arquivo que Armazena os Defeitos Injetados........................................69 69

Figura 27: Algoritmo para Execução do Experimento ........................................... 71

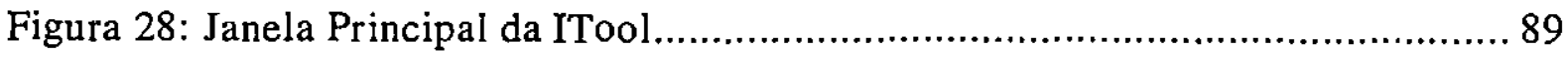

Figura 29 : Código Fonte do Programa Identifier............................................... 90 
Figura 30: Opção para Manipular Sessão de Teste .................................................... 91

Figura 31: Criando uma Sessão de Teste …........................................................... 92

Figura 32: Opção para Manipular Modelos de Defeitos .......................................... 93

Figura 33: Selecionando um Modelo de Defeitos .................................................. 93

Figura 34: Visualizando um Modelo de Defeitos .................................................... 94

Figura 35: Ativando/Desativando Classes de Defeitos e Operadores de Mutação...... 95

Figura 36: Opção para Manipular Casos de Teste .................................................... 96

Figura 37: Parâmetro para Inserção de Casos de Teste............................................... 96

Figura 38: Entrando com Dados para o Programa ................................................. 97

Figura 39: Visualizando Casos de Teste ........................................................... 97

Figura 40: Opção para Manipular o Programa com Defeitos Injetados ..................... 98

Figura 41: Aplicando o Modelo de Defeitos ........................................................ 99

Figura 42: Arquivo Identifier.FLT que Armazena os Defeitos Injetados................. 100

Figura 43: Selecionado Casos de Teste a Serem Utilizados .................................. 100

Figura 44: Executando Programa com Defe itos Injetados .................................. 100

Figura 45: Ativação/Desativação de Defeitos Injetados ........................................ 101

Figura 46: Eliminando um Defeito Real ..................................................... 102

Figura 47: Visualizando Andamento do Teste ….............................................. 102 


\section{Lista de Quadros}

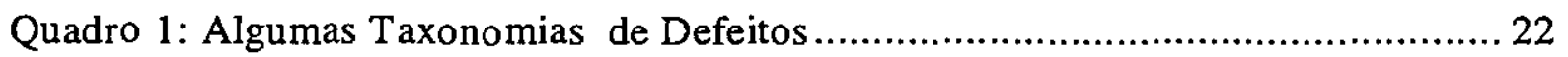

Quadro 2: Taxonomia de Defeitos de DeMillo/Mathur............................................ 31

Quadro 3: Classes de Defeitos x Operadores de Mutação .......................................... 33

Quadro 4: Unidades da Interface Gráfica ........................................................ 40

Quadro 5: Módulos Funcionais da Ferramenta ITool .......................................... 46

Quadro 6: Número de Offsets dos Operadores da Classe Mutação de Comandos ....... 51

Quadro 7: Operadores de Mutação para Geração de Defeitos ..................................... 53

Quadro 8: Exemplo de Seleção de Defeitos ......................................................... 57

Quadro 9: Classificação dos Defeitos do Space Realizada por Pasquini [DEL97b] .... 63

Quadro 10: Índice de Dificuldade dos Defeitos do Space .........................................65

Quadro 11: Número de Defeitos Gerados, Selecionados e Injetados ......................... 66

Quadro 12: Resultados dos Experimentos I-1 a I-5 ............................................... 72

Quadro 13: Resultados dos Experimentos II-1 a II-5 ............................................ 73

Quadro 14 : Operadores da Classe Mutação de Comandos ........................................ 84

Quadro 15: Operadores da Classe Mutação de Operadores........................................ 85

Quadro 16: Operadores da Classe Mutação de Constantes........................................... 86

Quadro 17:Operadores da Classe Mutação de Variáveis........................................... 86

Quadro 18: Operadores de Mutação de Interface - Grupo 1 1...................................... 87

Quadro 19: Operadores de Mutação de Interface - Grupo 2 …................................... 88

Quadro 20: Defeitos Gerados e Selecionados de Cada Classe.................................. 99 


\section{Capítulo 1 \\ Introdução}

Neste capítulo são apresentados o contexto em que se insere este trabalho, as motivações e a sua relevância nas áreas de Teste de Software e de Tolerância a Defeitos (Fault Tolerance). Em seguida são descritos sucintamente os objetivos e por último a organização deste trabalho.

\subsection{Contexto}

A Engenharia de Software é uma disciplina em evolução e que está em consonância com a tecnologia de computadores e com os requisitos de novas áreas de aplicação, tendo como objetivo principal produzir softwares de alta qualidade e de baixo custo. Abrange inúmeras áreas de pesquisa: engenharia de requisitos, projeto, verificação, validação e teste, manutenção, planejamento, gerenciamento de configuração, entre outras.

Dentre as fases do ciclo de vida de desenvolvimento de um software, a fase de teste apresenta-se como uma revisão de todas as outras fases, bem como um elemento crít ico para assegurar a qualidade do software [PRE92].

As atividades de teste de software consomem, em projetos típicos, na ordem de $40 \%$ do esforço total. $O$ fato de se ter um programa testado não garante a ausência de defeitos, o que não permite afirmar que o programa está correto. Assim, o teste de software tem o objetivo de revelar defeitos, contribuindo para demonstrar que as funções do software estão sendo desempenhadas de acordo com a especificação [PRE92].

Para apoiar a fase de teste de software, vários métodos, técnicas e ferramentas têm sido propostos [BEI90, HOR92, LUT90, MAL91], os quais contribuem para a sistematizaçāo e para o aprimoramento da qualidade dessa atividade e, consequentemente, da qualidade final do produto em desenvolvimento.

Dentre as atividades de teste de software, o projeto e a avaliação de casos de teste são tarefas essenciais; essas atividades englobam um conjunto de técnicas, 
critérios e métodos de projeto e avaliação de casos de teste, fornecendo ao projetista de software uma abordagem sistemática e teoricamente fundamentada.

As técnicas de teste podem ser classificadas em: funcional, estrutural, baseada em defeitos ou uma combinação das anteriores. O que diferencia essas três classes é a origem da informação utilizada para avaliar ou para construir conjuntos de casos de teste [MAL91].

A técnica funcional aborda o software do ponto de vista macroscópico, tratando o programa como uma caixa preta, na qual o conteúdo (detalhes de implementação) não é conhecido. Por outro lado, a técnica estrutural, ou teste da caixa branca, é baseada no conhecimento da estrutura interna da implementação, mais especificamente no fluxo de controle e em informações do fluxo de dados necessárias para derivar os requisitos de teste [MAL91]. A técnica baseada em defeitos utiliza informações sobre os tipos mais comuns de defeitos cometidos pelo programador no processo de desenvolvimento de software [DEM78], sendo a Semeadura de Erros (Error Seeding) [BUD81] e a Análise de Mutantes [BUD81, DEL93a] critérios dessa técnica.

Basicamente, a Análise de Mutantes é composta de quatro fases: a geração dos mutantes utilizando-se os operadores de mutação (esses operadores realizam transformações sintáticas no código fonte do programa), a execução do programa em teste, a execução dos mutantes e a análise dos mutantes. Esse critério utiliza-se de um processo de eliminação para mostrar que o programa em teste está correto, mostrando que nenhum dos mutantes, não equivalentes ao programa em teste, é correto. Esse critério é discutido em mais detalhes na Seção 2.2 .

As técnicas de teste devem ser vistas como complementares, sendo que a questão está em como empregá-las de forma que as vantagens de cada uma delas resultem na determinação de uma atividade de teste de melhor qualidade.

Com o objetivo de automatizar as atividades de teste, várias ferramentas têm sido projetadas e implementadas, apoiando critérios de teste de diferentes técnicas [BUD81, CHO89, HOR92, LUT90, RAP85] . Como exemplos dessas ferramentas pode-se citar a Proteum [DEL93b, DEL94] que implementa o critério Análise de Mutantes [BUD81, DEL93a] para o teste de unidade, um critério da técnica baseada em defeitos e a POKE-TOOL [CHA91, MAL89] que apóia os critérios Potenciais Usos, que são critérios baseados em fluxo de dados e critérios baseados em fluxo de controle. A ferramenta Proteum tem sido estendida - Proteum/IM - no sentido de apoiar a aplicação do critério Mutação de Interface (Interface Mutation) [DEL96, DEL97a, DEL97b] no teste de integração. No contexto de teste de software, essas ferramentas 
têm um papel fundamental para se obter maior qualidade e produtividade na atividade de teste, além de viabilizar a aplicação e a condução de estudos empíricos comparativos entre as técnicas de teste.

$\mathrm{Na}$ literatura de Teste de Software, muitas vezes, os termos defeito (fault) e erro (error) têm sido utilizados como tendo o mesmo significado [YOU91]. Neste trabalho, será utilizado o termo erro como conseqüência de defeitos contidos no software e que possivelmente manifestam-se em falhas no sistema no qual o software faz parte.

Serão adotados os termos defeito para fault, erro para error e falha para failure, segundo o Padrão IEEE para Engenharia de Software [IEE91] e em concordância com a terminologia utilizada na comunidade de Teste de Software no Brasil. Será utilizado também o termo Tolerância a Defeitos referindo-se a Fault Tolerance, embora usualmente este seja empregado como Tolerância a Falhas.

A comunidade de Tolerância a Defeitos no Brasil tem adotado o termo falha para fault, erro para error e defeito para failure, assim, referindo-se ao termo Fault Injection por Injeção de Falhas. Martins [MAR95a] salienta que não existe ainda um consenso quanto à terminologia a ser utilizada em Português para os termos fault, error e failure. Para manter uma uniformização, adaptam-se os termos utilizados em trabalhos nacionais da área de Tolerância a Defeitos à terminologia utilizada neste trabalho.

Segundo Clark [CLA95], uma abordagem que vem sendo bastante empregada na validação de sistemas de computadores que precisam ser altamente confiáveis é a Injeção de Defeitos (Fault Injection). Além disso, segundo Voas [VOA96], a Injeção de Defeitos de software é uma tecnologia emergente que pode ser utilizada para observar como o sistema de software comporta-se sob circunstâncias anômalas e experimentalmente controladas, podendo ser utilizada, assim como a atividade de teste de software, como uma medida da qualidade do sistema de software. Além da Injeção de Defeitos, Geist [GEI92] sugere que o critério Análise de Mutantes poderia ser valioso no projeto (desenvolvimento de software) de sistemas de software tolerantes a defeitos.

Inicialmente, a Injeção de Defeitos era uma técnica aplicada exclusivamente para hardware. Recentemente, essa técnica tem sido estendida para abordar defeitos de software; ainda sāo raros na literatura de Tolerância a Defeitos trabalhos que englobem essa abordagem e por isso, é alvo deste trabalho. 
Para que a atividade de injeção de defeitos seja realizada de forma mais objetiva e eficaz, são requeridos modelos de defeitos e métodos de injeção de defeitos. Modelos de defeitos e métodos de injeção para hardware têm recebido bastante atenção da comunidade científica, en quanto que para software ainda é um ponto em aberto como linha de pesquisa [CLA95].

Nesse contexto, diversas ferramentas [DAW96a, DEM94, ECH92, KAN92, LOV93, ROS93, SEG88a, VOA97] têm sido projetadas e implementadas. Para defeitos de software existem poucas ferramentas; uma delas é a FINE [KAO93], uma ferramenta mais abrangente que aborda tanto defeitos de hardware como de software.

Em paralelo, existem diversos trabalhos que buscam entender e classificar os defeitos que ocorrem em sistemas de software [BAS84, BEI90, CHI92, END75, G0075, GRA97, KNU89, OST84]. Um desses trabalhos é a taxonomia de DeMillo/Mathur [DEM95] que classifica os defeitos que ocorrem durante a fase de codificação do software. As taxonomias de defeitos podem ser consideradas um passo importante no estabelecimento de modelos de defeitos de software.

Este trabalho propõe um esquema de injeção de defeitos de software baseado na taxonomia de defeitos de DeMillo e nos operadores de mutação do critério de teste Análise de Mutantes para a geração e injeção de defeitos.

\subsection{Motivação}

Dado o contexto no qual este trabalho está inserido, pode-se citar alguns pontos que foram relevantes para que a motivação fosse estabelecida:

- a Engenharia de Software, mais especificamente as atividades de teste de software, visa assegurar a qualidade do software;

- defeitos ainda são encontrados na maioria dos softwares liberados;

- as atividades de teste de software podem consumir, em sistemas típicos, um esforço total maior que 40\%;

- a injeção de defeitos, assim como o teste de software, vem sendo utilizada como uma técnica de validação de sistemas que necessitam ser altamente confiáveis;

- existem autores que têm sugerido a Análise de Mutantes como um valioso critério no projeto de sistemas de software tolerantes a defeitos; 
- o projeto e a implementação de ferramentas para as atividades de Teste de Software e de Injeção de Defeitos permitem a automatização e a utilização dessas atividades na prática aumentando assim, a qualidade dos produtos que venham a ser avaliados com essas ferramentas; e

- apesar de ser reconhecida a relevância da injeção de defeitos de software, muito pouco é encontrado na literatura sobre essa abordagem.

\subsection{Objetivos}

O principal objetivo deste trabalho é a implementação de uma ferramenta de injeção de defeitos de software. Uma tarefa essencial nessa linha é o estudo de taxonomias de defeitos e de modelos de defeitos, base essencial para a definição de um esquema de injeção de defeitos de software para a ferramenta.

Este trabalho procura estabelecer um mapeamento de uma taxonomia de defeitos de software para os operadores de mutação utilizados no critério Análise de Mutantes, obtendo assim um esquema de injeção de defeitos para a implementação da ferramenta. A primeira versão dessa ferramenta apoiará a injeção de defeitos em programas escritos na linguagem $\mathrm{C}$.

Para ilustrar a relevância e factibilidade das idéias exploradas neste trabalho será conduzido um experimento piloto utilizando-se o programa Space, um programa desenvolvido pela ESA (European Space Agency).

\subsection{Organização do Trabalho}

Neste capítulo são apresentados o contexto, as motivações e os principais objetivos deste trabalho.

No Capítulo 2 são discutidos os conceitos relacionados à Injeção de Defeitos, abordando a terminologia utilizada, além de fornecer uma visão dos modelos de defeitos e dos métodos de injeção encontrados na literatura. Visto a relevância da automatização da atividade de injeção de defeitos, são discutidas algumas ferramentas, com destaque para a FINE [KAO93], uma ferramenta mais abrangente em termos de tipos de defeitos injetados. 
No Capítulo 3 são apresentadas as taxonomias de defeitos de software identificadas na literatura e que servirão de base para o estabelecimento de um esquema de injeção de defeitos de software para este trabalho. É descrito também o esquema de injeção de defeitos baseado em uma das taxonomias e nos operadores de mutação do critério Análise de Mutantes.

No Capítulo 4 é apresentada a ferramenta de injeção de defeitos implementada, denominada ITool, que apóia a aplicação do esquema de injeção de defeitos estabelecido e discutido no Capítulo 3; juntamente com os aspectos mais relevantes da implementação dessa ferramenta.

No Capítulo 5 é descrito um experimento piloto utilizando-se a ferramenta ITool aplicado sobre o programa Space, um sistema real de razoável complexidade, desenvolvido pela ESA (European Space Agency).

No Capítulo 6 são sumarizados os principais resultados e descritas as conclusões e os des dobramentos deste trabalho.

Nos Apêndices A e B listam-se os operadores de mutação do critério Análise de Mutantes e do critério Mutação de Interface, respectivamente. No Apêndice C é mostrado um exemplo da utilização da ITool, juntamente com as janelas que fazem parte da interface do usuário dessa ferramenta. Finalmente, no Apêndice D são listados os defeitos do programa Space que foram utilizados no experimento piloto. 


\section{Capítulo 2}

\section{Injeção de Defeitos}

Neste capítulo são apresentados os conceitos básicos relacionados à Injeção de Defeitos (Fault Injection), e em seguida, são abordados os modelos de defeitos e os métodos de injeção mais conhecidos na literatura. Algumas ferramentas de injeção de defeitos são descritas brevemente, com destaque para a ferramenta FINE que, além de tratar a injeção de defeitos de hardware, aborda também defeitos de software. Por último são apresentadas as considerações finais.

\subsection{Considerações Iniciais}

$\mathrm{Na}$ sociedade atual, sistemas de computadores tornaram-se cada vez mais necessários, sendo que falhas nesses sistemas podem levar a grandes perdas econômicas e de vidas humanas em certos domínios de aplicação. Como exemplos desses sistemas, pode-se citar os sistemas para controle de aeronaves, de tráfego aéreo, de produção, os sistemas de controle de reatores nucleares, de transações bancárias, entre outros. Para esses tipos de sistemas, a dependability é um requisito extremamente importante.

A comunidade de Tolerância a Defeitos traduz o termo dependability por segurança no funcionamento. Entende-se por segurança no funcionamento de um sistema computacional a propriedade que permite a seus usuários terem confiança no serviço fornecido por esse sistema. O serviço fornecido pelo sistema é o seu comportamento, tal como ele é visto pelo usuário. O usuário é um outro sistema humano ou físico - que interage com o sistema considerado [LAP92].

Uma abordagem que vem sendo bastante utilizada para estudar o impacto e a avaliação dos defeitos na dependability de sistemas de computadores é a Injeção de Defeitos [KAO93, ROS93].

A Injeção de Defeitos é uma solução eficaz para o problema de validação de sistemas de computadores altamente confiáveis [CLA95]; Martins [MAR95a] define Injeção de Defeitos como uma técnica que vem sendo muito utilizada para validação de sistemas na presença de entradas especiais: os defeitos. 
$\mathrm{Na}$ área de Tolerância a Defeitos, entende-se por sistemas de computadores altamente confiáveis ou sistemas tolerantes a defeitos aquela classe de sistemas na qual a segurança no funcionamento é um requisito indispensável [MAR93].

Rosenberg [ROS93] diz que a Injeção de Defeitos é um nome geral dado a um conjunto de técnicas usadas para acelerar a ocorrência de defeitos, erros e falhas em um sistema durante sua execução ou análise dinâmica. Na prática, um mecanismo de Injeção de Defeitos deve ser barato e ser capaz de modelar uma grande variedade de tipos de defeitos [BIE96].

Existem diversas definições dadas à Injeção de Defeitos. Pode-se concluir que, do ponto de vista mais geral, a Injeção de Defeitos é uma técnica que tem por objetivo principal a melhoria da qualidade dos sistemas de software.

Pode-se definir um defeito (fault) como um passo incorreto, um processo ou uma definição de dados incorreta [IEE91], ou então, como um desvio de um dos componentes de hardware ou software de sua função destinada [CLA95]. Os defeitos de software podem ser causados por uma especificação, projeto ou codificação incorreta. Assim, os defeitos podem surgir no decorrer de todos os estágios da evolução de um sistema de computadores - especificação, projeto, desenvolvimento, produção (manufacturing), montagem e instalação - e também durante sua operação [CLA95].

O erro (error) é a diferença de um valor ou uma condição computada, observada ou medida, com relação a um valor "real" [IEE91]. Segundo Clark [CLA95], quando um defeito causa uma mudança incorreta no estado do sistema, um erro ocorre.

A falha (failure) é um resultado incorreto, ou então, a incapacidade de um sistema em desempenhar as funções destinadas dentro de requisitos de desempenho especificados [IEE91]. Clark [CLA95] define falha como um mau funcionamento do sistema.

Existe uma relação entre os termos defeito, erro e falha, sendo mostrada na Figura 1. Quando um defeito torna-se ativo interferindo no estado do sistema, um erro ocorre, sendo que o tempo entre a ocorrência do defeito e o aparecimento de um erro é chamado latência do deffeito. 


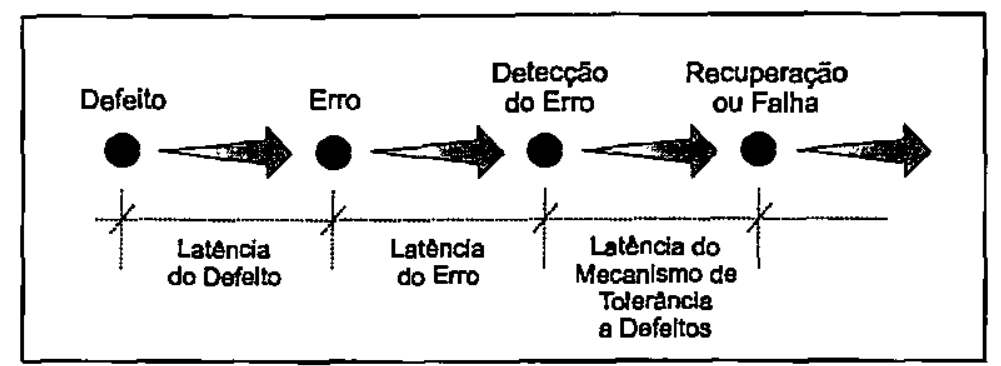

Figura 1: Relação entre Defeito, Erro e Falha [CLA95]

Um defeito presente no sistema pode ocasionar também múltiplos erros que podem se propagar pelo sistema. A latência do erro é o período de tempo entre a ocorrência do erro e a sua deteç̧ão.

Quando um mecanismo de tolerância a defeitos detecta um erro, ele deve iniciar várias ações para manipular os erros. A recuperação ocorre se essas ações forem bem sucedidas, caso contrário, ocorre um mau funcionamento, ou seja, uma falha do sistema. Essas falhas podem variar de acordo com sua causa, severidade e custo de recuperação [GHO97].

A Injeção de Defeitos pode ser utilizada não somente para observar o aspecto comportamental do sistema na presença dos defeitos injetados. Através de um outro ponto de vista, o de teste de software, os defeitos injetados podem ser considerados como defeitos artificiais de software, em contraste aos defeitos naturais, isto é, aqueles que estão presentes no software que está sendo testado. Dado que um certo número de defeitos são descobertos durante a fase de teste, a razão entre o número de defeitos artificiais e o número de defeitos naturais encontrados poderia, na teoria, dar uma indicação do número de defeitos naturais que ainda restam no programa, sendo essa filosofia a utilizada pelo critério Semeadura de Erros (Error Seeding) [BUD81], também referenciado na literatura por Semeadura de Defeitos (Fault Seeding) [PFL98].

Um dos problemas com o critério Semeadura de Defeitos está no fato de que alguns defeitos artificiais podem interagir com os naturais fazendo com que os defeitos naturais sejam mascarados pelos defeitos semeados [BUD81]. Outro ponto é a dificuldade de encontrar programas grandes o suficiente para conter 10.000 defeitos ou quantidade parecida e que dêem aos valores calculados estatisticamente um significado não questionável. Além disso, para aplicar esse critério, é preciso assumir que os defeitos estão uniformemente distribuídos no programa, o que, em geral, não é verdade. Na prática, encontram-se longos trechos de programas com código simples, pouco propensos a defeitos, e trechos pequenos, porém complexos, no qual os defeitos 
tendem a acumular [DEL93b]; uma região onde um defeito é encontrado, em geral, tem grande probabilidade de conter outros defeitos [PRE92].

Pflleger [PFL98] cita o trabalho de Mills [MIL72] que aplica o critério Semeadura de Erros para estimar o número de defeitos em programas. Para isso, são semeados defeitos em um programa e em seguida, dois grupos de testadores são designados para detectar defeitos.

Considere $x$ e $y$ o número de defeitos localizados pelos grupos 1 e 2, respectivamente. Alguns defeitos são localizados por ambos os grupos ( $q$ defeitos) e assim, tem-se que $q \leq x$ e $q \leq y$. Considere $n$ o total de defeitos - injetados e reais no programa e deseja-se estimar $n$. A eficácia (effectiveness) pode ser calculada da seguinte forma: $E_{1}=x / n$ e $E_{2}=y / n$, no qual $E_{1}$ e $E_{2}$ são as eficácias dos grupos 1 e 2 , respectivamente. Considere que a eficácia dos dois grupos é igual. Considere também que o domínio dos defeitos é $y$ e não mais $n$ para o grupo 1 e este encontrou $q$ dos $y$ defeitos, assim a eficácia do grupo 1 é $q / y$; em outras palavras tem-se $E_{1}=x / n=q / y$. Sabe-se que $E_{2}$ é $y / n$, então $n=q /\left(E_{1} * E_{2}\right)$. Tendo-se o valor de $q$, pode-se estimar $q / y$ para $E_{l}$ e $q / x$ para $E_{2}$, tendo-se assim dados suficientes para o cálculo de $n$.

Um outro problema relacionado ao critério Semeadura de Defeitos é a complexidade dos defeitos. No critério Semeadura de Defeitos, assume-se que a complexidade dos defeitos semeados é a mesma dos defeitos reais do programa. Assim, há dificuldades na elaboração de um conjunto representativo de defeitos a serem injetados; uma maneira de obter esse conjunto é recorrer ao histórico dos defeitos ocorridos em projetos "similares" no passado, quando isso é possível [PFL98].

Segundo Bieman [BIE96], a injeção de defeitos pode ser implementada através de modificações no estado do sistema em tempo de execução ou através de modificações no código fonte do sistema em questão. Denomina-se Injeção de Defeitos Dinâmica, também referenciada como State Injection, aquela forma de injeção que modifica o estado do sistema e Injeção de Defeitos Estática ou Code Injection, aquela que modifica o código do sistema que está sendo avaliado.

A Injeção de Defeitos Dinâmica não requer múltiplas compilações como ocorre na Injeção de Defeitos Estática, uma vez que o estado do sistema que está sendo avaliado sofre mudança. Esta forma de injeção é comumente utilizada para simular e injetar defeitos de hardware, possibilitando a emulação de grande quantidade de defeitos. Como exemplo de Injeção de Defeitos Estática, pode-se citar o Teste de Mutação [BIE96]. 
No contexto de Injeção de Defeitos, basicamente, os defeitos são classificados em defeitos de hardware e defeitos de software. Os defeitos de hardware podem ocorrer em alguma parte do sistema do computador (por exemplo: processador, memória, meio de comunicação), afetando diretamente a execução do programa ou propagando-se pelo software, isto é, erros de software induzidos por defeitos de hardware. Com relação aos defeitos de software, estes podem ser classificados de acordo com suas causas e sintomas, sendo que na literatura, diversas classificações têm sido dadas a esses defeitos [KAO93]. A injeção de defeitos de hardware significa "imitar" a causa de falhas de hardware sobre o sistema, enquanto que a injeção de defeitos de software relaciona-se aos defeitos no projeto/implementação do software, chamados também de defeitos de concepção [MAR95b]. Neste trabalho serão considerados somente os defeitos de software.

Assim, trabalhos envolvendo defeitos de hardware têm recebido bastante atenção da comunidade científica, enquanto que o estudo sobre defeitos de software é bastante recente. Segundo Martins [MAR93], isso ocorre pela falta de modelos de defeitos de software representativos e amplamente aceitos e a existência de um número limitado de mecanismos visando a tolerância a defeitos de software.

Como se observou, a Injeção de Defeitos tem-se tornado uma técnica bastante válida para avaliar a segurança no funcionamento de sistemas de computadores e, por isso, tem sido alvo de muitas pesquisas; no entanto, muitos problemas ainda permanecem. Um dos problemas é reduzir o espaço de defeitos de sistemas altamente integrados, requerendo melhoria nas técnicas e modelos utilizados. Um outro aspecto ainda não muito explorado são os defeitos nas fases de especificação e de projeto de sistemas de software. Uma outra dificuldade é controlar o ambiente no qual o defeito é injetado, além de que ainda é pouco conhecida a relação entre os defeitos injetados em laboratório e aqueles que ocorrem em condições reais de funcionamento do sistema [CLA95].

A confiabilidade em sistemas de software pode ser alcançada através de três estratégias complementares [SOM96]:

- Prevenção de Defeitos: é a estratégia mais importante e que pode ser aplicável em todos os tipos de sistemas. O processo de projeto e implementação poderia ser organizado com o objetivo de produzir sistemas livres de defeitos;

- Tolerância a Defeitos: Assume-se que existem defeitos residuais no software e mecanismos são incorporados ao sistema de modo que mesmo com a manifestação desses defeitos causando erros no sistema, este continue funcionando. Como 
exemplo de alguns mecanismo de tolerância a defeitos de software pode-se citar o Recovery Blocks, o N-Version Programming, o Recover-and-retry e o Fix-theerrors [LEE94];

- Detecção de Defeitos: Os defeitos são detectados e removidos antes que o software seja liberado para operação. O processo de validação do software utiliza-se de métodos estáticos e dinâmicos para detectar defeitos que restam no software após sua implementação.

As estratégias Prevenção de Defeitos e Deteç̧ão de Defeitos são, muitas vezes, suficientes para alcançar um nível de confiabilidade requerido. As falhas no sistema de software devido aos poucos defeitos que talvez restem nesse sistema devem ser aceitáveis. Entretanto, quando o software é crítico ou apresenta como requisito uma alta confiabilidade, o programa deve ser projetado de forma que os defeitos residuais não causem falhas catastróficas. Quando um defeito ocorre, o software deve gerenciar esses defeitos e continuar a operar, mesmo com um certo nível de degradação [SOM96].

\subsection{Modelos de Defeitos e Métodos de Injeção}

Tanto para injeção de defeitos em hardware quanto em software necessita-se de um modelo de defeitos que sirva de suporte à atividade de injeção, sistematizando essa atividade e tornando-a mais objetiva e eficaz. Vários modelos de defeitos podem ser utilizados, desde os mais detalhados modelos em nível de dispositivo até os mais simples em nível funcional para representar os defeitos ou suas manifestações [CLA95]. Na atividade de injeção de defeitos são requeridos também métodos de injeção que devem determinar como injetar defeitos dentro do sistema em questão.

Como exemplos de modelos de defeitos de hardware pode-se citar o Modelo Stuck-at Fault, utilizado para defeitos permanentes de hardware, e o Modelo de Inversão, usado para defeitos transientes de hardware, isto é, defeitos temporários originários do ambiente.

Os métodos de injeção de defeitos determinam como injetar defeitos no sistema. Dentre os métodos de injeção pode-se citar o Método State Mutation e o Método Trace Injection, ambos para defeitos em componentes de hardware.

$\mathrm{Na}$ literatura pesquisada, foram identificadas poucas iniciativas para o estabelecimento de modelos de defeitos e métodos de injeção de software. Assim, são 
bastante relevantes estudos no sentido de estabelecer modelos de defeitos e métodos de injeção abordando defeitos em sistemas de software. Esses modelos poderiam captar os defeitos mais comuns na atividade de desenvolvimento de software, e assim, auxiliar na priorização das atividades relacionadas ao teste e à validação. Além da falta de modelo de defeitos, não existe na literatura um consenso sobre o que seria, exatamente, um modelo de defeitos de software e quais atributos - tipo, freqüência, origem, severidade dos defeitos, entre outros - deveriam estar presentes no modelo. No Capítulo 3 (Esquema de Injeção de Defeitos) são discutidos diversas taxonomias de defeitos de software, o que parece ser um importante passo na definição de modelos de defeitos de software.

Um "bom" modelo de defeitos deveria ser capaz de retratar os defeitos contidos em sistemas reais, bem como os atributos desses defeitos. Obviamente, quanto mais próximo da realidade for o modelo, maior a confiabilidade e qualidade dos mecanismos e sistemas que venham a ser testados e validados com a utilização do modelo. Um outro problema para a definição de um modelo é quanto ao modelamento do domínio a que pertence o sistema. Para um sistema de um determinado domínio, um modelo pode ser "bom", mas para outro sistema de outro domínio, esse mesmo modelo talvez não seja capaz de modelar os defeitos segundo seus atributos.

Existem estudos que visam obter defeitos e falhas em sistemas de software pertencentes a diversos domínios [WAL97], diferentemente do que ocorre com muitas taxonomias identificadas na literatura. Dessa forma, ter-se-á uma amostra bastante representativa dos defeitos e falhas que ocorrem em sistemas de software.

Os modelos de defeitos e os métodos de injeção apóiam as formas de injeção de defeitos. Na atividade de injeção de defeitos, os defeitos de hardware podem ser injetados de diferentes formas dependendo do nível de abstração (modelo ou protótipo) utilizado para representar o sistema e do nível de aplicação dos defeitos (físico ou lógico) [CLA95, MAR95b]; formas de injeção de defeitos de software năo foram identificadas na literatura pesquisada.

As formas de injeção de defeitos de hardware mais empregadas são:

- simulação de defeitos: defeitos são injetados em um modelo do sistema, podendo ser empregada em diversos esquemas de representação do sistema (arquitetural, funcional, lógico ou elétrico);

- injeção física de defeitos: defeitos físicos são injetados diretamente em um protótipo de hardware a ser avaliado; 
- injeção de defeitos implementada por software: defeitos lógicos são injetados em um protótipo do hardware do sistema com o objetivo de emular a consequiência de defeitos físicos. Uma classificação pode ser dada a essa forma de injeção:

口 injeção ativa: realizada por um outro processo que é executado concorrentemente com a aplicação em teste;

- alteração do fluxo de controle: utilizada para modificar o comportamento do sistema, sendo que, estando em modo de injeção, o sistema realiza uma seqüência de instruções alternativas, fazendo com que uma determinada função seja realizada de maneira incorreta;

- alteração de código: utilizada quando áreas da aplicação em teste não podem ser acessadas por outros processos. O código do sistema é alterado, fazendo com que operações incorretas sejam executadas. Essas alterações podem ser realizadas em tempo de compilação ou de execução.

A terceira forma de injeção apresenta vantagens se comparada com as duas anteriores: maior facilidade de controle e observação do sistema se comparado com a simulação de defeitos e não há necessidade de hardware específico como é o caso da injeção física de defeitos [MAR95b].

Deve-se ressaltar a diferença entre injeção de defeitos de software (software fault injection) e injeção de defeitos implementada por software (software-implemented fault injection e também referenciado nos trabalhos de Tolerância a Defeitos como software fault injection). A primeira relaciona-se com defeitos que ocorrem durante o processo de desenvolvimento do software (levantamento de requisitos, análise, projeto, entre outros) ou também no código de um programa, durante a fase de implementação e a segunda relaciona-se com defeitos de hardware, como descrita anteriormente.

Na linha de Teste de Software, diversos critérios têm sido utilizados para a deteç̧ão de defeitos, entre eles encontra-se o critério de teste Análise de Mutantes, um dos critérios de teste baseado em erros que se utiliza de informações sobre as classes de defeitos mais comuns que o programador ou o projetista pode cometer durante o processo de desenvolvimento de software e nas abordagens que podem ser utilizadas para detectar a sua ocorrência [BUD81]. Esse critério tem-se mostrado bastante eficaz na detecção de defeitos [MAT94, OFF95, SOU96, WON94a, WON94b, WON94c]. Além disso, Geist [GEI92] sugere a Análise de Mutantes como um valioso critério no projeto de sistemas tolerantes a defeitos. 
No critério Análise de Mutantes, dado um programa $P$ e um conjunto de casos de teste $T$, constrói-se um conjunto $\Phi(P)$, denominado vizinhança de $P$, do qual $P$ também é membro e os outros elementos são os mutantes gerados através de pequenas alterações em $P$. Cada programa gerado dessa forma é um mutante $M$ de $P$. A intenção é mostrar que o programa $P$ está correto através de um processo de eliminação, mostrando que nenhum programa em $\Phi(P)$, não equivalente a $P$, é correto. Além disso, segundo esse critério, um conjunto de casos de teste $T$ é adequado para testar um programa $P$ se para cada mutante $M$ em $\Phi(P)$ não equivalente a $P$ existe um caso de teste $t \in T$ tal que $P(t) \neq M(t)$; ou seja, $T$ contém casos de teste capazes de distinguir o comportamento de $P$ e o comportamento dos mutantes não equivalentes a $P$ [DEL93a].

De um modo geral, o critério Análise de Mutantes apresenta basicamente quatro fases: Geração do Conjunto de Mutantes, Execução do Programa Original $P$, Execução dos Mutantes e Análise dos Mutantes. A automatização parcial desse critério é realizada através da ferramenta de teste denominada Proteum [DEL93b, DEL94].

Para a geração do conjunto de mutantes, ou a vizinhança $\Phi(P)$, a Análise de Mutantes utiliza-se de um conjunto de operadores de mutação que são capazes de gerar transformaçб̃es sintáticas no código fonte do programa. Esses operadores retratam os defeitos mais comuns cometidos pelo programador ao longo do processo de desenvolvimento de software [DEM78]. Baseado em estudos empíricos [BUD80, ACR79], um conjunto de casos de teste que consegue revelar defeitos simples, consegue, em geral, revelar os defeitos mais complexos; esse é o chamado efeito de acoplamento (coupling effect). Um ponto essencial do critério Análise de Mutantes é justamente a definição desses operadores. No trabalho de DeMillo [DEM95], os operadores de mutação foram projetados para a geração de mutantes para programas escritos em linguagem $\mathrm{C}$.

No trabalho de Delamaro [DEL93b], foram utilizados um total de 71 operadores de mutação [AGR89] divididos em quatro classes - Mutação de Comandos, Mutação de Operadores, Mutação de Constantes e Mutação de Variáveis — sendo listados e descritos no Apêndice A.

Tradicionalmente, a Análise de Mutantes tem sido utilizada para o teste de unidade; recentemente, foi proposta uma extensão para o teste de integração, resultando em um critério interprocedimental baseado em mutantes denominado Mutação de Interface [DEL96, DEL97a, DEL97b]. Para esse critério, foram estabelecidos 33 operadores de mutação divididos em dois grupos, como listados no Apêndice B. 
Do ponto de vista mais abstrato, esses operadores podem compor um modelo de defeitos mais específico em nível de implementação. Na realidade, esses operadores geram um subconjunto de todos os defeitos que ocorrem em sistemas reais; mas, baseado no efeito de acoplamento, espera-se que defeitos mais complexos não gerados pelos operadores sejam também revelados.

Neste trabalho, as mutações geradas por operadores de mutação serão os defeitos a serem injetados no programa que está sendo avaliado. Assim, utilizar-se-á o termo defeito para referir-se a uma mutação gerada.

\subsection{Automatização da Atividade de Injeção de Defeitos}

Para apoiar as atividades de injeção de defeitos, muitas ferramentas têm sido desenvolvidas para automatizar sua aplicação. Um estudo comparativo realizado por Martins [MAR95a] descreve várias ferramentas para injeção de defeitos - FIAT [SEG88a, SEG88b], FERRARI [KAN92], EFA [ECH92], SFI [ROS93], ProFI [LOV93] e FINE [KAO93] — sendo a maioria voltada para a injeção de defeitos de hardware, com exceção da ferramenta FINE, que também considera os defeitos de software.

A ferramenta FIAT (Fault Injection based Automatic environmenT)[SEG88a, SEG88b], por exemplo, combina a flexibilidade de controle por software, com a emulação do hardware, para avaliar a segurança no funcionamento de sistemas distribuídos/paralelos tolerantes a defeitos, sendo que a injeção de defeitos se dá através da modificação de dados contidos na memória. Essa ferramenta tem sido utilizada para medidas de cobertura e latência, classificação das falhas e investigação do efeito de tipos de defeitos e da carga do sistema sobre essas medidas.

A FERRARI (Fault and ERRor Automatic Real-time Injector) [KAN92], como a FIAT, utiliza-se da injeção de defeitos por software para emular defeitos de hardware, injetando defeitos permanentes e transientes, além de erros no controle de fluxo do programa e defeitos definidos pelo usuário. Essa ferramenta foi projetada para estimar a cobertura e a latência de mecanismos tolerantes a defeitos.

Uma ferramenta mais abrangente que trata tanto os aspectos de hardware quanto os de software é a FINE (Fault Injection and moNitoring Environment) [KAO93], sendo assim discutido em mais detalhes a seguir. As demais ferramentas - EFA, SFI e ProFI - bem como outras encontradas na literatura, basicamente, tratam de aspectos 
bastante semelhantes aos tratados pela FIAT e pela FERRARI, sendo a maioria dedicada à injeção de defeitos de hardware. Além dessas ferramentas, mais recentemente, pôde-se identificar ainda na literatura outras ferramentas como a TAMER [DEM94], ORCHESTRA [DAW96a], e PSN [VOA97].

A ferramenta TAMER (a Testing, Analysis, and Measurement Environment for Robustness) [DEM94] pode ser utilizada para a injeção de defeitos baseada em interface para o teste de sistemas distribuídos tolerantes a defeitos. Essa ferramenta injeta defeitos nas interfaces entre módulos do software, sendo que o usuário pode determinar em quais interfaces e qual o defeito que deseja injetar.

A ORCHESTRA [DAW96a] é uma ferramenta para injeção de defeitos para o teste de sistemas distribuídos tolerantes a defeitos e de tempo-real, mais especificamente, a detecção de defeitos no projeto e implementação e violações na especificação de protocolos de comunicação. Essa ferramenta injeta defeitos nas mensagens trocadas entre os protocolos e tem sido utilizada para a condução de experimentos em diversos sistemas comerciais e acadêmicos [DAW96b, GHO97].

A PSN (Pisces Safety Net) não é propriamente uma ferramenta, mas sim um módulo de uma ferramenta denominada Whitebox Software Analysis Toolkit [VOA97]. Esse módulo auxilia na identificação de "fraquezas" (trecho de código) no software que poderiam causar falhas catastróficas e na localização dessas "fraquezas" dentro do código fonte, através de injeção de defeitos artificiais nos níveis de software e hardware. Esses defeitos simulam problemas internos - defeitos de software no código - e externos - falhas de outros softwares ou por erros no hardware que interagem com o software em teste [VOA97, GHO97].

Não se identificou na literatura, ferramentas de injeção de defeitos que tenham por base um modelo de defeitos explícito para as atividades de injeção. Até mesmo as ferramentas mais recentes como a $P S N$ necessitam que defeitos sejam selecionados manualmente.

\subsubsection{Ferramenta FINE}

A FINE é uma ferramenta que possibilita o estudo da propagação de defeitos no kernel UNIX, avaliando a segurança no funcionamento e a eficácia dos mecanismos de deteç̧ão de erros e de recuperação. 
Essa ferramenta injeta erros de software induzidos pelo hardware e defeitos de software dentro do kemel UNIX, rastreando o fluxo de execução e as variáveis chaves do kernel. Segundo os autores da ferramenta [KAO93], a FINE foi a primeira ferramenta a tratar a injeção de defeitos de software.

Embora existam diversos tipos de defeitos de hardware que possam ocorrer em muitas das partes do sistema, na ferramenta FINE são considerados somente os defeitos de hardware que possam afetar a execução do programa e propagar-se pelo software, isto é, defeitos de software induzidos pelo hardware. Assim, os defeitos injetados são relacionados aos defeitos na memória, na CPU, nos dutos de dados e de comunicação e aos defeitos de entrada/saída (dispositivos periféricos).

A injeção de defeitos tanto de hardware quanto de software é realizada on-line. Para o estudo de Kao [KAO93], os defeitos de software são classificados em: Defeitos de Inicialização (Inicialization Faults), Defeitos de Atribuição (Assignment Faults), Defeitos de Condição (Condition Check Faults), Defeitos de Função (Function Faults) e Defeitos de Documentação (Documentation Faults), sendo descritos mais detalhadamente a seguir.

- Defeito de Inicialização: inclui variáveis e parâmetros inicializados incorretamente e variáveis não inicializadas;

- Defeito de Atribuição: esse defeito relaciona-se à ausência de uma atribuição ou a uma atribuição inçorreta;

- Defeito de Condição: inclui ausência de condições e condições incorretas;

- Defeito de Função: significa que a parte "defeituosa" não está restrita somente a um único comando (statement), mas sim envolvendo vários comandos ou funções;

- Defeito de Documentação: as mensagens ou a documentação do sistema estão incorretas; uma vez que essa classe de defeitos não afeta a execução do software em questão, essa classe é desconsiderada para o estudo de Kao.

Observa-se que os defeitos de software injetados pela FINE podem ser considerados um subconjunto das mutações geradas pelos operadores de mutação dos critérios de teste Análise de Mutantes e Mutação de Interface, comentados na Seção 2.2 deste capítulo. 


\subsection{Considerações Finais}

Neste capítulo foram apresentados vários aspectos relacionados à técnica de Injeção de Defeitos, a terminologia utilizada, além de uma visão dos modelos de defeitos e dos métodos de injeção.

Relacionou-se as atividade de Teste de Software e de Injeção de Defeitos através da apresentação do critério de teste Análise de Mutantes, um dos critérios da técnica de teste baseada em defeitos. Mais particularmente, foram comentados sobre os operadores de mutação utilizados nesse critério, que podem ser utilizados como um modelos de defeitos mais específica em nível de implementação para a geração de defeitos de software.

Visto a importância da automatização da técnica de Injeção de Defeitos, foram apresentadas algumas ferramentas de suporte a essa atividade, com destaque à FINE, uma ferramenta que, além de tratar a injeção de defeitos de hardware como a maioria das ferramentas, implementa também a injeção de defeitos de software.

Mais recentemente, no contexto de Tolerância a Defeitos, o estudo da segurança no funcionamento de sistemas distribuídos tem recebido atenção da comunidade científica, como pode ser observado nas ferramentas de injeção de defeitos identificadas na literatura. Dentre as ferramentas pesquisadas, não se identificaram ferramentas que tivessem por base um modelo de defeitos explícito para a atividade de injeção de defeitos.

Na seção seguinte será apresentada uma revisão sobre algumas taxonomias de defeitos de software identificadas na literatura e, em seguida, é apresentado o esquema de injeção de defeitos elaborado através de um mapeamento da taxonomia de defeitos de DeMillo/Mathur para os operadores de mutação do critério Análise de Mutantes. 


\section{Capítulo 3}

\section{Esquema de Injeção de Defeitos}

Como comentado no capítulo anterior, as taxonomias de defeitos podem ser consideradas um passo importante para a definição de modelos de defeitos. Assim, neste capítulo são apresentadas as taxonomias de defeitos de software identificadas na literatura, e mais detalhadamente a taxonomia de DeMillo/Mathur que será utilizada neste trabalho. Em seguida, são mostrados os aspectos mais relevantes do esquema de injeção de defeitos de software estabelecido e baseado no mapeamento da taxonomia de DeMillo/Mathur para os operadores de mutação do critério de teste Análise de Mutantes.

\subsection{Considerações Iniciais}

Desde a década de 70 , já havia uma certa preocupação em estudar e entender os defeitos que ocorriam em sistemas de software [END75, GO075, MYE79, SHO75]. Atualmente, pode-se identificar diversos trabalhos na literatura que visam à taxonomia de defeitos encontrados nas diversas fases do ciclo de vida de desenvolvimento de um software.

Segundo Beizer [BEI90], uma classificação de defeitos não deve ser rígida, pois classificar um defeito é uma tarefa difícil e inexata; isso ocorre porque os defeitos podem ser classificados considerando-se diversos fatores: o comportamento do programador, o efeito causado pelo defeito no programa, entre outros.

$\mathrm{Na}$ literatura, diversos termos têm sido utilizados para referir-se à classificação de defeitos. Existem autores que utilizam termos como esquema de classificação de defeitos, categorização de defeitos, entre outros; no entanto, neste trabalho, será utilizado o termo taxonomia de defeitos para referir-se a classificação de defeitos. Wallace [WAL97] afirma que com relação aos trabalhos sobre taxonomia de defeitos, existe uma certa dificuldade em sintetizar os termos utilizados nessas diversas taxonomias.

A maioria das taxonomias de defeitos identificadas na literatura apresenta problemas de ambigüidade, ou seja, um mesmo defeito pode ser relacionado a mais de 
uma classe [DEM95]. Em uma taxonomia, não é desejável a ambigüidade, uma vez que, se o número de defeitos em cada classe é significativo, perde-se o significado se um defeito pode ser classificado em mais de uma classe. Assim, uma taxonomia de defeitos deve ser clara de modo que dois desenvolvedores possam classificar um determinado defeito de uma mesma maneira [PFL98].

Além do problema de ambigüidade, DeMillo [DEM95] aponta um outro problema bastante comum nas taxonomias de defeitos: a dificuldade de automatização.

O estabelecimento dessas taxonomias deve ser norteado por aspectos teóricos e empíricos e vários trabalhos têm destacado a relevância de seu estabelecimento, como os trabalhos de Basili/Perricone [BAS84], de Beizer [BEI90] e de DeMillo/Mathur [DEM95]; além dessas taxonomias, grandes empresas, como é o caso da HP [GRA97] e da IBM [CHI92], têm desenvolvido trabalhos nessa linha.

Além das taxonomias citadas acima, DeMillo [DEM95] apresenta uma visão geral de outras taxonomias como a de Endres [END75], Goodenough/Gerhart [GOO75], Ostrand/Weyuker [OST84] e de Knuth [KNU89].

Considerando a diversidade de taxonomias, pode-se observar a preocupaçāo em entender os defeitos de software, o que é um importante passo para o estabelecimento de modelos de defeitos de software. As taxonomias de defeitos podem ser vistas como modelos de defeitos de alto nível, no qual o único atributo é o tipo ou classe do defeito.

As taxonomias de defeitos podem ser mais abrangentes englobando muitas das fases do ciclo de desenvolvimento do software - desde a fase de levantamento de requisitos até a fase de teste - como o trabalho de Beizer [BEI90], ou podem ser mais específicas, como a de DeMillo/Mathur [DEM95], que engloba somente a fase de codificação.

Essas taxonomias melhoram o processo de desenvolvimento de sistemas de software, pois retratam os defeitos que podem ser encontrados nas atividades de desenvolvimento; assim, esforços podem ser concentrados nas atividades que têm maior probabilidade de apresentar defeitos [PFL98]. 


\subsection{Taxonomia de Defeitos}

No Quadro 1 são mostradas algumas das taxonomias de defeitos que foram selecionadas para serem descritas mais detalhadamente. Os trabalhos de Beizer, da IBM, de Basili/Perricone e de DeMillo/Mathur são descritos adiante, dando ênfase à taxonomia de DeMillo/Mathur, uma vez que esta será utilizada neste trabalho.

Quadro 1: Algumas Taxonomias de Defeitos

\begin{tabular}{|c|c|c|}
\hline Taxonomia & Fase de Desenvolvimento & Classes \\
\hline Beizer & $\begin{array}{l}\text { Levantamento de requisitos } \\
\text { Especificação } \\
\text { Projeto } \\
\text { Codificação } \\
\text { Teste }\end{array}$ & $\begin{array}{ll} & \text { Requisitos, características e } \\
& \text { funcionalidade } \\
\text { - } & \text { Estruturais } \\
\text { - } & \text { Dados } \\
\text { - } & \text { Codificação } \\
\text { - } & \text { Projerface } \\
\end{array}$ \\
\hline $\begin{array}{c}\text { IBM } \\
\text { (Classificação } \\
\text { Ortogonal) }\end{array}$ & $\begin{array}{c}\text { Projeto } \\
\text { Codificação }\end{array}$ & 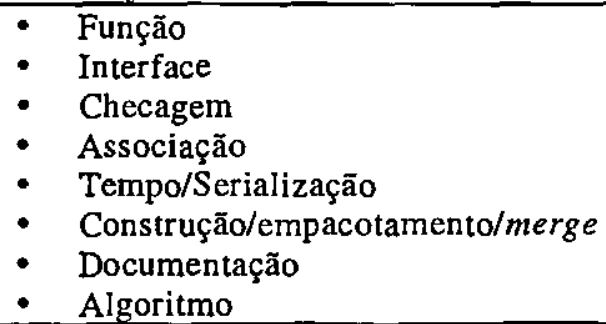 \\
\hline Basili/Perricone & Codificação & $\begin{array}{ll}- & \text { Inicialização } \\
- & \text { Estrutura de Controle } \\
\text { - } & \text { Interface } \\
\text { - } & \text { Dados } \\
\end{array}$ \\
\hline DeMillo/Mathur & Codificação & $\begin{array}{ll}\text { - } & \text { Entidade Simples Incorreta } \\
\text { - } & \text { Falta de Entidade } \\
\text { - } & \text { Entidade Espúria } \\
\end{array}$ \\
\hline
\end{tabular}

\subsubsection{Taxonomia de Beizer}

O trabalho de Beizer [BEI90] faz a classificação dos defeitos mais freqüentemente encontrados no processo de desenvolvimento de software nas seguintes classes: defeitos de requisitos, de características e de funcionalidade; defeitos estruturais; defeitos de dados; defeitos de codificação; defeitos de interface e defettos de projeto de teste. A taxonomia de Beizer é mais abrangente e menos específica do que, por exemplo, a de Basili/Perricone que abrange somente a fase de codificação. Abaixo são descritas cada uma das classes definidas por Beizer: 
- Defeitos de requisitos, de características e de funcionalidade: relacionados aos requisitos e à especificação do software que estão incompletos, ambíguos, contraditórios ou que podem ser interpretados de forma incorreta. Isso pode levar a softwares com características indesejáveis, supérfluas ou não apresentar características desejáveis;

- Defeitos estruturais: englobam defeitos de controle, lógicos, de processamento, de fluxo de controle e de inicialização;

- Defeitos de dados: decorrem de defeitos nos dados do programa, quer seja em seu formato, número de objetos ou valores iniciais;

- Defeitos de codificação: são classificados os defeitos na sintaxe, embora muitos compiladores sejam capazes de detectar esse tipo de defeito. São classificados ainda, defeitos de digitação que não causam defeitos de sintaxe, além daqueles causados pelo não entendimento da semântica de algum comando ou instrução; englobam também os causados por efeitos colaterais surgidos com a execução de alguma instrução ou comando;

- Defeitos de interface: nessa classe agrupam-se os defeitos relacionados à interligação do software ao mundo exterior (comunicação com usuário, sistema operacional ou hardware) ou de partes (subrotinas e funções) do software entre si;

- Defeitos de projeto de teste: essa classe não trata dos defeitos no software em si. Ela abrange problemas no planejamento das atividades de teste, fazendo com que defeitos não sejam revelados.

Um experimento estatístico realizado por Beizer [BEI90] mostra que as três classes relacionadas à fase de codificação - defeitos estruturais, de dados e de codificação - são responsáveis pela maior parte do total de defeitos.

\subsubsection{Taxonomia da IBM}

A taxonomia estabelecida pela IBM é denominada Classificação de Defeitos Ortogonal (Orthogonal Defect Classification) [CHI92]. Essa taxonomia apresenta oito classes, sendo elas: defeitos de função, de interface, de checagem (checking), de atribuição, de tempo/serialização (timing/serialization), de construção/pacote/merge, de documentação e de algoritmo. Cada uma dessas classes é descrita a seguir: 
- Função: pertencem a esta classe defeitos que afetam a capacidade do software, a interface do usuário, a interface com a arquitetura de hardware ou com outros softwares ou que afetam a estrutura de dados global ou que requerem mudanças no projeto;

- Interface: esta classe relaciona-se com defeitos na interação do software com outros componentes, módulos ou drivers, comandos de chamadas, blocos de controle e listas de parâmetros;

- Checagem: defeitos na lógica do programa para a validação de dados ou valores;

- Atribuição: relaciona-se com defeitos na inicialização de uma estrutura de dados ou de um bloco de controle;

- Tempo/Serialização: esta classe engloba os defeitos relacionados ao gerenciamento de recursos de tempo-real e de recursos compartilhados;

- Construção/empacotamento/merge: defeitos causados devido aos problemas nas bibliotecas do programa, no gerenciamento de mudanças ou no controle de versōes;

- Documentação: relaciona-se com defeitos que afetam as publicações e as anotações de manutenção;

- Algoritmo: envolve defeitos relacionados à eficiência ou à corretude dos algoritmos ou das estrutura de dados, mas não no projeto.

\subsubsection{Taxonomia de Basili/Perricone}

A taxonomia de Basili/Perricone [BAS84] envolve defeitos decorrentes da fase de codificação, mais especificamente, no código do software. Esta taxonomia divide os defeitos e cinco classes: defeitos de inicialização, defeitos de estrutura de controle, defeitos de interface, defeitos de dados e defeitos de computação.

Abaixo são descritas cada uma das classes definidas por Basili/Perricone.

- Defeitos de inicialização: relacionados aos defeitos que ocorrem na inicialização ou na reinicialização de estrutura de dados; 
- Defeitos de estrutura de controle: consistem em defeitos que causam um caminho incorreto dentro de um módulo; como exemplo, comandos condicionais incorretos que causam a execução de um caminho incorreto;

- Defeitos de interface: são defeitos que estão associados às estruturas que estão fora do ambiente local do módulo, mas que são utilizadas neste; por exemplo, uma incorreta declaração de uma variável global ou uma chamada incorreta de subrotina;

- Defeitos de dados: consistem em defeitos na utilização incorreta de uma estrutura de dados; por exemplo, uso incorreto de índices de arrays, uso de uma variável incorreta em uma equação ou uma declaração incorreta de uma variável;

- Defeitos de computação: são aqueles que causam uma avaliação incorreta no valor de uma variável.

\subsubsection{Taxonomia de DeMillo/Mathur}

O trabalho de DeMillo/Mathur [DEM95] aborda os defeitos que ocorrem na fase de codificação e classifica os defeitos em quatro classes, baseando-se em transformações sintáticas. Na convenção de DeMillo/Mathur, o termo entidade referese a uma cadeia de caracteres que se relaciona com um defeito. São caracterizadas quatro classes de defeitos:

- Falta de Entidade (Missing Entity Fault): são colocados nesta classe os defeitos cuja inserção de uma cadeia de caracteres faz com que o programa se comporte corretamente;

- Entidade Espúria (Spurious Entity Fault): são defeitos cuja correção requer a remoção de uma cadeia de caracteres que está causando o mau funcionamento do programa;

- Entidade Mal Empregada (Misplaced Entity Fault): são defeitos cuja correção do programa requer uma mudança na posição de uma cadeia de caracteres dentro do código.

- Entidade Simples Incorreta (Simple Incorrect Entity Fault): esta classe engloba todos os defeitos que não pertencem a nenhuma das outras classes acima. 
Para uma definição mais formal, considere a seguinte gramática livre de contexto que define a sintaxe de uma linguagem de programação:

$$
G=(N, \Sigma, R, S) \text {, onde: }
$$

$N$ denota o conjunto de símbolos não-terminais;

$\Sigma$ denota o conjunto de símbolos terminais;

$R$ é o conjunto de regras (mapeamento definido como $r: N \rightarrow(N \cup \Sigma) *$ );

$S$ é o símbolo inicial.

Considere ainda as letras gregas $\alpha, \beta, \ldots$ denotando elementos de $(N \cup \Sigma)^{*}$ e as letras minúsculas $a, b, c, \ldots$ denotando elementos de $\Sigma^{*}$. Considere também $L(G)$ uma linguagem gerada por $G$.

$\mathrm{O}$ símbolo $\Rightarrow$ corresponde a uma derivação em um passo usando derivação à esquerda. Os símbolos $\Rightarrow * \mathrm{e} \Rightarrow+$ correspondem, respectivamente, a zero ou mais a a um ou mais passos de derivação. Uma boa referência sobre os termos utilizados nessa definição formal é [AHO72].

Considere $P$ um programa em teste e $P^{\prime}$ um programa derivado de $P$ através da remoção de um ou mais defeitos; assume-se que $P$ e $P^{\prime}$ são programa sintaticamente válidos. Além disso, considere $X \in N$, sendo que:

$X: \because=\alpha_{1}\left|\alpha_{2}\right| \alpha_{3}|\ldots . ..| \alpha_{n}$

Considere $P^{\prime}$ um programa derivado do símbolo inicial $S$ como segue:

$$
\begin{aligned}
& S \Rightarrow+r X \delta \Rightarrow r \alpha_{i} \delta \Rightarrow * r s t \\
& \text { no qual } I \leq i \leq n, \alpha_{i} \Rightarrow * s \text { e } \delta \Rightarrow * t
\end{aligned}
$$

Definicão 1: $P$, consistindo de uma cadeia de caracteres $r s^{\prime} t$, é dito conter um defeito de Entidade Simples Incorreta se $P^{\prime}$ é derivado como em (1) e $P$ pode ser derivado como segue a seguir. Na Figura 2 é mostrada uma transformação genérica de defeitos dessa classe. 
$S \Rightarrow+r X \delta \Rightarrow r \alpha_{j} \delta \Rightarrow * r s^{\prime} t$

no qual $l \leq i \leq n, l \leq j \leq n, i \neq j, \alpha_{j} \Rightarrow * s^{\prime}$ e $\delta \Rightarrow * t$

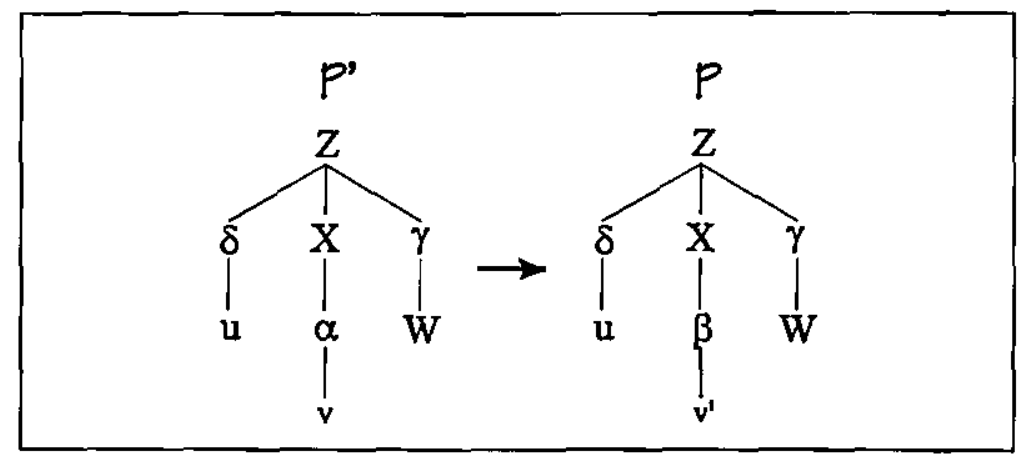

Figura 2: Transformação Genérica - Classe Entidade Simples Incorreta

Assuma agora que o elemento $X$ não-terminal é definido recursivamente pela seguinte regra:

$X \because:=\alpha X \beta \mid \gamma$

Considere $P^{\prime}$ podendo ser derivado como:

$$
\begin{aligned}
& S \Rightarrow^{*} u X \delta \Rightarrow i u^{i+1} X \beta^{l} \delta \Rightarrow * r \gamma \beta^{i} \delta \Rightarrow * r s t v \\
& \text { no qual } i \geq 0, u \alpha^{i} \equiv u^{i+1}, u^{i+1} \Rightarrow * r, \gamma \Rightarrow * s, \beta^{i} \Rightarrow * t \text { e } \delta \Rightarrow * v
\end{aligned}
$$

Definicão 2: $P$, consistindo de uma cadeia de caracteres $r^{\prime} s t^{\prime} v$, é dito conter um defeito de Falta de Entidade se $P^{\prime}$ é derivado como em (2) e $P$ pode ser derivado como segue abaixo. Na Figura 3, observa-se uma transformação genérica de defeitos da classe Falt a de Entidade.

$$
\begin{aligned}
& S \Rightarrow * u X \delta \Rightarrow(i-1) u^{i} X \beta^{i-1} \delta \Rightarrow u^{i} \gamma \beta^{i-l} \delta \Rightarrow * r^{\prime} s t^{\prime} v \\
& \text { no qual } u \alpha^{i-1} \Rightarrow * u^{i}, \gamma \beta^{i-1} \delta \Rightarrow * t^{\prime}, u^{i} \Rightarrow * r^{\prime}, \gamma \Rightarrow * s, \beta^{\prime-1} \Rightarrow * t^{\prime} \text { e } \delta \Rightarrow * v
\end{aligned}
$$




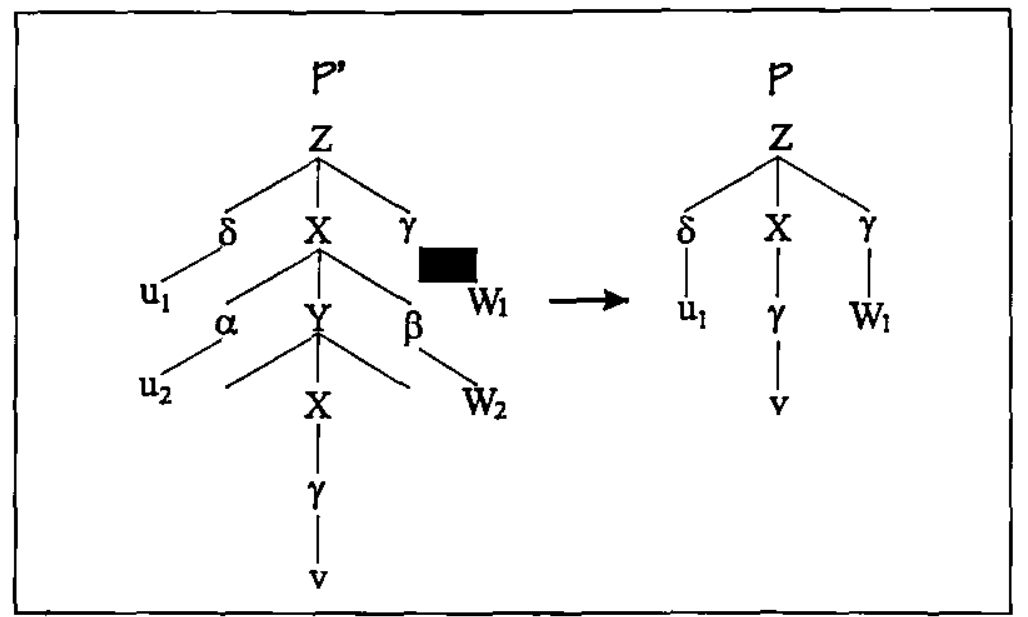

Figura 3: Transformą̧āo Genérica - Classe Falta de Entidade

Definicão 3: $P$, consistindo de uma cadeia de caracteres $r r^{\prime} t^{\prime} t v$, é dito conter um defeito de Entidade Espúria se $P^{\prime}$ é derivado como em (2) e $P$ pode ser derivado como segue abaixo. Uma transformação genérica dessa classe de defeitos pode ser vista na Figura 4.

$$
\begin{aligned}
& S \Rightarrow * u X \delta \Rightarrow i u^{i+1} X \beta^{i} \delta \Rightarrow * r \alpha X \beta \beta^{i} \delta \Rightarrow * r r^{\prime} \gamma \beta \beta^{i} \delta \Rightarrow * r r^{\prime} s t^{\prime} t v \\
& \text { no qual } i \geq 0, u \alpha^{i} \equiv u^{i+1}, u^{i+1} \Rightarrow * r, \gamma \Rightarrow * s, \beta^{i} \Rightarrow * t, \delta \Rightarrow * v, \alpha \Rightarrow * s^{\prime} \mathrm{e} \\
& \beta \Rightarrow * t^{\prime}
\end{aligned}
$$

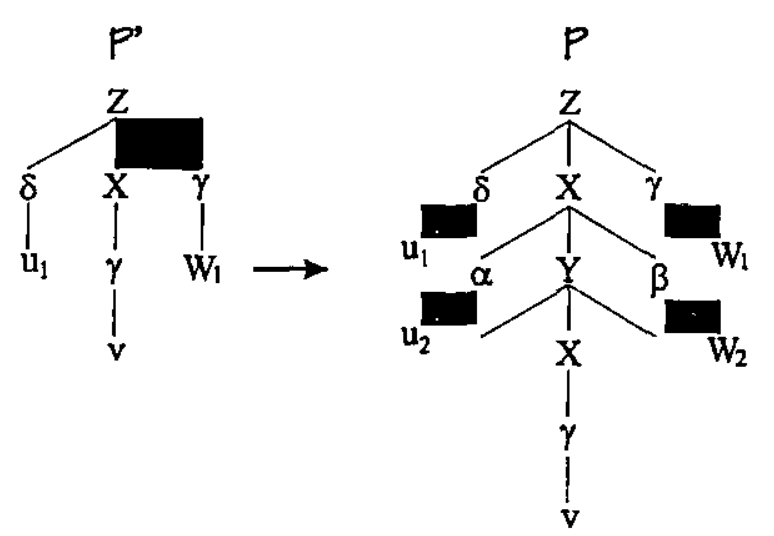

Figura 4: Transformação Genérica-Classe Entidade Espúria 
Definicão 4: O programa $P$ é dito conter um defeito de Entidade Mal Empregada se $P$ é uma permutação de $P^{\prime}$. Na Figura 5 é mostrada uma transformação genérica de defeitos dessa classe.

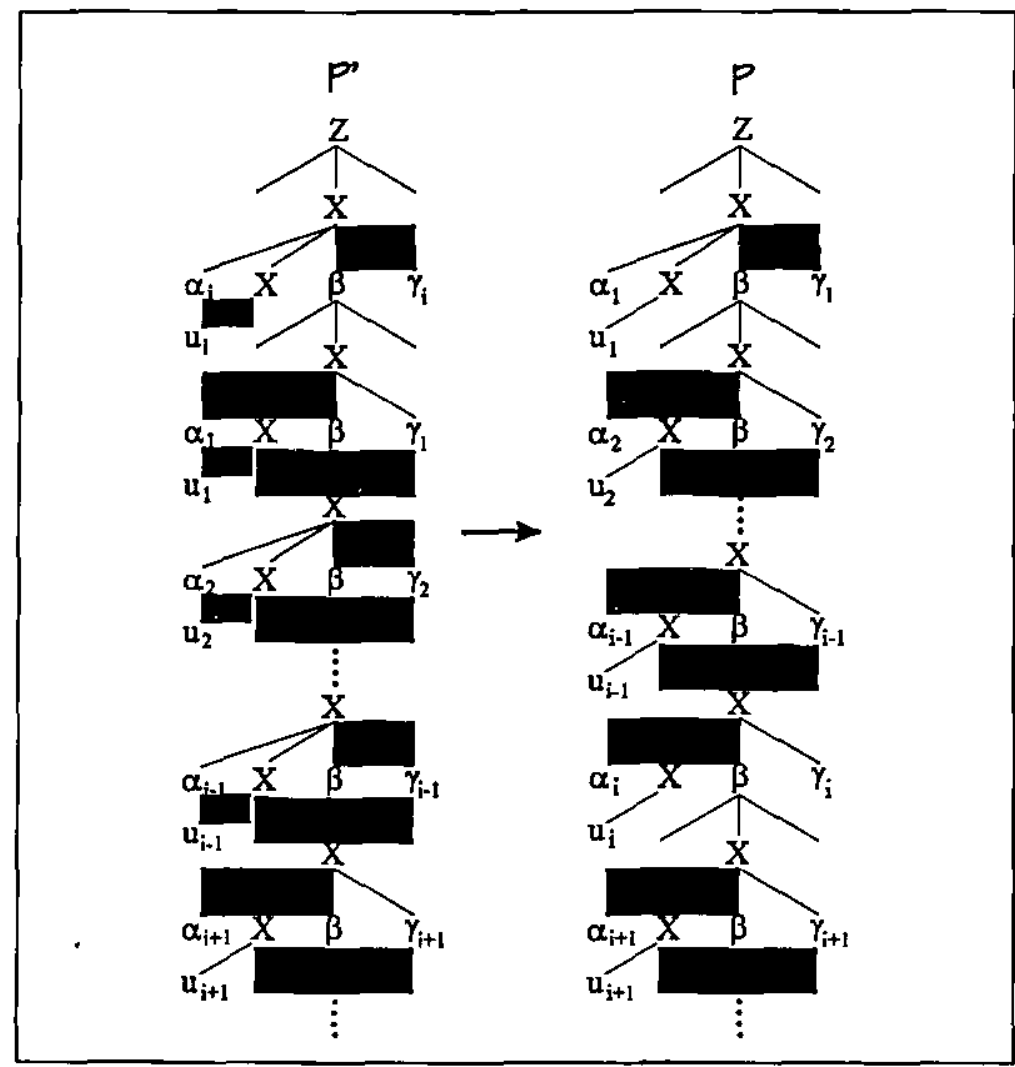

Figura 5: Transformação Genérica - Classe Entidade Mal Empregada

Além dessas quatro classes de defeitos, foram definidas outras subclasses para essas quatro classes modelando assim, defeitos mais específicos. No Quadro 2 são mostradas as classes e as subclasses propostas para essa taxonomia. Por exemplo, para defeitos de Entidade Simples Incorreta, foram estabelecidas as subclasses de defeitos de expressão, de comando, de tipo e de algoritmo. Além dessas subclasses, para aquelas que permitem mais detalhamento, foram criadas ainda outras subclasses. Como exemplo, tem-se para os defeitos de expressão - subclasse dos defeitos de Entidade Simples Incorreta - as subclasses de defeitos de precedente, de composição, de uso de ponteiro, de identificador, de constante e de operador.

Para essas classes é estabelecida uma prioridade para a aplicação das quatro classes de defeitos. Assim, se duas ou mais transformações em um programa estão associadas a um mesmo elemento terminal, aquela transformação que possuir maior prioridade será aplicada primeiro. 
As classes de defeitos da taxonomia de DeMillo são ordenadas de acordo com a seguinte ordem de prioridade: Entidade Mal Empregada com maior prioridade, em seguida Falta de Entidade, Entidade Espúria e Entidade Simples Incorreta tendo a menor prioridade. Essa priorização é atribuída às classes de defeitos com o objetivo de evitar ambigüidades na classificação dos defeitos.

DeMillo [DEM95] utilizou-se de sua taxonomia para classificar os defeitos do programa TEX relacionados por Knuth [KNU89] durante mais de dez anos de observações. Durante esse período foram identificados 867 defeitos. O TEX possui o equivalente a 21.573 LOC (linhas de código) escritas em linguagem C não incluindo comentários, assim tem-se aproximadamente 40 FKLOC (defeitos a cada 1.000 linhas de código).

Em seu trabalho, DeMillo utilizou-se dos 291 defeitos mais persistentes. Dos 291 defeitos, 155 foram classificados como pertencentes à classe Entidade Simples Incorreta; dessa forma, observa-se no Quadro 2 que $53,26 \%$ do total de defeitos são da classe Entidade Simples Incorreta, 40,55\% da classe Falta de Entidade, 0,69\% da classe Entidade Espúria e 5,50\% da classe Entidade Mal Empregada.

Observa-se que defeitos da classe Entidade Espúria ocorrem com a menor frequiência $(0,69 \%)$, enquanto que defeitos da Entidade Simples Incorreta são os que mais ocorrem $(53,26 \%)$. Observa-se também que existem subclasses, por exemplo, operador unário da subclasse expressão, este pertencente à classe Falta de Entidade, que não tem nenhum defeito classificado com tal. Logicamente, essa distribuição da freqüência dos defeitos que ocorrem em cada classe varia de programa para programa.

No material disponível sobre a taxonomia de DeMillo/Mathur não foi identificada a descrição de cada uma das subclasses. 
Quadro 2: Taxonomia de Defeitos de DeMillo/Mathur

\begin{tabular}{|c|c|c|c|}
\hline Classe & & Subclasse & \\
\hline \multirow{10}{*}{$\begin{array}{l}\text { Entidade Simples } \\
\text { Incorreta } \\
(53,26 \%)\end{array}$} & \multirow[t]{6}{*}{ expressão $(23,71 \%)$} & precedente $(2,06 \%)$ & \\
\hline & & composiçāo $(5,16 \%)$ & \\
\hline & & uso de ponteiro $(0,69 \%)$ & \\
\hline & & identificador $(11,34 \%)$ & \\
\hline & & constante $(2,06 \%)$ & \\
\hline & & operador $(2,40 \%)$ & \\
\hline & \multirow[t]{2}{*}{ comando $(1,03 \%)$} & chamada $(0,69 \%)$ & \\
\hline & & laço $(0,34 \%)$ & \\
\hline & tipo $(3,09 \%)$ & & \\
\hline & algoritmo $(25,43 \%)$ & & \\
\hline \multirow{11}{*}{$\begin{array}{l}\text { Falta de Entidade } \\
\qquad(40,55 \%)\end{array}$} & \multirow{2}{*}{$\begin{array}{l}\text { seqüiência de código } \\
(9,96 \%)\end{array}$} & case $(1,03 \%)$ & \\
\hline & & outros $(8,93 \%)$ & \\
\hline & \multirow{5}{*}{ comando $(19,59 \%)$} & atribuição $(12,37 \%)$ & inicializaçāo $(4,81 \%)$ \\
\hline & & & outros $(7,56 \%)$ \\
\hline & & chamada $(2,41 \%)$ & \\
\hline & & goto $(0,69 \%)$ & \\
\hline & & condicional $(4,12 \%)$ & \\
\hline & \multirow{4}{*}{ expressão $(11,00 \%)$} & condicãa $(11,00 \%)$ & \\
\hline & & parâmetro $(0,00 \%)$ & \\
\hline & & operador unário $(0,00 \%)$ & \\
\hline & & outros $(0,00 \%)$ & \\
\hline \multicolumn{4}{|l|}{$\begin{array}{c}\text { Entidade Espúria } \\
(0,69 \%)\end{array}$} \\
\hline \multirow{2}{*}{$\begin{array}{c}\text { Entidade Mal } \\
\text { Empregada }(5,50 \%)\end{array}$} & parâmetro $(0,69 \%)$ & & \\
\hline & comando $(4,81 \%)$ & & \\
\hline
\end{tabular}

\subsection{Esquema de Injeção de Defeitos}

O esquema de injeção de defeitos estabelecido é baseado na taxonomia de defeitos de DeMillo/Mathur, uma modelagem mais de alto nível, e nos operadores de mutação [AGR89] do critério de teste denominado Análise de Mutantes [BUD81, DEL93b] para o teste de unidade, que modelam defeitos mais específicos em nível de implementação.

A escolha da taxonomia de DeMillo deve-se ao fato desta identificar-se com os objetivos deste trabalho — a injeção de defeịtos de software em nível de implementação - além de fornecer um mecanismo mais rigoroso para a classificação dos defeitos através de uma definição formal das classes de defeitos, consequientemente facilitando a automatização se comparado com outras taxonomias. 
Além disso, essa taxonomia não apresenta o problema de ambigüidade como identificada nas demais taxonomias comentadas anteriormente.

Os operadores de mutação são capazes de gerar transformações sintáticas — que podem ser encaradas também como defeitos - no código fonte do programa em avaliação. Segundo DeMillo [DEM78], esses operadores retratam os defeitos mais comuns cometidos pelo programador ao longo do processo de desenvolvimento do software. A descrição dos operadores de mutação do critério Análise de Mutantes é apresentada no Apêndice A.

Retomando, os tipos de defeitos injetados pela ferramenta FINE [KAO93] podem ser gerados por alguns dos operadores de mutação dos critérios Análise de Mutantes [DEL93b, DEL94] e Mutação de Interface [DEL96, DEL97a, DEL97b], o que vem a monstrar a relevância da utilização dos operadores de mutação no processo de geração e injeção de defeitos. Por exemplo, o operador Vsrr (Scalar Variable Reference Replacement) que modela defeitos de uso incorreto de uma variável escalar no lugar de outra e pertencente à classe Mutação de Variável da classificação de Agrawal [AGR89] pode modelar a classe Defeitos de Atribuição injetados pela FINE.

No Quadro 3 observa-se o mapeamento da taxonomia de DeMillo/Mathur para os 71 operadores de mutação. Para a realização deste mapeamento, considerou-se somente o nível das classes.

A tarefa de classificação dos operadores de mutação pode ser considerada uma atividade subjetiva e é um ponto crítico da proposta de trabalho. Dependendo do código no qual é aplicado, o operador pode pertencer a uma ou a outra classe, pois apresenta um comportamento variado. Isso ocorre com alguns dos operadores: Oido, SWDD e SDWD. Uma estratégia adotada para classificar esses operadores foi o número de operadores já classificados em tal classe. Dessa forma, os três operadores foram associados à classe Entidade Mal Empregada, a classe que possuía menos operadores.

Considere o operador Oido (Increment/Decrement), pertencente à classe Mutação de Operadores. Esse operador modela defeitos relacionados ao uso incorreto de $++\mathrm{e}$ - - no programa. Se sobre um comando $a++$ são gerados defeitos utilizando-se o operador Oido, este irá gerar dois defeitos: $a--\mathrm{e}++a$. Considerando o defeito $a--$, Oido é classificado como Entidade Simples Incorreta, mas considerando $++a$, Oido é colocado na classe Entidade Mal Empregada. 
Quadro 3: Classes de Defeitos $x$ Operadores de Mutaçäo

\begin{tabular}{|c|c|c|c|c|c|}
\hline & $\begin{array}{c}\text { Mutação de } \\
\text { Comandos }\end{array}$ & \multicolumn{2}{|c|}{ Mutação de Operadores } & $\begin{array}{l}\text { Mutação de } \\
\text { Constantes }\end{array}$ & $\begin{array}{l}\text { Mutação de } \\
\text { Variáveis }\end{array}$ \\
\hline $\begin{array}{l}\text { Entidade } \\
\text { Simples } \\
\text { Incorreta }\end{array}$ & $\begin{array}{l}\text { SBRC } \\
\text { SBRn } \\
\text { SCRB } \\
\text { SCRn } \\
\text { SGLR } \\
\text { SRSR } \\
\text { STRP }\end{array}$ & $\begin{array}{l}\text { OAAA } \\
\text { OAAN } \\
\text { OABA } \\
\text { OABN } \\
\text { OALN } \\
\text { OARN } \\
\text { OASA } \\
\text { OASN } \\
\text { OBAA } \\
\text { OBAN } \\
\text { OBBA } \\
\text { OBBN } \\
\text { OBLN } \\
\text { OBRN } \\
\text { OBSA } \\
\text { OBSN } \\
\text { OCOR } \\
\text { OLAN }\end{array}$ & $\begin{array}{l}\text { OLBN } \\
\text { OLLN } \\
\text { OLRN } \\
\text { OLSN } \\
\text { ORAN } \\
\text { ORBN } \\
\text { ORLN } \\
\text { ORRN } \\
\text { ORSN } \\
\text { OSAA } \\
\text { OSAN } \\
\text { OSBA } \\
\text { OSBN } \\
\text { OSLN } \\
\text { OSRN } \\
\text { OSSA } \\
\text { OSSN }\end{array}$ & $\begin{array}{l}\text { CRCR } \\
\text { Cccr } \\
\text { Ccsr }\end{array}$ & $\begin{array}{c}\text { Varr } \\
\text { Vprr } \\
\text { VSCR } \\
\text { Vsrr } \\
\text { Vtrr } \\
\\
.\end{array}$ \\
\hline $\begin{array}{l}\text { Entidade } \\
\text { Espúria }\end{array}$ & $\begin{array}{c}\text { SMTT } \\
\text { SMTC } \\
\text { SSWM } \\
\text { STRI }\end{array}$ & $\begin{array}{l}\text { OBNG } \\
\text { OCNG } \\
\text { OEAA } \\
\text { OEBA }\end{array}$ & $\begin{array}{l}\text { OESA } \\
\text { OIPM } \\
\text { OLNG }\end{array}$ & & $\begin{array}{l}\text { VDTR } \\
\text { VTWD }\end{array}$ \\
\hline $\begin{array}{l}\text { Falta de } \\
\text { Entidade }\end{array}$ & SSDL & $\begin{array}{l}\text { OAEA } \\
\text { OBEA }\end{array}$ & OSEA & & \\
\hline $\begin{array}{l}\text { Entidade } \\
\text { Mal } \\
\text { Empregada }\end{array}$ & $\begin{array}{l}\text { SDWD } \\
\text { SMVB } \\
\text { SWDD }\end{array}$ & & & & \\
\hline
\end{tabular}

A classificação mostrada no Quadro 3 é o resultado de um estudo bastante rigoroso do comportamento real de cada um dos operadores de mutação da ferramenta Proteum [DEL93b]. De modo geral, os operadores que manipulam comandos (Mutação de Comandos) foram os mais difíceis de serem analisados e classificados, pois os defeitos gerados por esses operadores geralmente envolvem trechos de código maiores. Além disso, para gerar um defeito, alguns dos operadores realizam modificaçōes em mais de um ponto dentro do código. Por exemplo, o operador SWDD que troca o comando while por do-while; esse operador faz modificações em dois pontos dentro do código do programa. 
Como exemplo de mapeamento, considere o operador SSDL (Statement Deletion) que tem a função de apagar comandos no código do programa, pertencente à classe Mutação de Comandos da classificação de Agrawal [AGR89], retratando defeitos de falta de comandos. Esse operador foi então relacionado à classe Defeito de Falta de Entidade da taxonomia adotada.

Um outro exemplo é o operador ORRN (Operator Relational Relational Nonassignment) que troca um operador relacional por outro relacional, pertencente à classe Mutação de Operador e representando defeitos de operadores relacionais empregados incorretamente. Por realizar esse tipo de mudança no código, esse operador foi classificado como Defeito de Entidade Simples Incorreta. Na Figura 6 é mostrada a transformação sintática que modela um defeito gerado por esse operador.

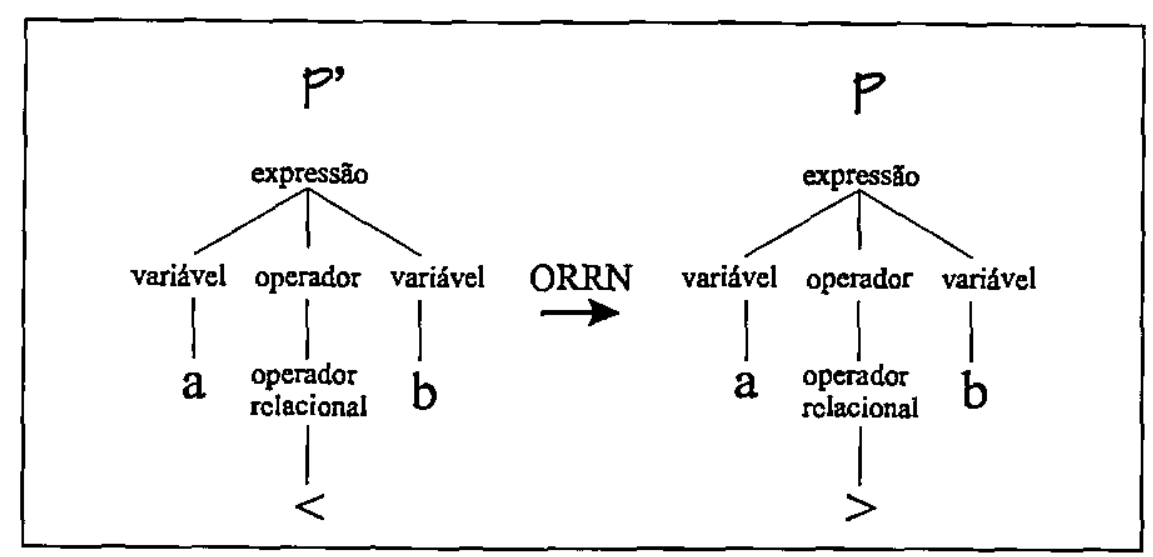

Figura 6: Exemplo de Transformação - Entidade Simples Incorreta

O operador OEAA (Operator plain assignmEnt Arithmetic Assignment) troca um operador de igualdade $(\Rightarrow$ pelos operadores aritméticos com atribuição $(*=, 1=, \%=$, $+=,-=)$, representando defeitos na aplicação de operadores aritméticos com atribuição no lugar do operador de igualdade. Observando-se na Figura 7 a transformação gerada por esse operador, conclui-se que o operador deve ser associado à classe Entidade Espúria. 


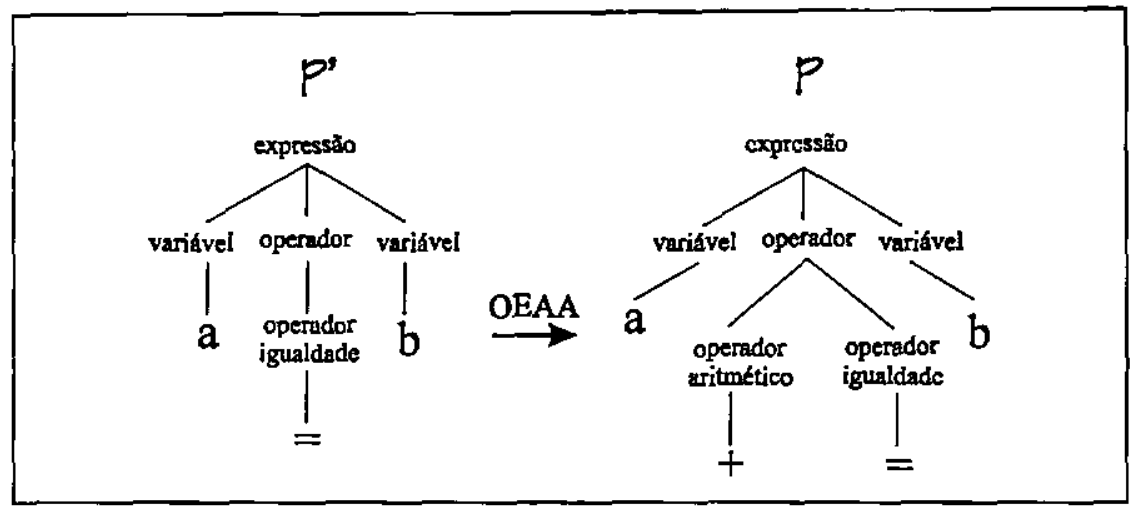

Figura 7: Exemplo de Transformaçāo - Entidade Espúria

\subsection{Considerações Finais}

Neste capítulo foram apresentadas e descritas as taxonomias de defeitos identificadas na literatura, como a taxonomia da IBM e de DeMillo/Mathur. Considerando a diversidade de taxonomias, observa-se a preocupação em entender os defeitos de software, o que pode ser considerado um importante passo para o estabelecimento e validação de modelos de defeitos de software. Como dito no Capítulo 2, os modelos de defeitos são essenciais para as diversas atividades relacionadas ao desenvolvimento de software.

Apresentou-se também o esquema de injeção de defeitos baseado no mapeamento da taxonomia de DeMillo/Mathur para os operadores de mutação do critério Análise de Mutantes para o teste de unidade. Esse mapeamento não é trivial, uma vez que, dependendo do código sobre o qual está se aplicando o operador, seu comportamento é ambíguo.

Um passo que poderia complementar a atividade de elaboração do esquema de injeção de defeitos seria o projeto de novos operadores de mutação que gerem defeitos para as subclasses que não tiveram operadores relacionados. Por exemplo, dentre os operadores de mutação do critério Análise de Mutantes, nenhum operador é classificado na subclasse expressão da classe Falta de Entidade.

No capítulo seguinte será apresentada a especificação e a implementação de uma ferramenta de injeção de defeitos de software, denominada ITool, que aplica o esquema de injeção de defeitos baseado na taxonomia de DeMillo/Mathur e nos operadores de mutação do critério Análise de Mutantes. 


\section{Capítulo 4}

\section{Projeto e Implementação da Ferramenta}

Neste capítulo é apresentada a ferramenta de injeção de defeitos, denominada ITool, e suas principais características. A seguir, são comentados a interface gráfica e os módulos funcionais da ferramenta. Em seguida, são descritas a base de dados gerada pela ferramenta e as considerações finais sobre a ferramenta implementada.

\subsection{Considerações Iniciais}

O projeto e a implementação de uma ferramenta que automatize a atividade de injeção de defeitos é uma solução bastante relevante visto que, atualmente, os sistemas computacionais têm-se tornado cada vez mais complexos e essa atividade, realizada manualmente, é quase impraticável, além de estar propensa a erros decorrentes da intervenção humana.

Assim, o principal objetivo deste trabalho é o projeto e a implementação de um protótipo de uma ferramenta de injeção de defeitos de software, denominada ITool.

Esta ferramenta poderá ser empregada na área de Tolerância a Defeitos, viabilizando a condução de estudos teóricos e empíricos, validando mecanismos de tolerância a defeitos implementados. Se empregada à luz do critério Semeadura de Defeitos, um dos critérios de teste baseado em defeitos, poderá ser utilizada para avaliar a remoção de defeitos, além de contribuir para estimar o número de defeitos remanescentes no software frente ao número de defeitos removidos.

Um aspecto bastante importante é a característica de ser multilinguagem, a exemplo do que ocorre em outras ferramentas [CHA91, DEL93b]: Inicialmente, a ferramenta ITool será configurada para a geração, a injeção e a ativação/desativação de defeitos para programas escritos em linguagem $\mathrm{C}$, mas pode ser configurada para outras linguagens de programação como Fortran e $\mathrm{C}++$, uma vez que um conjunto de módulos da ferramenta será construído de forma genérica, isto é, independente da linguagem alvo (linguagem em que está escrito o programa a ser avaliado). 
Um outro aspecto relevante é a flexibilidade de uso. A utilização da ferramenta através de uma interface gráfica em um ambiente de janelas ou através dos módulos executáveis independentes via shell script permite ao usuário escolher o modo de utilização mais conveniente à sua necessidade. Uma das vantagens da utilização via shell scripts é a possibilidade de execução em batch de sessões de teste longas; no entanto, requer conhecimento por parte do usuário dos módulos e dos parâmetros requeridos por esses módulos.

Atualmente, interfaces gráficas têm sido cada vez mais necessárias em ferramentas de software, satisfazendo ao requisito de usabilidade dessas ferramentas [NIE90]. Uma ferramenta que vem sendo muito utilizada para a construção de interfaces gráficas é o Tc/Tk [OUS94, WEL95]. O Tcl é uma linguagem de script e o Tk é um toolkit (conjunto de bibliotecas) de objetos gráficos de interface do usuário. Será discutida adiante na Seção 4.2 , mais detalhes sobre o Tcl/Tk.

A independência da interface gráfica com os módulos funcionais executáveis traz vantagens, principalmente com relação à facilidade de manutenção, tanto da interface do usuário como dos módulos executáveis, e de portabilidade para outras plataformas de software.

Um outro aspecto interessante de ferramentas de teste são as sessões de teste, assim como ocorre na ferramenta Proteum [DEL93b, DEL94]. Uma sessão de teste é caracterizada por um conjunto de informaçōes, como por exemplo, o nome do arquivo fonte e do executável do programa em avaliação, o conjunto de casos de teste e os resultados alcançados referenciada por um nome. Tendo-se uma sessão de teste, após tê-la iniciada, pode-se interrompê-la e retomá-la mais tarde do ponto em que foi interrompida.

Nessa perspectiva, as funcionalidades desejáveis de uma ferramenta de injeção de defeitos podem ser resumidas em:

- gerenciamento da sessão de teste;

- tratamento de casos de teste: adição, eliminação, visualização e importação de casos de teste;

- seleção e visualização de um modelo de defeitos, ativação/desativação de classes e de operadores de mutação;

- geração, injeção, ativação/desativação de defeitos e execução do programa com defeitos injetados;

- identificação pelo usuário dos defeitos reais do programa; e 
- avaliação dos resultados e impressão de relatórios.

Na Figura 8 é mostrado o esquema geral da ferramenta. Através da interface gráfica, o usuário pode interagir com os módulos funcionais executáveis que acessam a base de dados da ferramenta. Para a execução de funções mais simples, como por exemplo, carregar um modelo de defeitos para visualização, os módulos da interface gráfica acessam diretamente a base de dados, sem a necessidade de chamar um módulo executável.

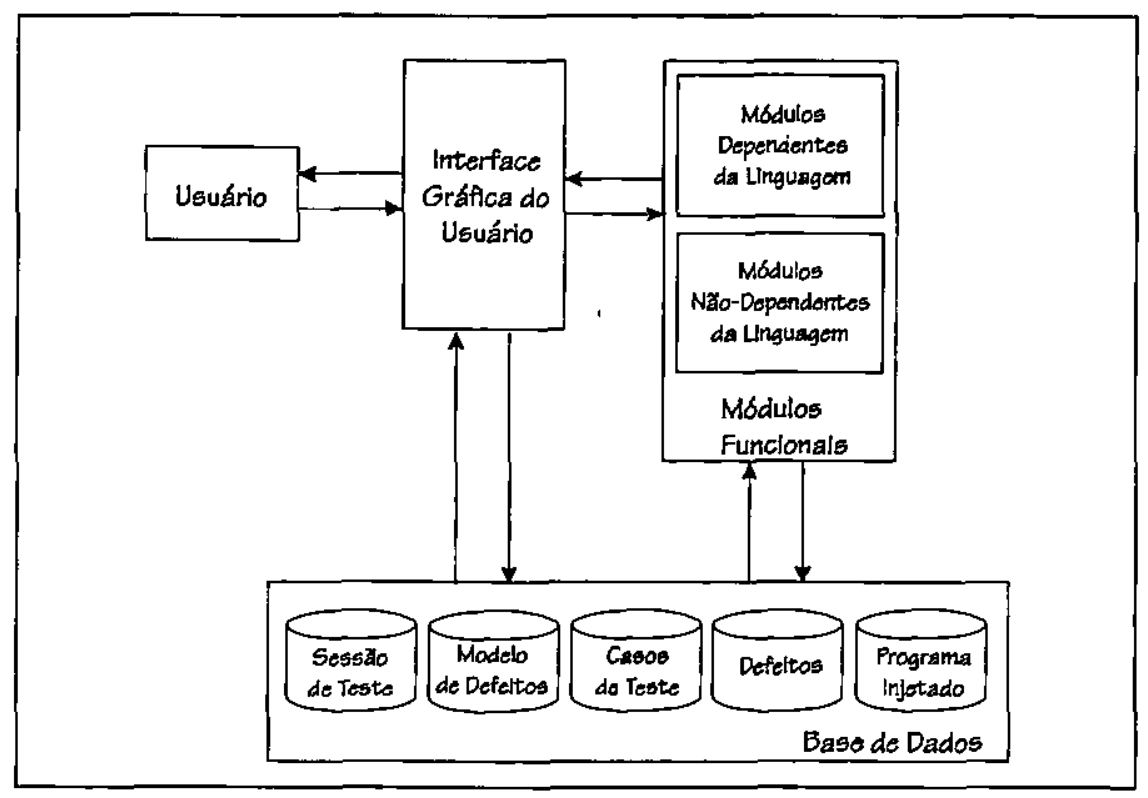

Figura 8: Esquema Geral da Ferramenta ITool

Os módulos funcionais da ferramenta dividem-se em: módulos dependentes da linguagem e módulos não-dependentes da linguagem. Os módulos dependentes da linguagem são aqueles que deverão ser modificados se a ferramenta for designada a avaliar programas que estejam escritos em outras linguagens diferentes de $\mathrm{C}$; por outro lado, os módulos não-dependentes da linguagem são aqueles que não dependem da linguagem em que estão escritos os programas em avaliação. Na Seção 4.3 deste capítulo sāo comentados os módulos funcionais da ITool.

Observa-se ainda na Figura 8, a base de dados da ferramenta. Nessa base de dados estão contidas as informações globais (Sessão de Teste), além dos arquivos contendo os modelos de defeitos (Modelo de Defeitos), dos casos de teste utilizados (Casos de Teste), dos defeitos gerados pelos operadores de mutação (Defeitos) e das informaçōes sobre os defeitos que foram injetados e seus estados de ativação sobre o 
programa em avaliação (Programa Injetado). Mais detalhes sobre a base de dados são comentados adiante na Seção 4.4.

Assim como a Proteum, a ITool trabalha com ambiente compilado, ou seja, o programa com defeitos injetados é compilado e não interpretado. No modo interpretado, que é muito "parecido" com a Injeção de Defeitos Dinâmica [BEI90], apresenta vantagens pois não requer diversas compilações, uma vez que o estado do sistema é modificado. Por outro lado, o modo compilado apresenta outras vantagens. $O$ tempo de execução de um programa compilado é inferior do que o de um programa interpretado; além disso, não existe a interferência de um interpretador, pois algumas vezes esse pode falhar em reproduzir o ambiente no qual o programa é executado, fazendo com que seu comportamento, no instante do teste, seja diferente do esperado [DEL93b].

\subsection{Interface do Usuário}

Como já comentado na seção anterior, o fator usabilidade implicou a implementação da interface gráfica para a ferramenta. Essa interface foi desenvolvida utilizando-se o Tcl/Tk em ambiente operacional Solaris.

O Tcl (Tool Command Language) é uma linguagem de script que oferece um conjunto de comandos e requer um interpretador denominado tclsh para sua utilização; os comandos dessa linguagem possuem uma interface clara e simples de ser utilizada.

Existem diversas extensões para o $\mathrm{Tcl}$, sendo que uma das mais conhecidas e utilizadas é o Tk, um toolkit que permite criar facilmente interfaces gráficas do usuário para o sistema $\mathrm{X}$ ( $X$ Window System), utilizando script $\mathrm{T} c \mathrm{l}$ ao invés de linguagens de programação, tais como $\mathrm{C}$ e $\mathrm{C}++$. O interpretador do Tk denomina-se wish, uma shell que permite também criar interativamente uma aplicação contendo objetos gráficos de interface - menus, botões, barras de rolagem, entre outros - utilizando-se de comandos do $\mathrm{Tcl}$ e funções do Tk.

A escolha do $T c l / T k$ deve-se às vantagens apresentadas por este se comparado com outros toolkits como o Xview [HEL91] e o wxWindows ${ }^{1}$, além de sua grande difusão em centros de pesquisa e universidades.

\footnotetext{
' http://web.ukonline.co.uk/julian.smart/wxwin' (03 de janeiro, 1998)
} 
Como vantagens apresentadas pelo $\mathrm{Tcl} / \mathrm{Tk}$ pode-se destacar a construção rápida de protótipos e a facilidade de portabilidade para diferentes plataformas operacionais, como Solaris e Linux. Além disso, por tratar-se de uma linguagem interpretada, apresenta um rápido turnaround, pois não requer tempo de compilação, embora o tempo de execução de um programa interpretado seja superior ao do programa compilado. O mesmo código em Tcl/Tk que roda em ambiente Solaris' pode ser executado em outro ambiente, por exemplo, em Linux, sem a necessidade de mudanças no código, havendo somente a necessidade do interpretador disponível nesse ambiente.

A interface gráfica implementada para a ITool possui 22 janelas, totalizando 4.837 linhas de código em Tcl/Tk, incluindo comentários e divididos em 12 unidades ${ }^{2}$ listadas e descritas brevemente no Quadro 4. No Apêndice $C$, juntamente com um exemplo, são mostradas as janelas que compõem a interface gráfica. Neste capítulo, somente as principais janelas serão mostradas e comentadas.

Quadro 4: Unidades da Interface Gráfica

\begin{tabular}{|l|l|c|}
\hline Unidade & \multicolumn{1}{|c|}{ Comentário } & LOC \\
\hline itool & Janela principal e menu principal. & 194 \\
\hline iprogram.tcl & Janelas relacionadas ao botão ProgTest do menu principal. & 312 \\
\hline imodel.tcl & Janelas relacionadas ao botão FaultModel do menu principal. & 495 \\
\hline itcase.tcl & Janelas relacionadas ao botão TestCase do menu principal. & 947 \\
\hline iinject.tcl & Janelas relacionadas ao botão Inject do menu principal. & 498 \\
\hline ireport.tcl & Janelas relacionadas ao botão Reports do menu principal. & 188 \\
\hline iprops.tcl & Janelas relacionadas ao botão Properties do menu principal. & 165 \\
\hline istatus.tcl & Janelas relacionadas ao botão Status do menu principal. & 147 \\
\hline iglobal.tcl & Variáveis e definiçōes globais. & 109 \\
\hline igeral.tcl & Procedimentos gerais relacionados à interface. & 341 \\
\hline geral.tcl & Procedimentos gerais não relacionados à interface. & 862 \\
\hline inter.tcl & Interface entre módulos funcionais e inter face do usuário. & 579 \\
\hline TOTAL & & 4.837 \\
\hline
\end{tabular}

Na Figura 9 é apresentada a janela principal da ITool. Essa janela apresenta um menu principal associado às principais funcionalidades da ferramenta.

${ }^{2}$ Está utilizand'-se o termo unidade para referir-se a um arquivo que agrupa um conjunto de procedimentos re:acionados 


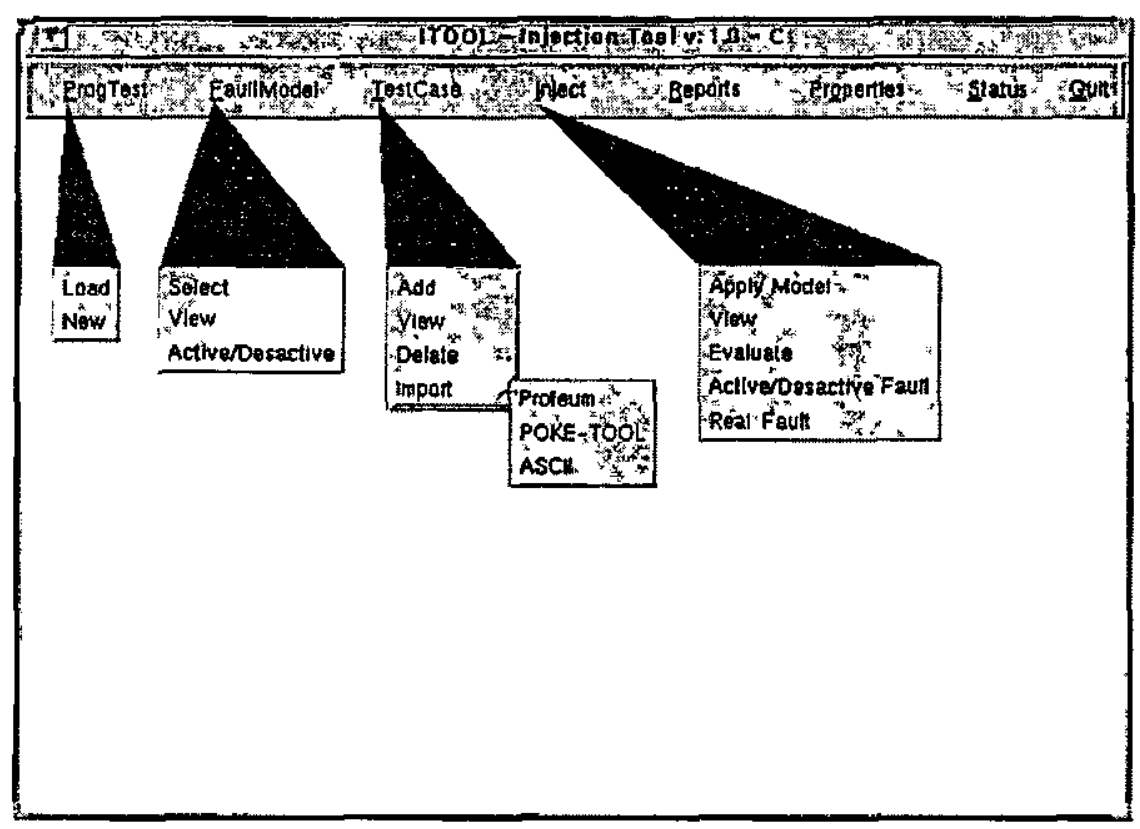

Figura 9: Janela Principal da Ferramenta ITool

De maneira geral, a ferramenta trabalha com sessões de teste (opção ProgTest do menu da janela principal apresentada na Figura 9). A ferramenta ainda permite a manipulação de modelos de defeitos (opção FaultModel), além da manipulação de casos de teste (opção TestCase), bem como do programa com defeitos injetados (opção Inject). Permite ainda a impressão de relatórios (opção Report) e o acompanhamento do andamento da avaliação dos defeitos injetados (opção Status). A opção Properties permite selecionar opções default que serão utilizadas no decorrer da utilização da ferramenta, como por exemplo, o nome de diretório de trabalho.

A opção ProgTest habilita um menu suspenso com as opções Load (carrega uma sessão de teste) e New (cria uma nova sessão de teste). Na opção FaultModel tem-se um menu com as opções Select (seleciona um modelo de defeito a ser utilizado); View (visualiza o modelo de defeitos) e Active/Deactive (ativa e desativa as classes de defeitos e os operadores de mutação). A opção TestCase disponibiliza um menu contendo as opções Add (adiciona casos de teste na base de dados); View (visualiza casos de teste); Delete (apaga casos de teste) e Import (importa casos de teste de arquivos ASCII e de sessões de teste de outras ferramentas - Proteum [DEL93b, DEL94] e POKE-TOOL [CHA91, MAL89] - adicionando-os à base de dados). A opção Inject habilita um menu que disponibiliza as opções Apply Model (aplica o modelo de defeitos na seleção e na injeção de defeitos); View (visualiza o programa com defeitos injetados); Evaluate (executa o programa com defeitos injetados utilizando os casos de teste e mostra os resultados); Active/Deactive Fault (permite ao 
usuário ativar e desativar defeitos injetados) e Real Fault (permite ao usuário, a localizar um defeito real, eliminar esse defeito através da edição do programa em avaliação).

De modo geral, os pontos mais relevantes desta ferramenta são as opções FaultModel e Inject, por isso serão comentadas dando-lhes ênfase.

Relacionados à opção FaultModel, estão as opções Select, View e Active/Deactive. Estas chamam as janelas vistas nas Figuras 10,11 e 12. Na Figura 10 é mostrada a janela que permite ao usuário selecionar um modelo de defeitos a ser utilizado para a seleção e injeção de defeitos. Na Figura 11 é possível visualizar o modelo de defeitos e na Figura 12 são apresentadas as janelas que permitem ao usuário manipular o modelo de defeitos através da ativação/desativação de classes de defeitos e de operadores de mutação para a geração dos defeitos.

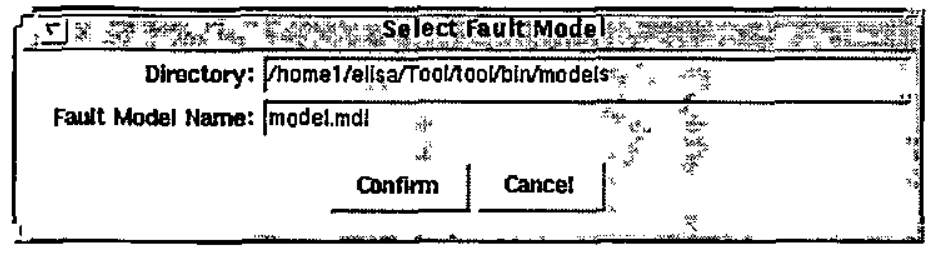

Figura 10: Selecionando um Modelo de Defeitos

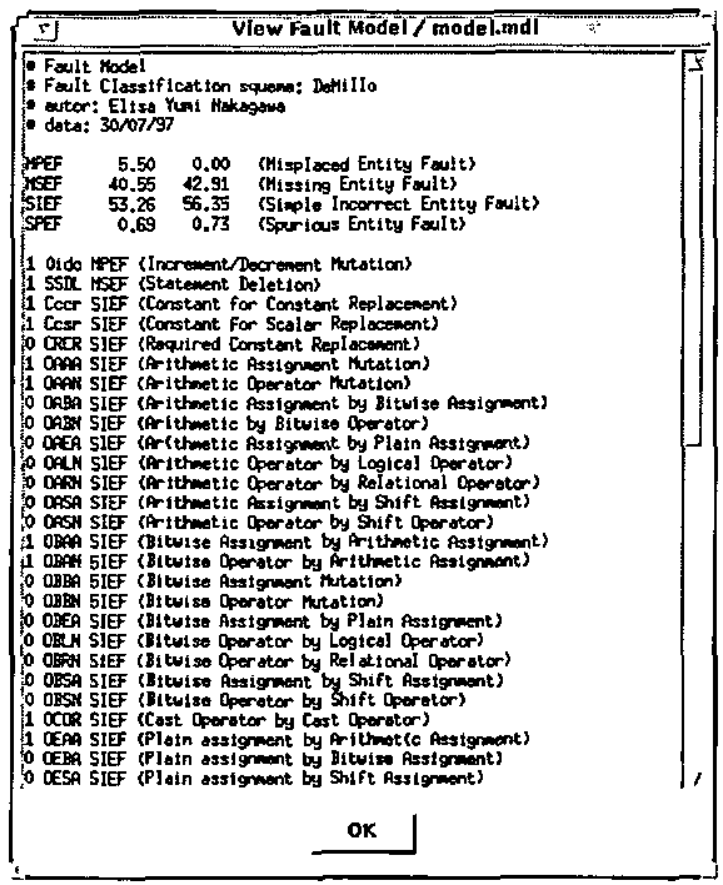

Figura 11: Visualizando um Modelo de Defeitos 


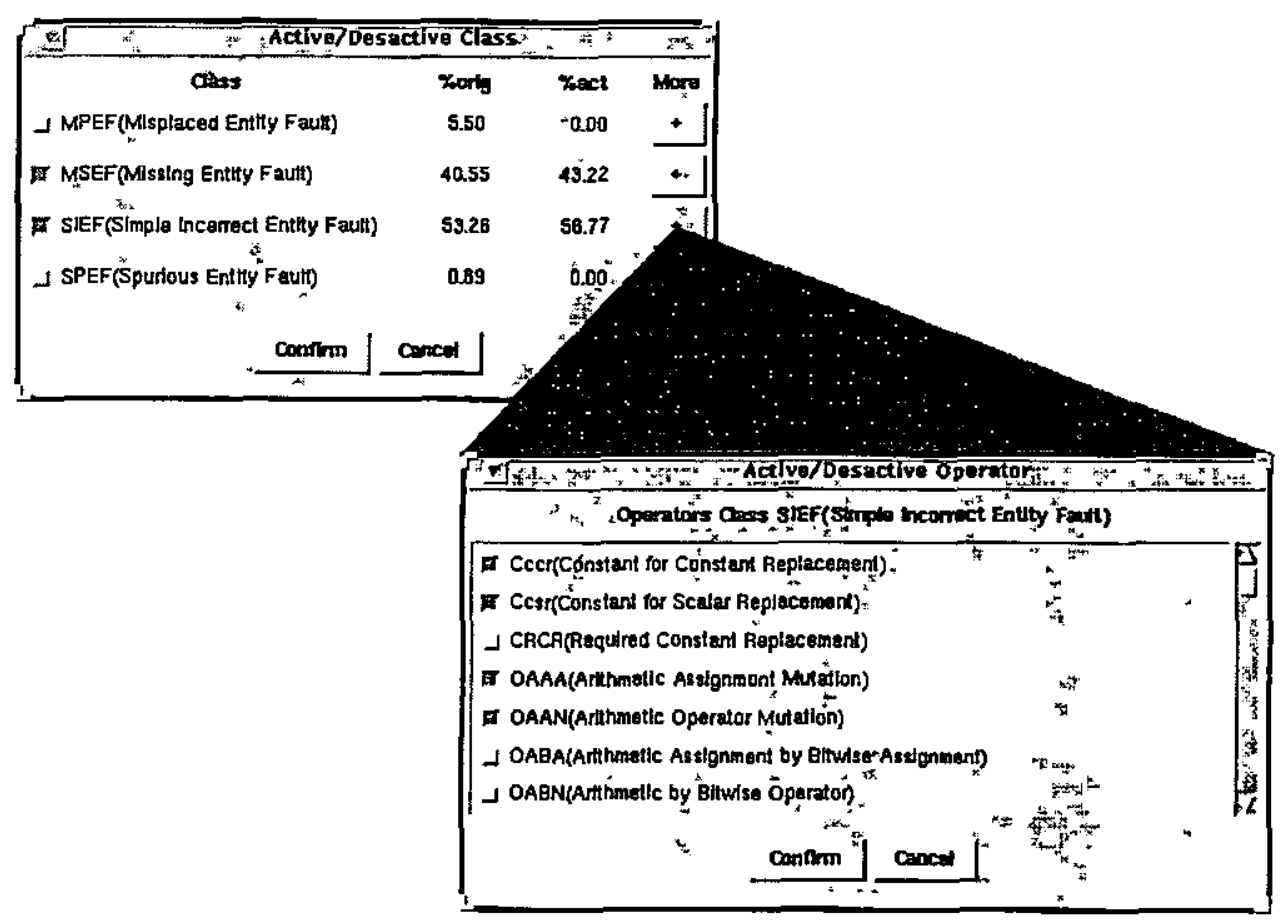

Figura 12: Ativando/Desativando Classes de Defeitos e Operadores de Mutação

Com relação à injeção de defeitos propriamente dita (opção Inject do menu principal), pode-se chamar a janela apresentada na Figura 13, que ilustra a aplicação do modelo de defeitos no processo de seleção e injeção de defeitos. Através dessa janela pode-se selecionar o número de defeitos que se deseja injetar (Fault/KLOC) e os blocos, ou seja, as unidades que se deseja avaliar.

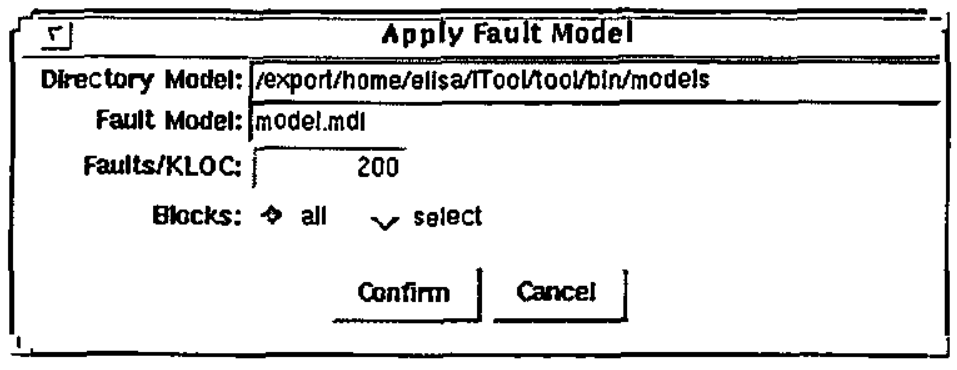

Figura 13: Aplicando o Modelo de Defeitos

Na Figura 14 é mostrada a janela que permite a visualização do código do programa com os defeitos injetados. Na Figura 15 é mostrada a janela que permite ao usuário a ativação/desativação de defeitos injetados no programa em avaliação, sendo esse um dos pontos fortes na utilização de uma interface gráfica. 


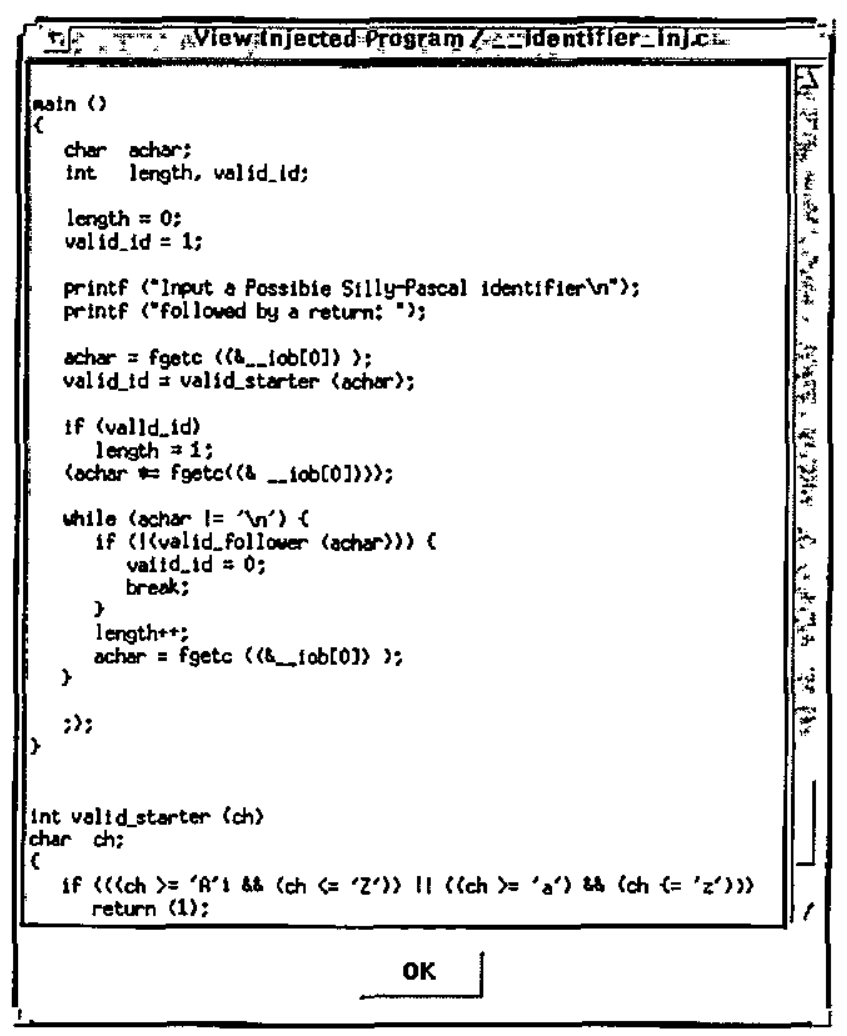

Figura 14: Visualizando o Programa com Defeitos Injetados

Utilizando-se somente os módulos e não a interface gráfica, a ativação/desativação é dificultada, uma vez que não é possível localizar o trecho do código no qual está o defeito e a ativação/desativação do defeito é realizada sem o conhecimento por parte do usuário da localização e das características do defeito; o usuário tem somente a informação da classe a que pertence esse defeito e do operador responsável pela sua geração. 


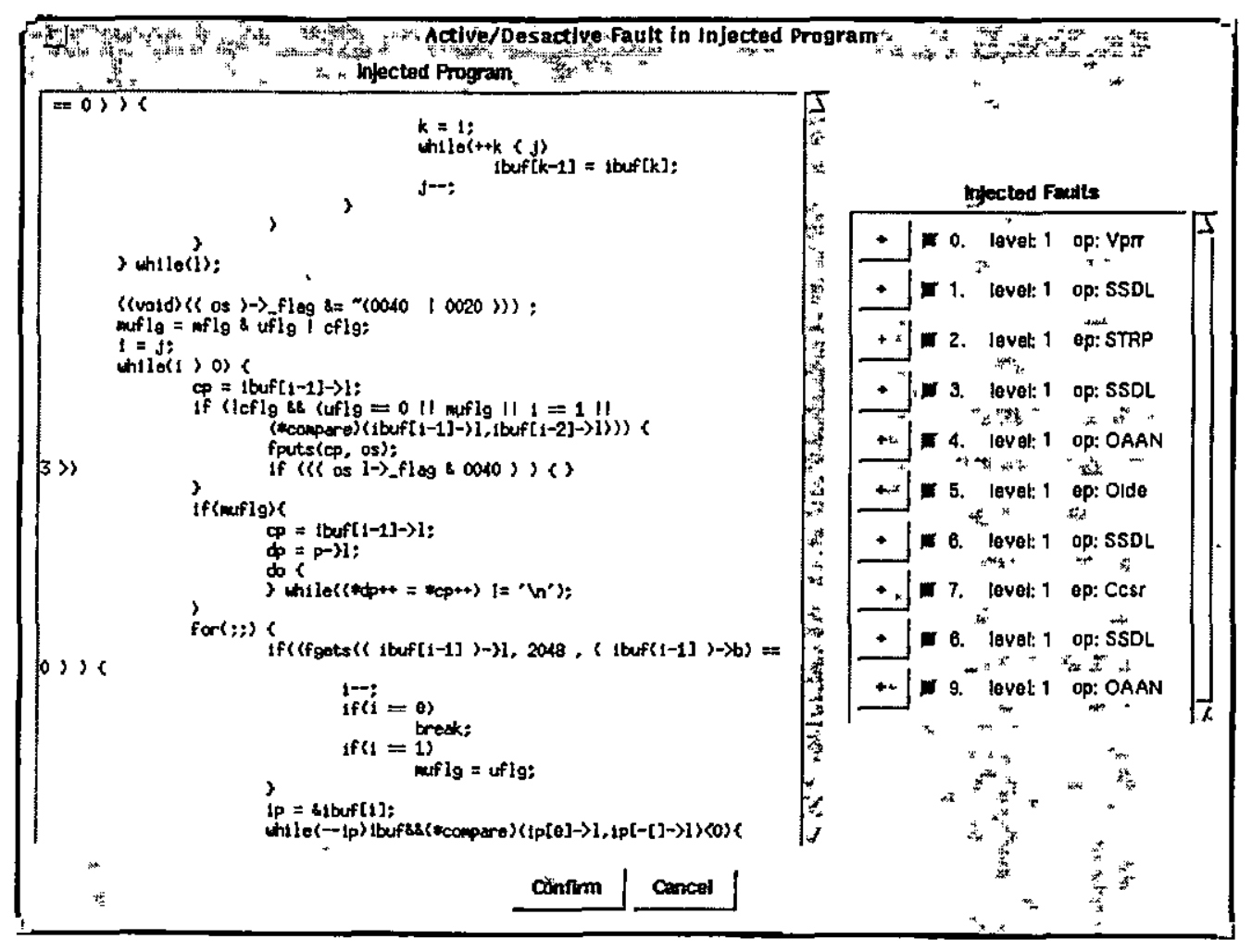

Figura 15: Ativando/Desativando Defeitos Injetados

Através da interface gráfica é possível ainda, uma vez identificado um defeito real pelo usuário, eliminar esse defeito através da edição do programa em avaliação.

A execução através da interface gráfica, com certeza, apresenta facilidades de uso, porém é menos flexível do que através da chamada direta dos módulos funcionais [DEL97b], pois exige uma interação constante do usuário com a interface gráfica, além de que os módulos funcionais disponibilizam um conjunto mais amplo de opções (parâmetros) do que atendidas pela interface do usuário.

\subsection{Módulos Funcionais da Ferramenta}

Como já mencionado anteriormente, a ITool apresenta a flexibilidade de uso pois pode ser utilizada através de shell script ou através da interface gráfica. A utilização da ferramenta através desses módulos se comparado com a utilização através da interface gráfica, requer experiência do usuário e profundo conhecimento de cada módulo e dos parâmetros disponíveis. 
Os módulos funcionais da ITool foram implementados utilizando-se a linguagem C no sistema operacional Solaris; também encontra-se disponível para Linux. Esses módulos totalizam, aproximadamente, 24.000 linhas de código incluindo-se os comentários, divididos em oito módulos funcionais executáveis independentes; além disso, um conjunto de funções gerais totalizando aproximadamente 5.000 linhas também faz parte da ferramenta. Alguns desses módulos foram baseados e outros extraídos da ferramenta Proteum [DEL93b, DEL94], que implementa o critério de teste Análise de Mutantes [BUD81, DEL93a]. Em [DEL93b, DEL94] a versão 1.0 da Proteum que era constituída de um único módulo com interface em Xview é discutida. Esta ferramenta baseia-se, mais diretamente, em uma versão mais recente da Proteum - na versão 1.4.1 - com interface em Tcl/Tk e cuja funcionalidade está dividida em módulos funcionais executáveis e independentes.

Muitos dos módulos básicos sofreram algumas alterações e foram incorporados à ferramenta implementada e outros módulos tiveram de ser implementados. No Quadro 5 estão listados os principais módulos que compõem a funcionalidade da ITool, juntamente com uma breve descrição e o número de linhas de código (LOC).

Quadro 5: Módulos Funcionais da Ferramenta ITool

\begin{tabular}{|l|l|c|}
\hline Módulo & \multicolumn{1}{|c|}{ Descrição } & LOC \\
\hline pteste & Cria e manipula base de dados de sessão de teste. & 526 \\
\hline tcase & Manipula base de dados de casos de teste. & 1.594 \\
\hline li & Transforma programa C em formato LI (linguagem intermediária). & 4.646 \\
\hline li2nli & Cria grafo de fluxo de controle de programa e adiciona informações na LI. & 68 \\
\hline fault & Cria e manipula base de dados de defeitos. & 1.542 \\
\hline opmuta & Aplica os operadores de mutação no código fonte. & 12.011 \\
\hline inject & Injeta, ativa/desativa e executa o programa com defeitos injetados. & 2.943 \\
\hline report & Constrói relatórios de informaçöes gerais e casos de teste. & 509 \\
\hline TOTAL & & 23.839 \\
\hline
\end{tabular}

Os módulos pteste, tcase, li, li2nli e opmuta da ferramenta Proteum sofreram pequenas adaftações e utilizados integralmente na ITool. Já os módulos fault e report tiveram grande parte de seu código modificado para atender à necessidade da nova ferramenta. O principal módulo da ITool é denominado inject e por isso descrito mais detalhadamente adiante. 
Cada um dos módulos funcionais da ITool apresenta um conjunto de parâmetros que permite a entrada de dados. Uma descrição completa dos módulos da ITool, bem como dos parâmetros disponíveis em cada módulo pode ser encontrada no "Manual do Usuário da ITool v.1.0-C" [NAK98b]. Neste manual também está disponível o modo de utilização da ITool atra vés da interface gráfica.

Para a execução de uma sessão de teste, inicialmente, cria-se uma sessão de teste utilizando-se o módulo pteste. Em seguida, para adicionar casos de teste para essa sessão, utiliza-se o tcase; esse módulo também permite a visualização, a remoção e a importação de casos de teste de outras fontes: sessão de teste das ferramentas Proteum e POKE-TOOL e de arquivos ASCII.

Para a manipulação de defeitos, utiliza-se o opmuta e o fault. O opmuta aplica os operadores de mutação para a geração de defeitos que serão gerenciados pelo módulo fault. A geração de defeitos é realizada sobre o programa em linguagem intermediária criada pela li e pela li2nli e não diretamente sobre o código em $\mathrm{C}$ do programa em avaliação.

A seleção e a injeção de defeitos no programa em avaliação são realizadas pelo módulo inject. Este módulo também é responsável pela "reinjeção", ou melhor, a reconstrução do programa com os defeitos injetados obedecendo à ativação/desativação de defeitos realizada pelo usuário. $O$ inject possui também a função de executar o programa com defeitos injetados e armazena os resultados para posterior avaliação.

Finalmente, o módulo report cria relatórios sobre a sessão de teste e os casos de teste, além de mostrar o andamento da avaliação do programa. A seguir, é descrito em mais detalhes o principal módulo desta ferramenta: o inject.

\subsubsection{Módulo Inject}

O inject é o principal módulo da ITool e realiza as seguintes funções: injeção de defeitos baseado em um modelo de defeitos, execução do programa com os defeitos injetados e tratamento da ativação/desativação de defeitos no programa injetado. Abaixo são descritos em mais detalhes cada uma das funções embutidas neste módulo:

- injeção de defeitos: baseado no modelo de defeitos selecionado, esse módulo consulta a base de dados de defeitos e seleciona defeitos a serem injetados no 
programa. Para o cálculo do número de defeito a ser injetado é considerado também o FKLOC (número de defeitos por 1.000 linhas de código) fornecido pelo usuário através de um parâmetro; se não for fornecido pelo usuário, o FKLOC considerado é 10. Pode-se também selecionar as unidades nas quais se deseja injetar defeitos;

- ativação/desativação de defeitos: a ativação/desativação de defeitos é realizada pelo usuário através da edição do arquivo de defeitos injetados (arquivo com extensão .FLT); o módulo inject realiza a reconstrução do programa com defeitos injetados baseado nesse arquivo de defeitos injetados; essa função também cria o executável do programa com defeitos injetados;

- execução do programa injetado: executa o programa com defeitos injetados, considerando-se os casos de teste selecionados pelo usuário. Essa função também armazena o resultado fornecido pelo programa com defeitos injetados para posterior avaliação dos resultados.

Se utilizado através de shell script ou chamado diretamente da linha de comando, o módulo inject necessita de um conjunto de parâmetros como descrido abaixo na sinopse desse módulo.

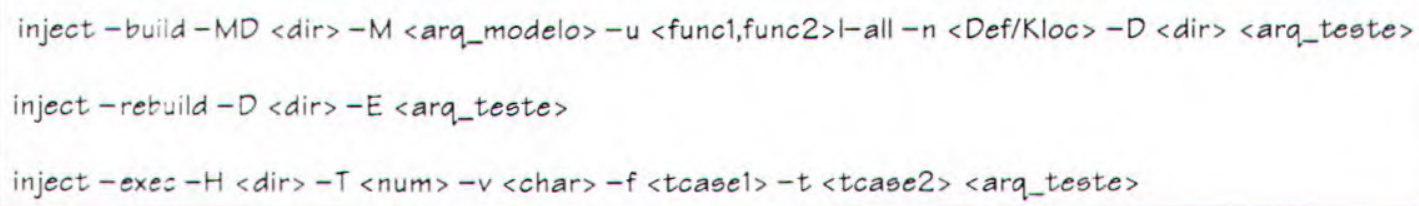

A seguir são descritos cada um dos parâmetros do módulo inject:

- build: para construir o programa com defeitos injetados;

- ebuild: para reconstruir o programa com defeitos injetados, no processo de ativação/desativação;

-exec: para executar o programa com defeitos injetados;

- MD < dir>: nome do diretório no qual se encontra o modelo de defeitos;

$-4<$ arq_modelo $>$ : arquivo contendo modelo de defeitos;

- - <func1, func2>: lista de funções a serem avaliadas;

- <Def/Kloc >: número de defeitos por KLOC (1.000 linhas de código);

- $\langle r\lrcorner m>:$ timeout de execução; 
-E: constrói o executável do programa com defeitos injetados;

$-v$ <char>: caracter a ser impresso para acompanhar o andamento da execução;

-f $\langle t c a s e 1\rangle$ : número do primeiro caso de teste a ser utilizado;

- $t<t$ case2 $>$ : número do último caso de teste a ser utilizado;

$-H<$ dir>: diretório onde se encontra o arquivo de inclusão itool.h;

$-D<$ <ir>: diretório no qual se encontra a sessão de teste;

$<$ arq_teste>: nome da sessão de teste.

\subsection{Base da Dados da Ferramenta}

Todos os dados gerados pela ITool - sessão de teste, casos de teste, entre outros - são armazenados em um base de dados, como ilustrado na Figura 8, mostrada anteriormente na Seção 4.1 deste capítulo. Essa base de dados é composta pelas seguintes bases:

- Sessão de Teste: trata-se de um conjunto de informações globais, como o nome do arquivo fonte, do executável, o comando de compilação utilizado para compilar o programa fonte e criar o executável, entre outras. O nome do arquivo que contém essas informações é o nome da sessão de teste com o sufixo .PTM. Assim, se uma sessão de teste é criada com o nome Test, o arquivo que contém as informações globais será Test.PTM;

- Modelo de Defeitos: os arquivos de modelos de defeitos são armazenados na base de dados em formato ASCII e possuem extensão .mdl. Esses arquivos contêm informações que possibilitam a seleção de defeitos a serem injetados segundo a classe a que pertencem e ao operador responsável pela geração;

- Casos de Teste: essa base de dados é composta por dois arquivos com extensōes .TCS e .IO. O arquivo com sufixo.TCS contém informações sobre os casos de teste: parâmetros iniciais, tempo de execução do programa utilizando o caso de teste, código de retorno, entre outras. $O$ arquivo com sufixo.$I O$ armazena as entradas dadas pelo teclado e as saídas fornecidas pelo programa relacionadas ao caso de teste. Se o nome da sessão de teste é Test, os arquivos da base de dados de casos de teste serão Test.TCS e Test.IO;

- Defeitos: essa base de dados corresponde a base de dados de mutantes da ferramenta Proteum. Ao gerar um defeito, fica impraticável armazenar as versões do programa 
cada um com um defeito. Dessa forma, os defeitos são armazenados em forma de descritores. Essa base é composta de dois arquivos com os sufixos .MUT e .IND para cada sessão. $O$ arquivo.MUT armazena os descritores de defeitos e $o$ arquivo .IND é um arquivo de índices e contém informações para auxiliar o acesso aos descritores. Se o nome da sessão de teste é Test, o arquivo de descritores será Test.MUT e o arquivo de índices será Test.IND; e

- Programa Injetado: nessa base de dados é armazenado um histórico dos defeitos injetados, como a localização do defeito, o tipo, entre outras informações; os arquivos responsáveis pelo armazenamento dessas informações possuem sufixo .FLT e os arquivos com formato _test_inj_x.c, no qual test é o nome do arquivo fonte e $x$ é o nível de injeção. Além desses arquivos, essa base de dados ainda armazena os arquivos_test_inj_exec.c e _test_inj_exec que são os arquivos fonte e o executável do programa com defeitos injetados e pronto para a execução.

As bases de dados que estão relacionadas aos módulos da Proteum utilizados, inteiro ou parcialmente, na ferramenta implementada - pteste, tcase, li, li2nli, opmuta, fault e report - são discutidas detalhadamente em [DEL93b, DEL97b]. As demais bases de dados - Modelo de Defeitos e Programa Injetado - são exclusivas da ITool e descritas a seguir.

\subsubsection{Modelo de Defeitos}

Para a geração dos defeitos a serem injetados pela ferramenta, foi selecionado um subconjunto inicial de operadores de mutação para compor o modelo de defeitos.

\subsubsection{Seleção dos Operadores de Mutação}

Basicamente foram selecionados aqueles operadores que geram defeitos mais simples, considerando-se também o trabalho de Wong [WON94b] E Barbosa [BAR98] sobre operadores essenciais do critério Análise de Mutantes.

Uma informação utilizada para realizar a seleção de operadores para a geração de defeitos foi o número de offsets - número de pontos dentro do código que são modificados - que cada operador usa para representar o defeito gerado. 
Observou-se que alguns dos operadores da classe Mutação de Comandos da classificação de Agrawal [AGR89] utilizam mais de um offset para cada defeito, como mostrado no Quadro 6. Todos os operadores pertencentes às demais classes Mutação de Operadores, Mutação de Constantes e Mutação de Variáveis apresentam um offset para cada defeito.

Quadro 6: Número de Offsets dos Operadores da Classe Mutaçāo de Comandos

\begin{tabular}{|c|l|}
\hline Número de Offsets & \multicolumn{1}{|c|}{ Operadores } \\
\hline Um & SBRC, SCRB, SGLR, STRI, SRSR, SSDL \\
\hline Dois & SMVB, SSWM, STRI \\
\hline Três & SBRn, SCRn, SMTC, SMTT \\
\hline Quatro & SDWD, SWDD \\
\hline
\end{tabular}

Por exemplo, na Figura 16 é mostrado o descritor de defeitos gerado pelo operador SWDD. Esse operador troca o comando while por do-while e utiliza quatro offsets. Assim, os defeitos gerados por esse operador não são fáceis de gerenciar, e adotando uma abordagem pragmática, esse operador não será considerado nesta primeira versão da ferramenta. Assim, os operadores que envolvem mais de um offset — SBRn, SCRn, SDWD, SMTC, SMTT, SMVB, SSWM, STRI, SWDD — não foram considerados.

Apesar do operador SGLR utilizar somente um offset, este não foi selecionado, pois realiza mutação sobre o comando goto, um comando não utilizado em programas estruturados.

Na Figura 17 é mostrado um descritor de defeitos de um operador da classe Mutação de Constantes da classificação de Agrawal [AGR89] que apresenta somente um offset. 


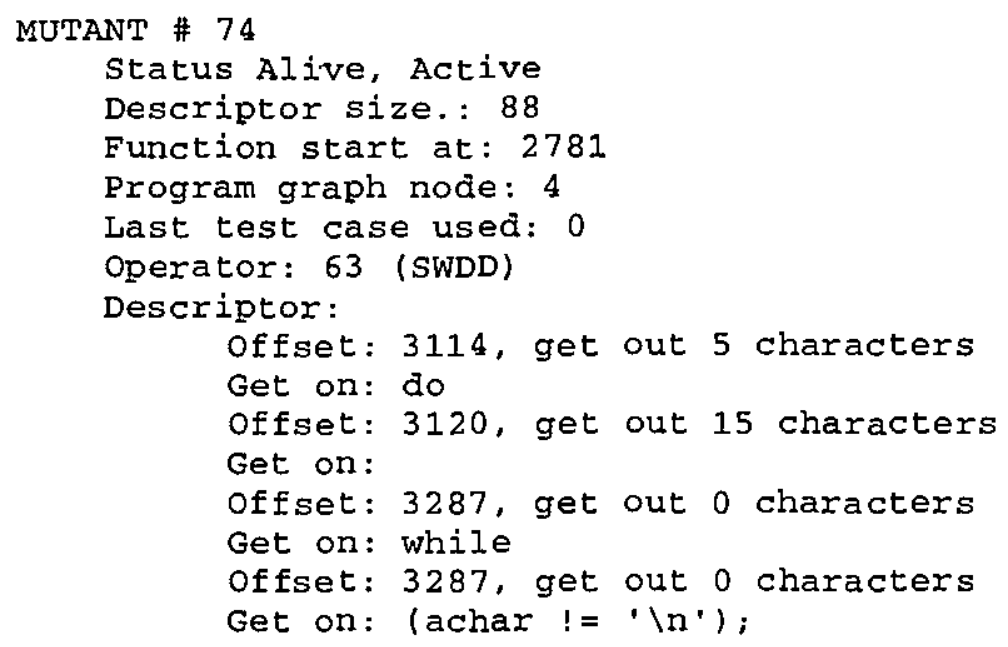

Figura 16: Descritor de Defeito de um Defeito Gerado pelo Operador SWDD

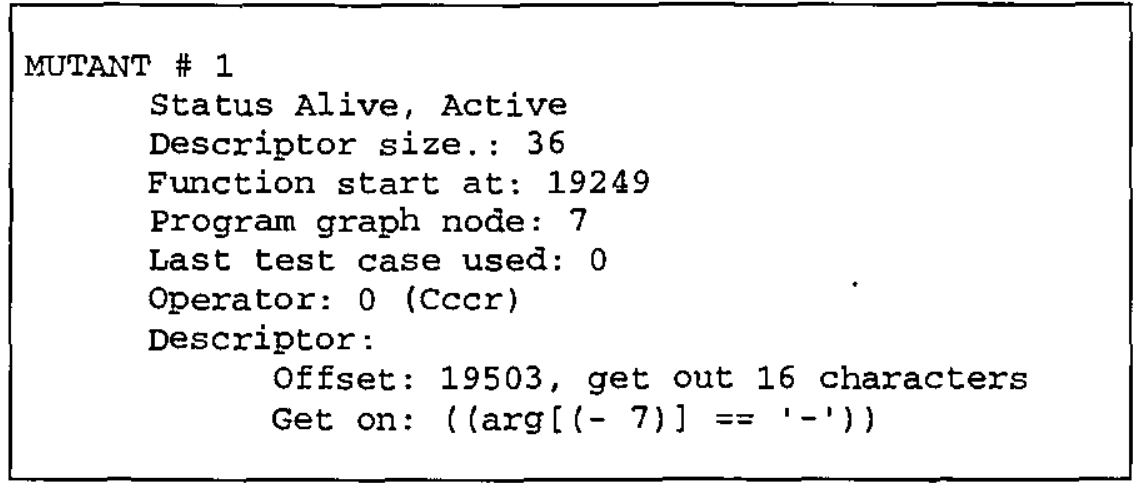

Figura 17: Descritor de Defeito de um Defeito Gerado pelo Operador Cccr

O trabalho de Wong baseia-se na mutação restrita (constrained mutation), na qual somente mutantes de tipos selecionados são gerados e examinados. Uma das maneiras de se aplicar a mutação restrita é a seleção dos operadores de mutação. Dessa forma, Wong selecionou 12 operadores de mutação, sendo eles: OALN, OCNG, OLAN, OLBN. OLLN, OLNG, OLRN, ORLN, ORRN, STRP, VDTR e VTWD. Esses operadores correspondem a uma primeira tentativa de selecionar operadores essenciais. A redução do número de operadores deveria reduzir o custo de execução e manter uma detecção eficaz (effectiveness) de defeitos [WON94b].

Mais recentemente, o trabalho de Wong tem sido reproduzido no contexto de um trabalho de mestrado, no qual tem-se observado que os operadores selecionados através de estucios empíricos têm apresentado as mesmas características do conjunto de operadores essenciais selecionados por Wong. No trabalho de Barbosa [BAR98], os 
operadores selecionados são: Cccr, Ccsr, OLBN, ORRN, SMTC, SSDL, SWDD, VDTR e VTWD.

Observa-se que a maioria dos operadores essenciais considerados nesses dois estudos - Wong e Barbosa - foram considerados no esquema de injeção de defeitos estabelecido.

Considerando-se esses dois aspectos - operadores essenciais e simplicidade dos defeitos - foram selecionados 61 operadores dos 71 implementados na ferramenta Proteum. Os operadores selecionados são apresentados no Quadro 7. Dos 15 operadores da classe Mutação em Comandos, foram selecionados cinco; das demais classes, todos foram selecionados.

Quadro 7: Operadores de Mutação para Geraçāo de Defeitos

\begin{tabular}{|c|c|c|c|c|c|}
\hline & $\begin{array}{l}\text { Mutação de } \\
\text { Comandos }\end{array}$ & \multicolumn{2}{|c|}{$\begin{array}{l}\text { Mutação de } \\
\text { Operadores }\end{array}$} & $\begin{array}{l}\text { Mutação de } \\
\text { Constantes }\end{array}$ & $\begin{array}{l}\text { Mutação de } \\
\text { Variáveis }\end{array}$ \\
\hline $\begin{array}{l}\text { Entidade } \\
\text { Simples } \\
\text { Incorreta }\end{array}$ & $\begin{array}{l}\text { SBRC } \\
\text { SCRB } \\
\text { SRSR } \\
\text { STRP }\end{array}$ & $\begin{array}{l}\text { OAAA } \\
\text { OAAN } \\
\text { OABA } \\
\text { OABN } \\
\text { OALN } \\
\text { OARN } \\
\text { OASA } \\
\text { OASN } \\
\text { OBAA } \\
\text { OBAN } \\
\text { OBBA } \\
\text { OBBN } \\
\text { OBLN } \\
\text { OBRN } \\
\text { OBSA } \\
\text { OBSN } \\
\text { OCOR } \\
\text { OLAN }\end{array}$ & $\begin{array}{l}\text { OLBN } \\
\text { OLLN } \\
\text { OLRN } \\
\text { OLSN } \\
\text { ORAN } \\
\text { ORBN } \\
\text { ORLN } \\
\text { ORRN } \\
\text { ORSN } \\
\text { OSAA } \\
\text { OSAN } \\
\text { OSBA } \\
\text { OSBN } \\
\text { OSLN } \\
\text { OSRN } \\
\text { OSSA } \\
\text { OSSN }\end{array}$ & $\begin{array}{l}\text { CRCR } \\
\text { Cccr } \\
\text { Ccsr }\end{array}$ & $\begin{array}{c}\text { Varr } \\
\text { Vprr } \\
\text { VSCR } \\
\text { Vsrr } \\
\text { Vtrr }\end{array}$ \\
\hline $\begin{array}{l}\text { Entidade } \\
\text { Espúria }\end{array}$ & & $\begin{array}{l}\text { OBNG } \\
\text { OCNG } \\
\text { OEAA } \\
\text { OEBA }\end{array}$ & $\begin{array}{l}\text { OESA } \\
\text { OIPM } \\
\text { OLNG }\end{array}$ & & $\begin{array}{l}\text { VDTR } \\
\text { VTWD }\end{array}$ \\
\hline $\begin{array}{l}\text { Falta de } \\
\text { Entidade }\end{array}$ & SSDL & $\begin{array}{l}\text { OAEA } \\
\text { OBEA }\end{array}$ & OSEA & & \\
\hline $\begin{array}{c}\text { Entidade } \\
\text { Mal } \\
\text { Empregada }\end{array}$ & & & & & \\
\hline
\end{tabular}


Espera-se que com o uso desses operadores de mutação que geram defeitos mais simples, os defeitos mais complexos que esses operadores não retratam também sejam representados.

Um outro problema apresentado no processo de injeção de defeitos é o conflito entre dois defeitos gerados sobre um mesmo ponto de aplicação, ou então, se um determinado operador aplica um defeito em todo um bloco de comandos e outro aplica dentro desse bloco. Esse problema pode ser visto na Figura 18. Na Figura 18.a é mostrada a aplicação de dois operadores de diferentes classes - operador SSDL da classe Mutação de Comandos e operador OAAR da classe Mutação de Operadores aplicados sobre um mesmo comando. A Figura 18.b mostra dois operadores de uma mesma classe - operadores OABN e OAAN da classe Mutação de Operadores também aplicados em um mesmo ponto de aplicação. Isso mostra que tanto entre operadores pertencentes à mesma classe, como às classes diferentes apresentam conflitos. A questão é: "Como resolver esse conflito?"

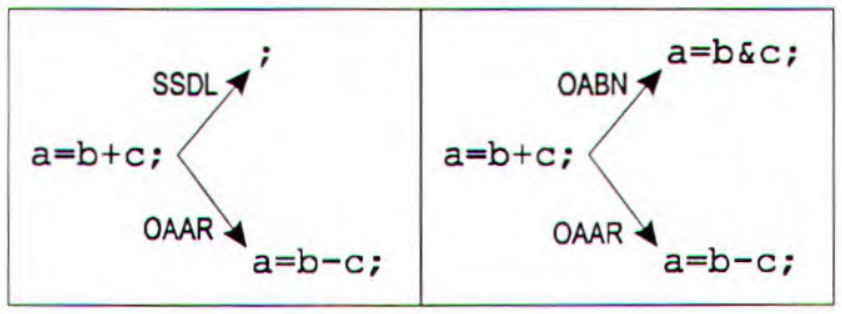

(a)

(b)

Figura 18: Conflito na Aplicação de Operadores de Mutação

Através de um estudo bastante rigoroso dos operadores de mutação, observou-se que esse conflito ocorre entre a maioria dos operadores [NAK98a]. Assim, no processo de injeção de defeitos, dentre os defeitos gerados por um operador é selecionado somente um defeito para cada ponto de aplicação. Se os operadores pertencem à classes diferentes, como no caso do exemplo da Figura 18.a, estabeleceu-se uma ordem de prioridade para aplicação. Esta ordem de prioridade é discutida em mais detalhes no relatório técnico "Estudo e Priorização da Aplicação dos Operadores de Mutação na Injeção de Defeitos" [NAK98a] .

\subsubsection{Formato do Arquivo de Modelo de Defeitos}

A base de dados de modelos de defeitos é composta de arquivos com sufixo .mdl. Esses arquivos estão em formato ASCII, permitindo assim que possam ser editados 
pelo usuário, no entanto, a interface gráfica disponibiliza recursos que permitem facilmente a ativação/desativação de classes de defeitos e operadores de mutação a serem aplicados.

$\mathrm{O}$ arquivo contendo o modelo de defeitos apresenta um formato pré-determinado, como observado na Figura 19: um cabeçalho contendo uma identificação, em seguida, as classes de defeitos juntamente com as porcentagens absolutas e as porcentagens relativas e finalmente os operadores de mutação, a classe a que pertence e o estado de ativação: ativado (1) ou desativado (0).

Esse formato pré-determinado permite que o modelo seja representado utilizando-se siglas para os nomes das classes de defeitos e para os operadores de mutação, além dos nomes por extenso, facilitando a manipulação do modelo.

$O$ arquivo de modelo de defeitos apresentado aqui baseia-se na taxonomia de defeitos de DeMillo/Mathur [DEM95]; no entanto, o formato do arquivo permite a utilização de outros modelos baseados em diferentes esquemas de classificação de defeitos, bem como outros mapeamentos dos operadores de mutação. Tanto a interface gráfica como os módulos funcionais foram construídos de modo a suportar diferente número de classes e diferentes classificações dadas aos operadores de mutação.

A porcentagem absoluta é a porcentagem de defeitos atribuída por DeMillo/Mathur [DEM95] a cada classe em sua taxonomia de defeitos; a porcentagem relativa é a porcentagem de defeitos de cada classe de defeito considerando-se o estado de ativação/desativação das classes. As porcentagens absolutas das classes devem tem como soma $100 \%$, assim como as porcentagens relativas.

Na Figura 19, a classe Entidade Mal Empregada (Misplaced Entity Fault) cuja sigla é MPEF tem a porcentagem absoluta de 5,5 e a porcentagem relativa de zero; isso significa que essa classe está em estado de desativação e nenhum defeito gerado pelos operadores relacionados a essa serão injetados. Esse é também o estado da classe Entidade Espúria (Spurious Entity Fault, sigla SPEF).

Já a classe Falta de Entidade (Missing Entity Fault, sigla MSEF) possui 40,55 e 43,22 para as porcentagens absoluta e relativa, respectivamente. A classe Entidade Simples Incorreta (Simple Incorrect Entity Fault, sigla SIEF) apresenta 53,26 e 56,77, respectivamente, para as porcentagens absoluta e relativa. 
\# Fault Model

\# Fault Taxonomy: DeMi11o/Mathur

\# autor: Elisa Yumi Nakagawa

\# data: $30 / 01 / 98$

$\begin{array}{lrrl}\text { MPEF } & 5.50 & 0.00 & \text { (Misplaced Entity Fault) } \\ \text { MSEF } & 40.55 & 43.22 & \text { (Missing Entity Fault) } \\ \text { SIEF } & 53.26 & 56.77 & \text { (Simple Incorrect Entity Fault) } \\ \text { SPEF } & 0.69 & 0.00 & \text { (Spurious Entity Fault) }\end{array}$

1 Oido MPEF (Increment/Decrement Mutation)

O OAEA MSEF (Arithmetic Assignment by Plain Assignment)

O OBEA MSEF (Bitwise Assignment by Plain Assignment)

0 OSEA MSEF (Shift Assignment by Plain Assignment)

1 SSDL MSEF (Statement Deletion)

1 Cccr SIEF (Constant for Constant Replacement)

1 Ccsr SIEF (Constant for Scalar Replacement)

o CRCR SIEF (Required Constant Replacement)

1 OAAA SIEF (Arithmetic Assignment Mutation)

SCRB SIEF (continue Replacement by break)

STRP SIEF (Trap on Statement Execution)

Vprr SIEF (Mutate Pointer References)

1 Vsrr SIEF (Mutate Scalar References)

1 OBNG SPEF (Bitwise Negation)

1 OEAA SPEF (Plain assignment by Arithmetic Assignment)

O OEBA SPEF (Plain assignment by Bitwise Assignment)

O OESA SPEF (Plain assignment by Shift Assignment)

O OIPM SPEF (Indirection Operator Precedence Mutation)

1 OCNG SPEF (Logical Context Negation)

1 OLNG SPEF (Logical Negation)

1 VDTR SPEF (Domain Traps)

1 VTWD SPEF (Twiddle Mutations)

Figura 19: Exemplo de um Arquivo de Modelo de Defeitos

Assim, no processo de seleção de defeitos, 43,22\% dos defeitos serão da classe Falta de Entidade e 56,77\% da classe Entidade Simples Incorreta.

Ainda na Figura 19, observa-se por exemplo que o operador Oido é da classe Entidade Espúria e está habilitado. Um outro exemplo é o operador OAEA relacionado à classe Entidade Mal Empregada e está em estado de desativação.

\subsubsection{Exemplo de Seleção de Defeitos Baseado no Modelo de Defeitos}

No Quadro 8 é mostrado um exemplo da aplicação do modelo de defeitos apresentado na Figura 19 sobre um programa exemplo. Esse programa possui 541 
linhas de código não incluindo comentários. O total de defeitos gerados pelos operadores de mutação foi de 22.004 defeitos divididos em quatro classes: 141 da classe Entidade Mal Empregada, 558 da classe Falta de Entidade, 18.882 da classe Entidade Simples Incorreta e 2.423 da classe Entidade Espúria.

Quadro 8: Exemplo de Seleção de Defeitos

\begin{tabular}{|l|r|r|r|r|c|}
\hline \multicolumn{1}{|c|}{ Classe } & $\begin{array}{c}\% \\
\text { Absoluta }\end{array}$ & $\begin{array}{c}\% \\
\text { Relativa }\end{array}$ & $\begin{array}{c}\text { Total de } \\
\text { Defeitos }\end{array}$ & $\begin{array}{c}\text { Defeitos } \\
\text { Selecio- } \\
\text { nados }\end{array}$ & $\begin{array}{c}\text { Defeitos } \\
\text { a Injetar }\end{array}$ \\
\hline Entidade Mal Empregada & 5,50 & 0,00 & 141 & 92 & 0 \\
\hline Falta de Entidade & 40,55 & 43,22 & 558 & 552 & 2 \\
\hline Entidade Simples Incorreta & 53,26 & 56,77 & 18.882 & 1.663 & 3 \\
\hline Entidade Espúria & 0,69 & 0,00 & 2.423 & 639 & 0 \\
\hline \multicolumn{1}{|c|}{ Total } & 100,00 & 100,00 & 22.004 & 2.946 & 5 \\
\hline
\end{tabular}

No processo de seleção de defeitos, primeiramente, são selecionados para cada operador um único defeito para cada ponto de aplicação, embora dois operadores diferentes possam estar aplicando defeitos em um mesmo ponto. A coluna Defeitos Selecionados do Quadro 8 mostra o número de defeitos selecionados para cada classe.

A partir desses defeitos selecionados é considerado a porcentagem relativa de cada classe ativa e o FKLOC para selecionar, os defeitos a serem injetados Aplicandose FKLOC igual a 10, tem-se a seleção aleatória de cinco defeitos: dois defeitos da classe Falta de Entidade e três da classe Entidade Simples Incorreta. Para esse exemplo, o módulo inject juntamente com um conjunto de parâmetros, foi utilizado para realizar a seleção de defeitos. O seguinte comando foi utilizado:

$$
\text { inject -build -MD -elisa/Itool/bin/models -M model.mal -n } 10 \text { Test }
$$

\subsubsection{Programa Injetado}

As informações sobre os defeitos injetados são armazenados em um arquivo criado pelo módulo inject e que possui o sufixo .FLT. Na Figura 20 é mostrado um exemplo de um arquivo que armazena os defeitos injetados . 


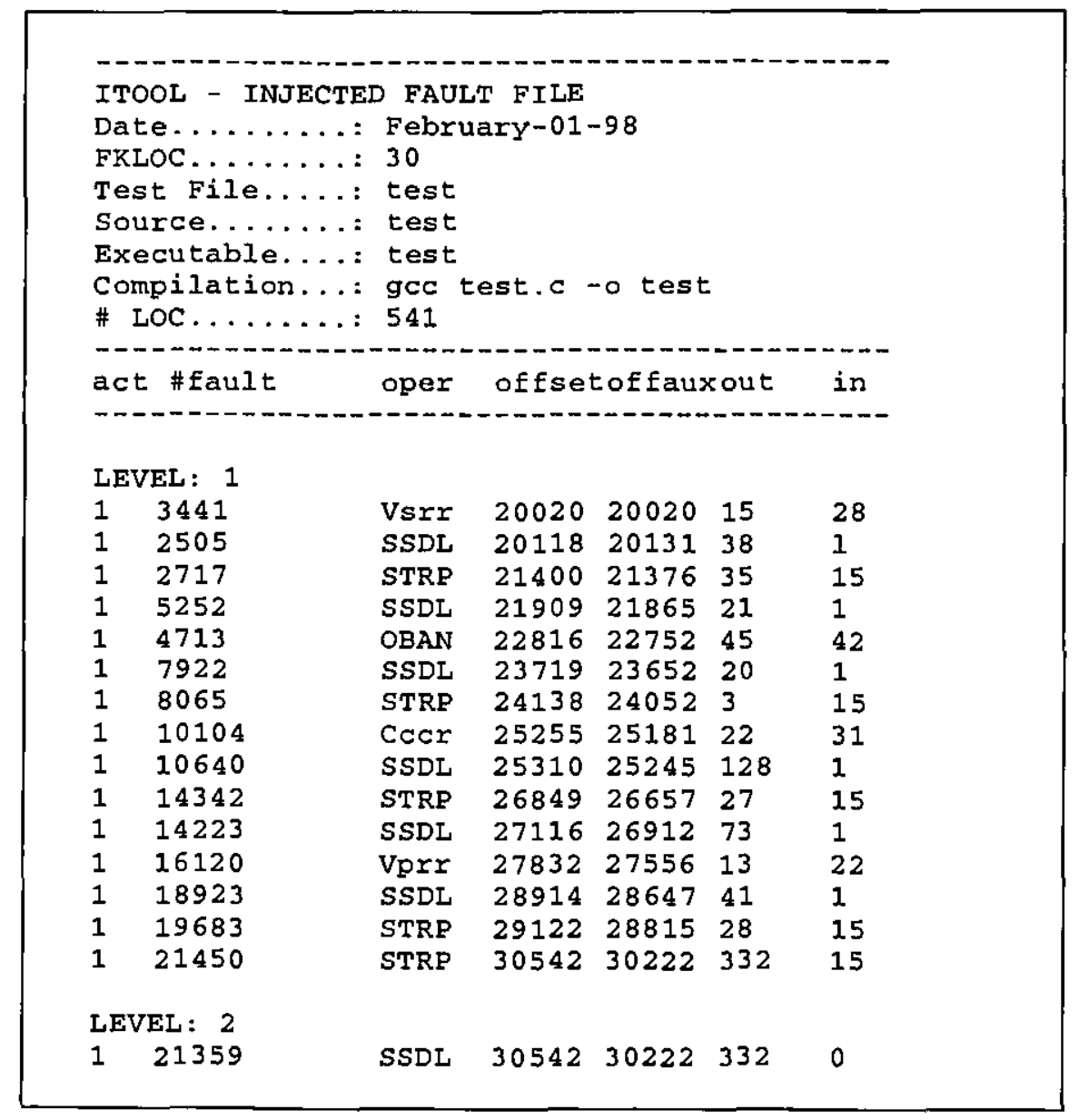

Figura 20: Exemplo de Arquivo de Defeitos Injetados

Observa-se que esse arquivo possui um cabeçalho no qual aparecem as informações gerais da sessão de teste, como por exemplo o nome da sessão, nome do arquivo fonte e número de linhas de código. Em seguida, aparecem os defeitos injetados separados por níveis de injeção. Os defeitos de nível 1 são injetados diretamente no programa original $P$, criando-se uma versão P'; os defeitos do nível 2 são injetados em P', criando-se a versão P" e assim por diante, como mostra a Figura 21. Essa estratégia foi adotada para resolver conflitos entre defeitos a serem injetados em um mesmo ponto de aplicação. Esse é um aspecto crítico do processo de injeção de defeitos.

Para cada defeito injetado, está associado um conjunto de informações como o estado de ativação, o número do defeito, o operador responsável pela sua geração, o offset e um offset auxiliar, o número de caracteres a retirar e número de caracteres a inserir. 


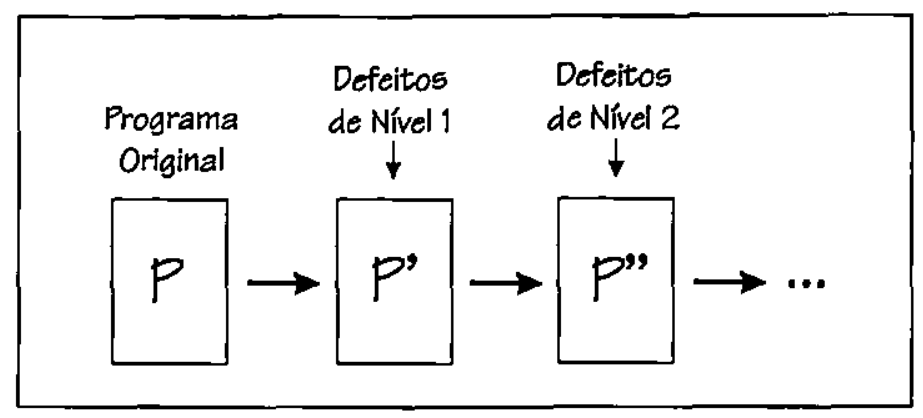

Figura 21: Niveis de de Injeção de Defeitos

Além desse arquivo, a ferramenta armazena também um histórico dos defeitos injetados para facilitar o processo de ativação/desativação de defeitos. Para cada nivel de injeção é criado um arquivo com nome _test_inj_x.c no qual test é o nome do arquivo fonte do programa em avaliação e $x$ é o nível de injeção. Se a injeção de defeitos necessita de dois níveis de injeção, serão criados os arquivos _test_inj_l.c e _test_inj_2.c.

Os arquivos relacionados ao programa com defeitos injetados são: _test_inj_exec.c e _test_inj_exec.

\subsection{Considerações Finais}

A atividade de injeção de defeitos realizada manualmente faz com que sua aplicação seja impossível por ser muito trabalhosa e propensa a erros, o que faz com que a automatização seja uma solução indispensável através da construção de ferramentas. Com a automatização do esquema de injeção de defeitos elaborado espera-se reduzir os custos, aumentando a produtividade, bem como a confiabilidade e a qualidade dos produtos que venham a ser testados com a ITool.

Os mecanismos implementados pela ITool podem ser utilizados com facilidade à luz da técnica Semeadura de Defeitos e em estudos que investigam a relação entre teste e confiabilidade de software. Através de defeitos injetados e reais detectados no software, procura-se estimar o número de defeitos remanescentes no software. Essa é a abordagem dada ao experimento piloto realizado e descrito no capítulo seguinte. 


\section{Capítulo 5}

\section{Experimento Piloto}

Este capítulo descreve um experimento piloto utilizando o programa Space desenvolvido pela ESA (European Space Agency) [DEL97b] e a ferramenta de injeção de defeitos ITool descrita no capítulo anterior. Inicialmente, é descrito o programa Space e, em seguida, o experimento realizado e a análise dos resultados obtidos. Por último estão as consideraçōes finais sobre o experimento realizado.

\subsection{Considerações Iniciais}

Um experimento piloto foi realizado com o objetivo de contribuir para a validação da ferramenta ITool e ilustrar sua aplicação à luz do critério Semeadura de Defeitos. Este tipo de experimento possibilita estimar o número de defeitos remanescentes no programa frente ao número de defeitos reais e injetados descobertos durante a realização da avaliação do programa. Esse processo é semelhante ao cálculo de estimativa de população a partir de dados de recaptura.

Nessa perspectiva através de defeitos injetados ou "semeados" no software e no processo de localização desses defeitos, espera-se que defeitos reais contidos no software sejam descobertos.

Esperava-se poder também realizar um experimento utilizando um sistema de software tolerante a defeitos, no entanto, no decorrer deste trabalho não se identificou um sistema contendo mecanismos de tolerância a defeitos disponível.

O programa Space é um sistema real desenvolvido na ESA (European Space Agency) e fez parte de um estudo de caso [DEL97b] que teve como objetivo medir o custo de aplicação e a efetividade em revelar defeitos injetados no contexto do critério Mutação de Interface. Esse programa possui também um histórico de desenvolvimento, bem como o registro dos defeitos encontrados, informação relevante e indispensável para a condução de um experimento mais realista.

O Space é constituído de 135 funções e um total de 4.449 LOC (linhas de código), incluindo-se os comentários. Isso demonstra uma moderada complexidade, sendo mais um motivo de sua escolha como alvo deste experimento. 
Na seção seguinte será descrito as características do programa Space.

\subsection{Descrição do Space}

O programa Space processa uma linguagem de alto nível que permite ao usuário descrever um vetor de antenas. Seu objetivo é produzir como saída um arquivo de dados com formato e características pré-definidas, a partir dessa descrição. A linguage $m$ desenvolvida para esse fim permite descrever o vetor de antenas a partir de alguns poucos comandos, ao invés de descrever-se uma lista completa de posiçōes e estímulos dos elementos. Essa lista é então produzida como saída do programa [DEL97b].

Para cada execução do Space é fornecido como entrada um arquivo com extensão .adl e a saída resultante é impressa na tela e também armazenada em um arquivo com o mesmo nome do arquivo de entrada, no entanto, com extensão.dat.

Na Figura 22 pode ser visto um exemplo de um arquivo de entrada e na Figura 23, o arquivo de saída. Além do arquivo de saída, uma saída para a tela é fornecida como a mostrada na Figura 24.

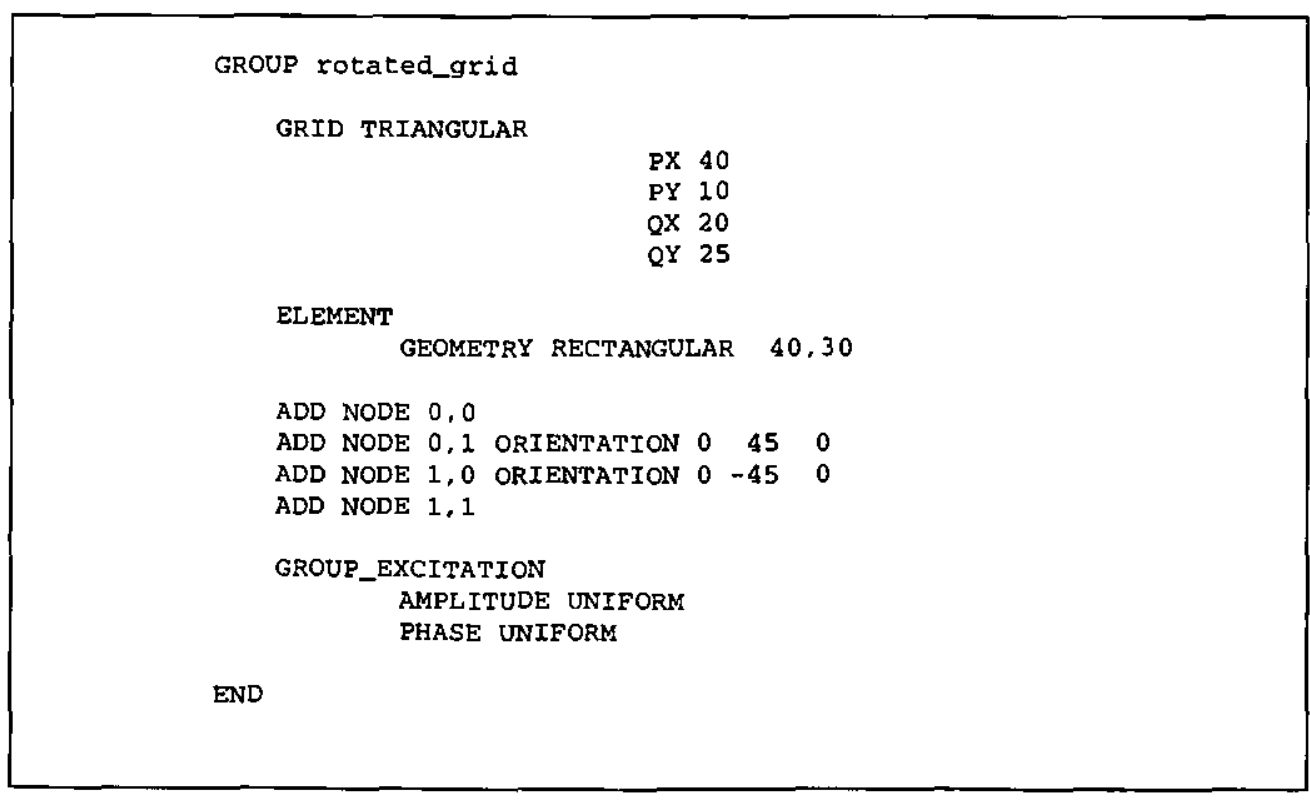

Figura 22: Arquivo de Entrada do Programa Space (arquivo com extensão adl) 


\begin{tabular}{|rrrrrrr|}
\hline 4 & & & & & & \\
1 & & & & & & \\
1 & 0.00 & 0.00 & 0.00 & 0.00 & 14.04 & 0.00 \\
& 1.00 & 0.00 & 0.00 & 90.00 & & \\
2 & 20.00 & 25.00 & 0.00 & 0.00 & 59.04 & 0.00 \\
& 1.00 & 0.00 & 0.00 & 90.00 & & \\
3 & 40.00 & 10.00 & 0.00 & 0.00 & -30.96 & 0.00 \\
& 1.00 & 0.00 & 0.00 & 90.00 & & \\
4 & 60.00 & 35.00 & 0.00 & 0.00 & 14.04 & 0.00 \\
& 1.00 & 0.00 & 0.00 & 90.00 & & \\
\hline
\end{tabular}

Figura 23: Arquivo de Saída do Programa Space (arquivo com extensão dat)

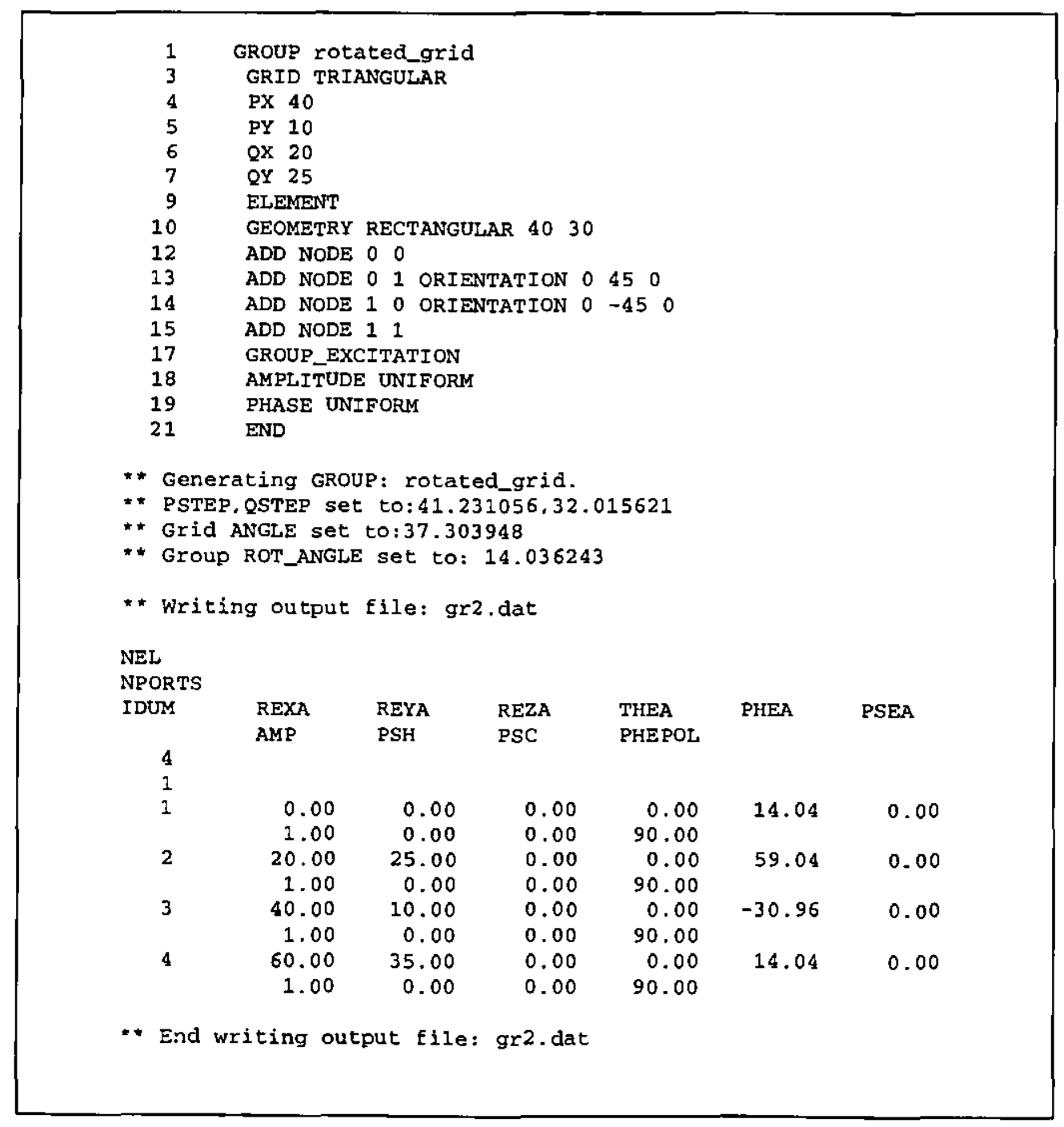

Figura 24: Saida para a Tela Fornecida pelo Programa Space 
O programa Space é constituído de três partes [DEL97b]:

- um parser que realiza a análise sintática da descrição e prepara as estruturas internas descrevendo o vetor de antenas;

- um módulo de cálculos que assinala e calcula parâmetros do vetor que foram omitidos pelo usuário na descrição, verifica a consistência dos parâmetros fornecidos na descrição e calcula a posição e os estímulos de cada elemento do vetor;

- um módulo de formatação que prepara a saída no formato pré-determinado.

Durante a fase de teste e manutenção do programa Space foram revelados e registrados 33 defeitos, sendo que eles foram classificados de acordo com o padrão IEEE 1044 "Standard Classification for Software Errors, Faults and Failures" [IEE95] como mostrado no Quadro 9. No Apêndice D estão listados e descritos os 33 defeitos.

Segundo Delamaro [DEL97b], não foi localizado na documentação disponível sobre o Space, a classificação de cada um dos 33 defeitos nos tipos de defeitos apresentados no Quadro 9, nem a ordem em que os defeitos foram encontrados e removidos.

Quadro 9: Classificaçāo dos Defeitos do Space Realizada por Pasquini [DEL97b]

\begin{tabular}{|l|l|c|}
\hline \multicolumn{1}{|c|}{ Tipo do Defeito } & \multicolumn{1}{|c|}{ Subtipo do Defeito } & Número de Defeitos \\
\hline \multirow{4}{*}{ Lógica omitida ou incorreta } & Casos ou passos esquecidos & 2 \\
\cline { 2 - 3 } & Função desnecessária & 1 \\
\cline { 2 - 3 } & Falta de condição de teste & 4 \\
\cline { 2 - 3 } & Verificaçāo de variável errada & 2 \\
\hline Problemas computacionais & Equação insu ficiente ou incorreta & 10 \\
\hline Interface incorreta ou incompleta & Módulos não combinam & 3 \\
\hline \multirow{2}{*}{ Problema na manipulação de dados } & Inicialização incorreta & 1 \\
\cline { 2 - 4 } & Acesso ou armazenamento incorreto & 10 \\
\hline & TOTAL & 33 \\
\hline
\end{tabular}


Os desenvolvedores estabeleceram ainda o perfil operacional do programa Space e para isso foram identificadas as possíveis subfunções ${ }^{3}$ do programa. Cada uma das subfunções corresponde a um nó de um grafo e esses nós estão ligados através de arestas. Existe um único nó inicial e também um único nó final. Um caminho do nó inicial até o nó final corresponde a uma função executada pelo programa. Para cada uma das arestas foi estabelecida uma probabilidade de transição; assim, por exemplo, um nó A ligado aos nós B e C com probabilidade de transição 0,4 e 0,6 , respectivamente, significa que se o nó $\mathrm{A}$ for executado, a probabilidade de execução dos nós B e C são 0,4 e 0,6, respectivamente. Essas probabilidades de transição foram determinadas através de entrevistas com usuários [DEL97b].

\subsection{Descrição do Experimento}

Para obter um resultado mais confiável, este experimento foi realizado dez vezes - experimentos I-1 a I-5 e experimentos II-1 a II-5 - utilizando cinco conjuntos de 2.000 casos de teste cada.

Os dados para a geração dos casos de teste são fornecidos por um programa que acompanha o Space. O perfil operacional do programa é a base para a geração dos casos de teste.

A cada conjunto de casos de teste associa-se um Índice de Dificuldade para cada um dos 33 defeitos. Esse índice corresponde à porcentagem de casos de teste desse conjunto que são capazes de revelar o defeito; assim, quando menor o valor desse índice, mais difícil o defeito de ser detectado.

Para os experimentos I- 1 a I-5 foram utilizados aqueles defeitos que possuem índices entre 3,8 a 10,6, ou seja, que podem ser revelados com razoável facilidade. Os defeitos selecionados para esses experimentos foram: $11,13,16,24$ e 29.

No Quadro 10 são mostrados os Índices de Dificuldade dos cinco defeitos com os menores índices diferentes que zero, de cada um dos cinco conjuntos de casos de teste. Por exemplo. para o Pool 1 , o defeito 33 é o mais difícil de ser detectado e o 27 o mais fácil. O defeito 33 tem índice 0,05 , isto é, $0,05 \%$ dos casos de teste desse Pool é capaz

\footnotetext{
${ }^{3}$ Subfunção não corresponde ao termo função que é uma unidade de processamento da linguagem $C$, mas ao comportamento que se espera de um trecho de programa.
} 
de revelar esse defeito, ou seja, somente um caso de teste dentre os 2.000 contidos nesse pool.

Quadro 10: Indice de Dificuldade dos Defeitos do Space

\begin{tabular}{|c|c|}
\hline POOL & \multicolumn{1}{|c|}{ defeito (HI) } \\
\hline 1 & $33(0,05), 12(0,15), 18(0,15), 22(0,25), 27(0,40)$ \\
\hline 2 & $12(0,10), 18(0,10), 22(0,25), 27(0,25), 8(0,80)$ \\
\hline 3 & $33(0,05), 27(0,10), 12(0,15), 18(0,15), 22(0,20)$ \\
\hline 4 & $27(0,10), 12(0,20), 18(0,20), 22(0,20), 8(1,25)$ \\
\hline 5 & $27(0,15), 12(0,25), 18(0,25), 22(0,50), 8(1,10)$ \\
\hline
\end{tabular}

Baseado nos valores dos Índices de Dificuldade mostrados no Quadro 10 foram selecionados cinco defeitos - 12,18,22, 27 e 33 - com os menores índices na média para serem utilizados nos experimentos II- 1 a II-5. Visto que os defeitos 12 e 18 ocorrem dentro de uma mesma unidade e o defeito 12 foi substituído pelo defeito 32 . Essa estratégia foi adotada devido as características do mecanismo de ativação/desativação de defeitos reais, que apresentava problemas na geração e seleção dos defeitos se dois defeitos reais ocorriam em uma mesma unidade.

Com relação aos defeitos a serem injetados, esses foram gerados utilizando-se os operadores de mutação e, para reduzir o universo de defeitos foi feita a seleção aleatória de $10 \%$ dos defeitos no momento de sua geração; mesmo assim, o número de defeitos gerados é satisfatoriamente grande e a seleção de defeitos dentro desse conjunto não é prejudicada; assim, foram gerados 14.140 defeitos candidatos à injeção.

A distribuição desses defeitos nas classes, como mostrada no Quadro 11, é baseada no modelo de defeitos utilizado. O modelo de defeitos é listado na Figura 25. Observa-se no modelo de defeitos que todas as classes estão habilitadas, isto é, defeitos de todas as classes serão injetados. De acordo com a política de seleção de operadores de mutação a serem utilizados para o esquema de injeção de defeitos, observa-se o estado de ativação e desativação dos operadores no modelo utilizado. 
Quadro 11: Número de Defeitos Gerados, Selecionados e Injetados

\begin{tabular}{|c|c|c|c|c|}
\hline Classe & $\begin{array}{c}\text { \# de Defeitos } \\
\text { Gerados }\end{array}$ & \% Relativa & $\begin{array}{c}\text { \# de Defeitos } \\
\text { Selecionados }\end{array}$ & $\begin{array}{c}\text { \# de Defeitos } \\
\text { a Injetar }\end{array}$ \\
\hline Entidade Mal Empregada & 8 & 5,50 & 8 & 1 \\
\hline Falta de Entidade & 415 & 40,55 & 58 & 7 \\
\hline Entidade Simples Incorreta & 11.885 & 53,26 & 77 & 10 \\
\hline Entidade Espúria & 1.832 & 0,69 & 1 & 0 \\
\hline Total & $\mathbf{1 4 . 1 4 0}$ & $\mathbf{1 0 0 , 0 0}$ & $\mathbf{1 4 4}$ & $\mathbf{1 8}$ \\
\hline
\end{tabular}

Considerando-se o estado de ativação das classes, a distribuição dos defeitos gerados é a seguinte: os operadores relacionados à classe Entidade Mal Empregada geraram um total de 8 defeitos; os operadores da classe Falta de Entidade, 415 defeitos; os operadores da classe Entidade Simples Incorreta, 11.885 defeitos e os operadores da classe Entidade Espúria, 1.832 defeitos.

Utilizando-se as porcentagens relativas do modelo de defeitos, é realizado uma seleção de defeitos dentro de cada classe de modo que as porcentagens correspondam ao número de defeitos. No total foram selecionados 144 defeitos, dos quais $5,5 \%-$ oito defeitos - são da classe Entidade Mal Empregada; 40,55\% - 58 defeitos - da classe Falta de Entidade; 53,26\% - 77 defeitos — da classe Entidade Simples Incorreta e 0,69\% - um defeito - da classe Entidade Espúria.

Utilizando-se o valor 5 FKLOC (5 defeitos a cada 1.000 linhas de código) e tendo-se o número de linhas de código do Space, foram selecionados 18 defeitos dos 144 defeitos para serem injetados, sendo eles: um defeito da classe Entidade Mal Empregada, sete da classe Falta de Ent idade, dez da classe Entidade Simples Incorreta e nenhum defeito da classe Entidade Espúria.

Na Figura 26 é listado o arquivo de extensão Space.FLT que armazena os defeitos injetados, juntamente com os operadores responsáveis por sua geração. Por exemplo, um dos defeitos injetados é o defeito número 1725 , gerado pelo operador Cccr, no qual o offset inicial é 35.321. Para esse defeito, são retirados 25 caracteres e acrescentados 29 . Os caracteres a acrescentar no programa, "injetando" o defeito, são armazenados nos descritores de defeitos, como discutido na Seção 4.4 . 


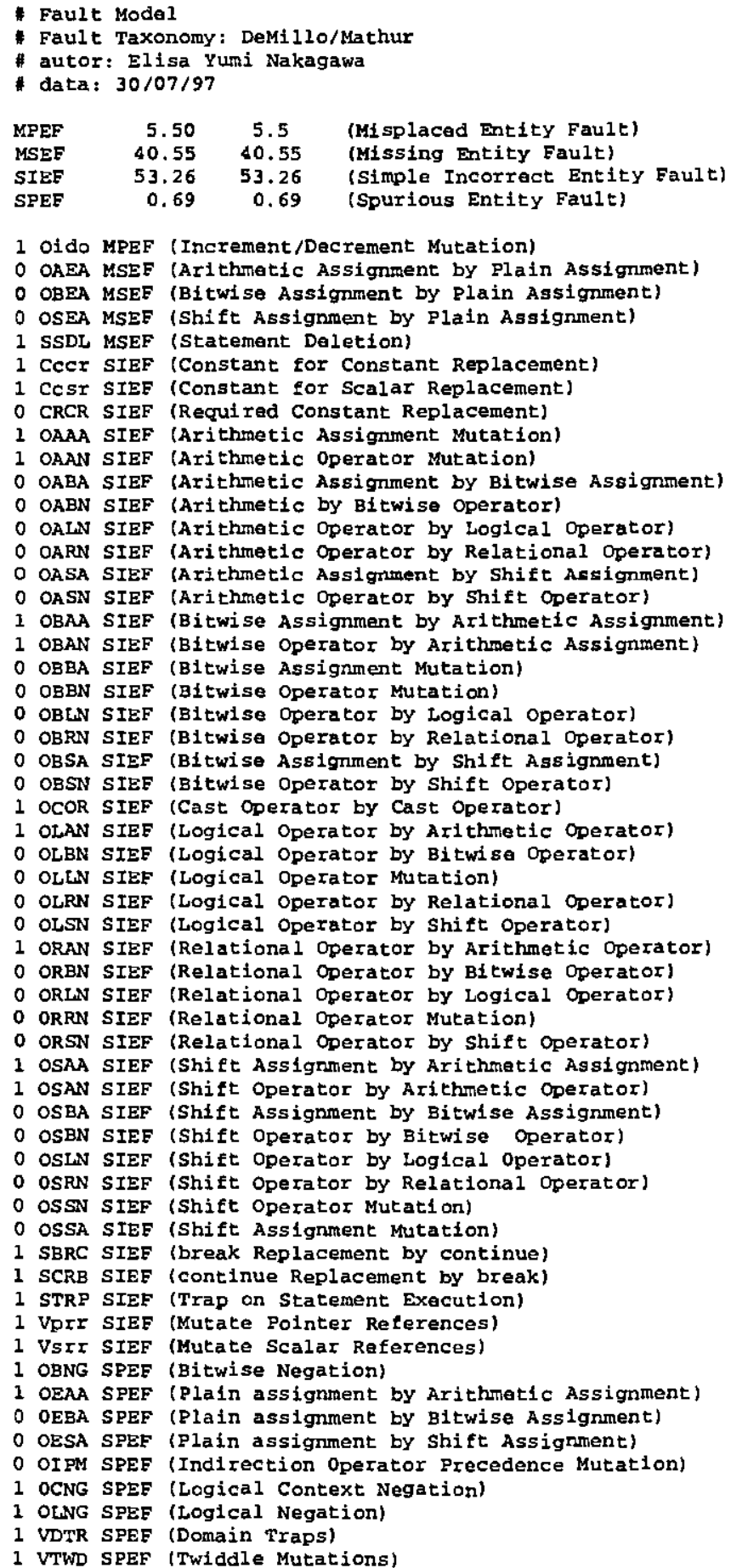

Figura 25: Modelo de Defeitos Utilizado no Experimento 
Dessa forma, o procedimento inicial de execução dos experimentos realiza os seguintes passos. No programa considerado oráculo - Space 0 - são inseridos os cinco defeitos reais, tendo-se a versão Spaces $_{5}{ }^{r}$. Em seguida foram semeados os 18 defeitos selecionados resultando na versão Spaces $^{r} 18^{i}$. Sobre esta versão é que será aplicado o processo de ativação/desativação de defeitos injetados, bem como o comportamento do testador que, nesse caso, foi simulado. O comportamento do testador seria a localização de defeitos reais no programa. A idéia seria detectar pelo menos todos os defeitos injetados e, de preferência, localizar o maior número possível de defeitos reais. Se isso ocorrer, a massa de teste pode ser considerada qualitativamente "boa", se o modelo de defeitos representar os defeitos reais típicos. 


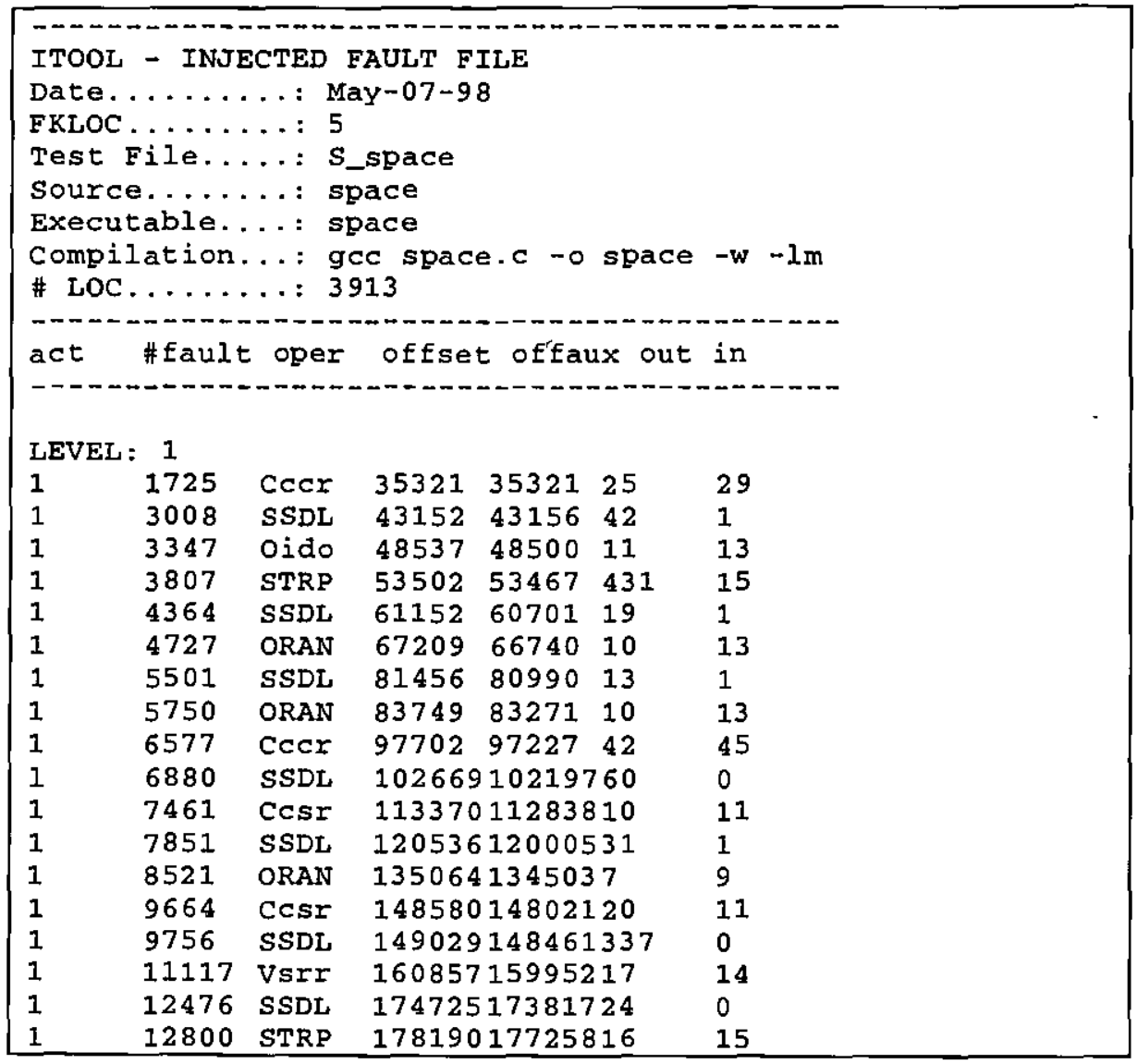

Figura 26: Arquivo que Armazena os Defeitos Injetados

Este experimento foi realizado utilizando-se a ITool via shell script ao invés utilizar a interface gráfica; isso por que se trata de um experimento extenso devido ao tamanho do programa Space. A execuçāo do experimento através de interface gráfica torna essa atividade trabalhosa frente ao número de interação necessária com a interface gráfica.

Para a execução desse experimento via shell script, foi necessária a implementaçāo de um módulo para gerenciamento (ativaçāo/desativação) dos defeitos reais, simulando o comportamento do testador.

Os seguintes passos são realizados pelo script:

- criação de uma sessão de teste (módulo pteste) e geração do arquivo $S_{-}$space.PTM;

- geração da linguagem intermediária e do grafo de fluxo de controle (módulos li e li2nli), gerando os arquivo _space.li $\mathrm{e} \_$space.nli; 
- geração de defeitos sobre a linguagem intermediária e manipulação de defeitos (módulos opmuta e fault) e geração dos arquivos $S_{-}$space.IND e $S_{-}$space.MUT;

- gerenciamento dos casos de teste (módulo tcase) e geração dos arquivos $S_{-}$space.IO e $S \_$space.TCS;

- injeção, ativação/desativação e execução do programa injetado de defeitos injetados (módulo inject), no processo de deteç̧ão de defeitos, gerando os arquivos _space_inj_l.c, _space_inj.c, _space_inj_exec.c, _space_inj_exec e S_space.RES.

Na Figura 27 é mostrado a parte principal do algoritmo para a execução do experimento, que é a detecção de defeitos (reais e injetados) utilizando os casos de teste.

De modo geral, a algoritmo pode ser traduzido nos passos descritos abaixo, considerando-se $x$ o número de defeitos reais e $y$ o número de defeitos injetados.

- procura-se sequiencialmente no pool de casos de teste $T$ um caso de teste $t$ no qual Space $_{0}(t) \neq \operatorname{Space}_{x y}^{r}{ }^{i}(t)$, ou seja, comportamento do programa em avaliação seja diferente do comportamento do oráculo. Em outras palavras, há algum defeito ou alguns defeitos que estão fazendo com que o programa não execute corretamente com aquele caso de teste;

- retira-se (desativa-se) aleatoriamente os defeitos (reais e injetados), primeiramente, de um em um; depois de dois em dois, de três em três, até que se consiga uma versão

Space $_{x-n}{ }^{r} y-m$, no qual $n, 0 \leq n \leq x$, é o número de defeitos reais identificados e $m$, $0 \leq m \leq y$ é o número de defeitos injetados detectados, que se comporte igual ao oráculo.

- os $n$ defeitos reais e os $m$ injetados são então removidos do programa em avaliação e marcados como detectados, e anotado também o caso de teste $t$ responsável pela detecção, restando-se localizar ainda $x-n+y-m$ defeitos;

- volta-se ao passo 1, considerando agora o $x$ inicial como $x$-n e o $y$ inicial como $y-m$ até que nenhum defeito (real ou injetado) possa ser detectado por um caso de teste ou que todos os defeitos injetados forem revelados. 


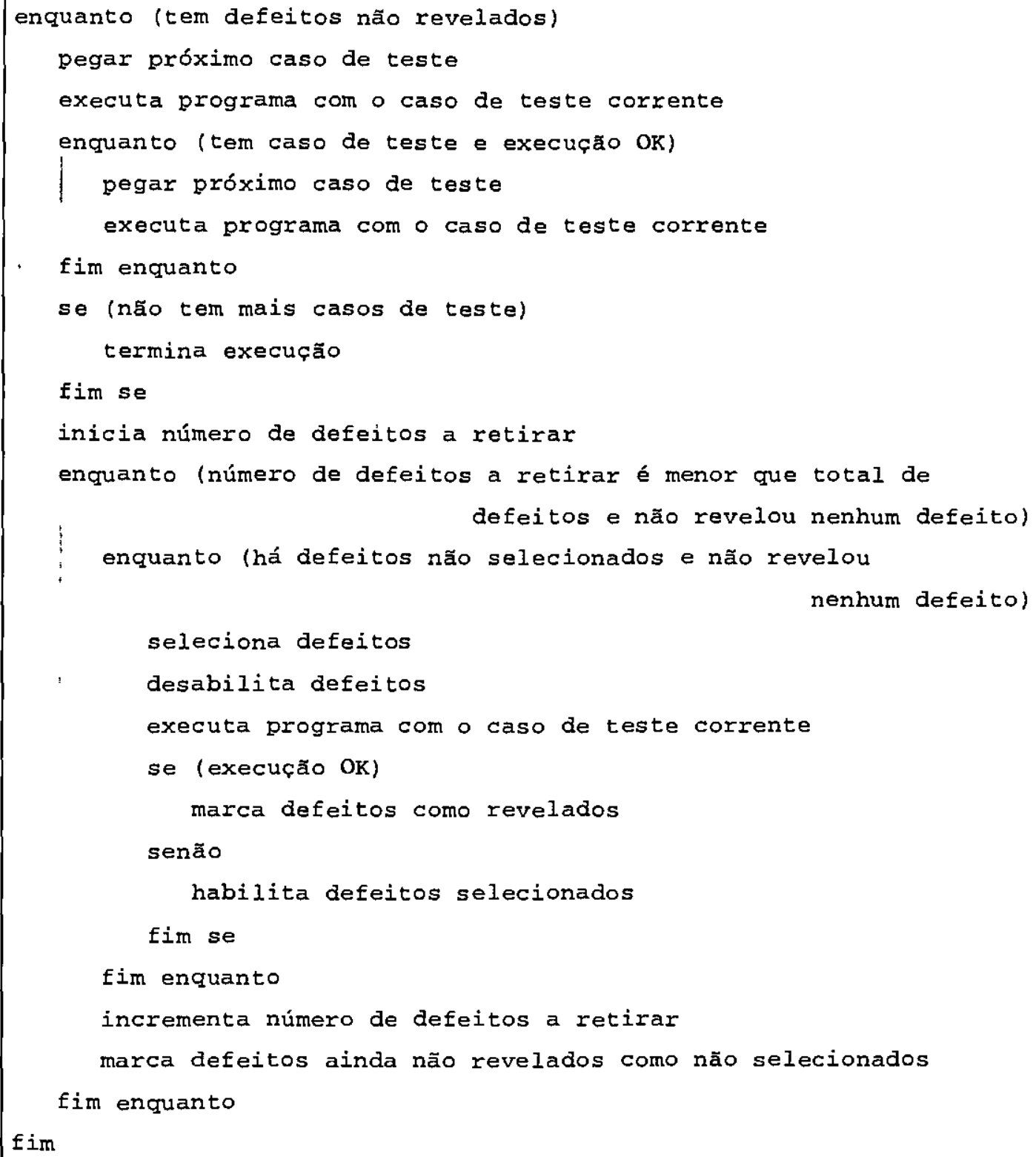

Figura 27: Algoritmo para Execução do Experimento

A ativação/desativaçāo (inserção/retirar o defeito do programa) é realizada pelo módulo inject e a ativação/desativação de defeitos reais é realizada diretamente no código fonte do programa Space. 
A seguir é mostrado o resultado da aplicação da ITool e do algoritmo acima sobre o programa Space.

\subsection{Coleta e Análise dos Resultados}

Um dos objetivos deste experimento foi observar o custo de aplicação, em relação ao tempo, do esquema de injeção de defeitos implementado, através da ferramenta ITool. Executando esse experimento em uma máquina Sun (Ultra1), com $128 \mathrm{Mb}$ de memória RAM, requereu em média 5 horas de processamento para cada um dos experimentos realizados, totalizando 50 horas. Esse tempo é uma estimativa, pois alguns dos experimentos necessitou de mais tempo do que outros, devido a utilização do processamento da máquina por outros processos, a carga da rede, entre outros.

Como já mencionado anteriormente, o experimento foi repetido dez vezes utilizando-se cinco conjuntos distintos de casos de teste para que pudesse alcançar um resultado mais confiável.

No Quadro 12 são listados os resultados dos experimentos I-1 a I-5, no qual foram utilizados como defeitos reais aqueles que possuíam razoável facilidade de serem detectados. No Quadro 13 são mostrados os resultados dos experimentos II-1 a II-5, para os quais foram utilizados os defeitos reais mais difíceis de serem revelados. Nesses quadros são apresentados o número de defeitos reais e injetados detectados, bem como os casos de teste responsáveis pela deteç̧ão.

Quadro 12: Resultados dos Experimentos I-1 a l-5

\begin{tabular}{|c|c|c|c|}
\hline \multirow{2}{*}{ Experimento } & \multicolumn{2}{|c|}{ \# Defeitos Detectados } & \multirow{2}{*}{ Casos de Teste } \\
\cline { 2 - 3 } & Reais & Injetados & \\
\hline I-1 & 5 & 15 & $1,7,8,13,15,16,44,62$ \\
\hline I-2 & 5 & 15 & $1,3,4,6,11,14,17,23$ \\
\hline I-3 & 5 & 17 & 1,7 \\
\hline I-4 & 5 & 13 & $1,9,13,24,40,42,200$ \\
\hline I-5 & 5 & 12 & $1,13,15,18,20,21,22,44,49,131,140$ \\
\hline Média & $\mathbf{5} \pm \mathbf{0}$ & $\mathbf{1 4 , 4} \pm 1,95$ & \\
\hline
\end{tabular}


Quadro 13: Resultados dos Experimentos $11-1$ a $11-5$

\begin{tabular}{|c|c|c|c|}
\hline \multirow{2}{*}{ Experimento } & \multicolumn{2}{|c|}{ \# Defeitos Detectados } & \multirow{2}{*}{ Casos de Teste } \\
\cline { 2 - 3 } & Reais & Injetados & $1,8,13,64,98,365,500,1171$ \\
\hline II-1 & 4 & 8 & $1,4,11,12,16,192,203,1541$ \\
\hline II-2 & 3 & 9 & $1,10,18,23,62,82,175,335,1023,1470$ \\
\hline II-3 & 3 & 7 & $1,9,13,19,24,50,421,629,1680$ \\
\hline II-4 & 3 & 6 & $1,6,18,29,131,204,274,733$ \\
\hline II-5 & 3 & 6 & \\
\hline Média & $3,2 \pm 0,45$ & $7,2 \pm 1,30$ & \\
\hline
\end{tabular}

Uma análise preliminar indica que os índices de dificuldade dos defeitos reais não sofrem influência dos defeitos injetados. Para os experimentos I-1 a I-5, todos os defeitos reais foram detectados e nos experimentos II-1 a II-5 foram detectados na média 3,2 defeitos reais com desvio padrão de 0,45 .

Para os experimentos I-1 a I-5, detectou-se em média 14,4 defeitos injetados com um desvio padrão de 1,95. Com relação aos experimentos II-1 a II-5, na média foram detectados 7,2 defeitos injetados com desvio padrão de 1,3. Um observação importante é que, tomando por exemplo o experimento II-l, mesmo contendo 11 defeitos no programa, este executa corretamente para quase 10.000 casos de teste, indicando que a massa de teste deve ser aprimorada de modo a revelar pelo menos todos os defeitos injetados, que em princípio, são conhecidos.

Aparentemente, a distribuição dos defeitos injetados modelam características dos defeitos reais. Observa-se que quanto mais fácil os defeitos reais de serem revelados, mais facilmente também são revelados os defeitos injetados e vice-versa, quanto mais difícil os defeitos reais de serem revelados, os defeitos injetados também apresentam dificuldade de serem revelados.

Este experimento aplicado à luz do critério Semeadura de Defeitos, possibilita estimar o número de defeitos remanescentes no programa frente ao número de defeitos reais e injetados descobertos. Esse processo é semelhante ao cálculo de estimativa de população a partir de dados de recaptura. Considerando-se que os defeitos injetados e reais estão uniformemente distribuídos no código do programa, pode-se utilizar a 
distribuição hipergeométrica [FEL67] para estimar o número de defeitos remanescentes no programa.

Tendo-se resultados de experimentos como aos descritos neste capítulo, fornece subsídios ao cálculo de estimativa de número de defeitos reais no contexto do critério Semeadura de Defeitos.

\subsection{Considerações Finais}

Neste capítulo foi apresentado o experimento piloto realizado utilizando-se o programa Space, um sistema real desenvolvido pela ESA (European Space Agency), e a ferramenta ITool para injeção de defeitos de software no contexto de Teste de Software, do ponto de vista do critério de Semeadura de Defeitos.

Os resultados dos experimentos realizados mostram que os defeitos injetados não influenciam no índice de dificuldade dos defeitos reais.

Se existem defeitos reais difíceis de serem localizados no programa, os defeitos injetados modelam as características desses defeitos reais e requerem que a massa de teste seja qualitativamente "boa" para localizar pelo menos todos os defeitos injetados, que em princípio, são conhecidos, mas também revelar o maior número de defeitos reais. 


\section{Capítulo 6}

\section{Conclusões e Desdobramentos}

Neste capítulo são sintetizados os principais resultados e contribuições deste trabalho e caracterizados os possíveis desdobramentos.

Este trabalho está inserido na área de Engenharia de Software, mais especificamente nas atividades de Teste e Validação de Software e na área de Tolerância a Defeitos, buscando integrar conceitos dessas duas áreas de pesquisa. Da área de Teste de Software utilizou-se o critério de teste Análise de Mutantes [BUD81, DEL93a, DEL93b], mais particularmente os operadores de mutação desse critério, e da área de Tolerância a Defeitos, a técnica de Injeção de Defeitos.

Uma contribuição deste trabalho foi o estudo e a síntese de algumas taxonomias de defeitos de software e o estabelecimento de um esquema de injeção de defeitos de software. Esse esquema é baseado na taxonomia de defeitos de DeMillo/Mathur [DEM95] e nos operadores de mutação do critério de teste Análise de Mutantes.

O principal objetivo deste trabalho foi a implementação de uma ferramenta, denominada ITool, para injeção de defeitos de software. Embora existam na literatura diversas ferramentas que realizam a injeção de defeitos, a maioria aborda defeitos de hardware. Poucas são as ferramentas que abordam defeitos de software, e dentre elas, não foram localizadas na literatura pesquisada ferramentas que considerassem um modelo ou uma taxonomia de defeitos que sintetizasse a atividade de injeção, como abordado pela ITool.

A ITool está operacional para os ambientes Solaris e Linux; ela foi desenvolvida em Solaris, utilizando-se a linguagem C, totalizando 29.082 linhas de código. Um interface gráfica baseada em janelas foi implementada para esta ferramenta com a utilização do Tcl/Tk [OUS94, WEL95] e totalizando 4.837 linhas de código. A ITool apresenta flexibilidade de uso uma vez que pode ser utilizada através da interface gráfica e também através de chamadas diretas aos módulos funcionais executáveis via shell script.

Objetivando a validação preliminar dos conceitos desenvolvidos neste trabalho, foi realizado um experimento piloto utilizando-se o Space, um sistema real 
desenvolvido pela ESA (European Space Agency) na perspectiva do critério Semeadura de Defeitos.

A disponibilização da ferramenta ITool viabilizará a condução de estudos empíricos, tanto na linha do experimento piloto realizado no contexto deste trabalho, como para avaliar a factibilidade do uso da ITool na avaliação de sistemas tolerantes a defeitos e estudos de modelos de confiabilidade de software.

Um aspecto relevante da ferramenta ITool é a flexibilidade quanto a utilização de modelos de defeitos como base para a injeção de defeitos.

Considerando essa flexibilidade, seria relevante a execução de outros experimentos utilizando-se modelos de defeitos mais refinados considerando-se as classes e subclasses da taxonomia de DeMillo/Mathur [DEM95] e também a utilização de outras taxonomias de defeitos como base para o estabelecimento do outros esquemas de injeção de defeitos de software. 


\section{Referências Bibliográficas}

[ACR79] Acree, A.; Budd, R.; DeMillo, R.A.; Lipton, R.J.; Sayward, F.G.; Mutation Analysis, Relatório Técnico GIT-ICS-79/08, Georgia Institute of Technology, setembro 1979.

[AGR89] Agrawal, H.; DeMillo, R.A.; Hathaway, B.; Hsu, W.; Hsu, Wy.; Krauser, E.W.; Martin, R.J.; Mathur, A.P.; Spafford, E.; Design of Mutant Operators for the $C$ Programming Language, Technical Report SERC-TR-41-P, Software Enginnering Research Center, Purdue University, março 1989.

[AHO72] Aho, A.V.; The Theory of Parsing, Translation and Compiling, Prentice Hall, 1972.

[BAR98] Barbosa, E.F.; Uma Contribuiçāo para Determinação de um Conjunto de Operadores de Mutação Essenciais para o Teste de Programas C, Dissertação de Mestrado, USP/ICMC, São Carlos, 1998 (mestrado em andamento).

[BAS84] Basili, V.R.; Perricone, B.T.; Software Errors and Complexity: An Empirical Investigation, Communications of the Acm, V.27, N.1, janeiro 1984.

[BEI90] Beizer, B.; Software Testing Techniques, $2^{\mathbf{a}}$ Edição, Van Nostrand Eeinhold, New York, 1990.

[BIE96] Bieman, J.M.; Dreilinger, D.; Lin, L.; Using Fault Injection to Increase Software Test Coverage, ISSRE'96 - The Seventh International, Symposium on Software Reliability Engineering, 1996.

[BUD80] Budd, T.A.; DeMillo, R.A.; Lipton, R.J.; Sayward, F.G.; Theoretical and Empirical Studies on Using Prog Mutation to Test the Functional Correctness of Prog, $7^{\text {th }}$ ACM Symposium on Principles of Programming Languages, janeiro 1980 .

[BUD81] Budd, T.A.; Mutation Analysis: Ideas, Examples, Problems and Prospects, Computer Program Testing, North-Holand Publishing Company, 1981. 
[CHA91] Chaim, M.L.; Poke-tool - Uma Ferramenta para Suporte ao Teste Estrutural de Programas Baseado em Análise de Fluxo de Dados, Dissertação de Mestrado, DCA/FEEC/UNICAMP, Campinas, SP, 1991.

[CHI92] Chillarege, R.; et a1.; Orthogonal Defect Classification: A Concept for Inporcess Measurements, IEEE Transactions on Software Engineering, novembro, 1992.

[CHO89] Choi, B.J.; DeMillo, R.A.; Krauser, E.W.; Mathur, A.P.; Martin, R.J.; Offutt, A.J.; Pan, H.; e Spafford, E.H.; The Mothra Toolset, Proc. of Hawaii International Conference on System Sciences, EUA, janeiro 1989.

[CLA95] Clark, J.A.; e Pradham, D.K.; Fault Injection - A Method for Validating Computer-System Dependability, IEEE Computer, V.28, N.6, junho 1995, p.47-56.

[DAW96a] Dawson, S.; Jahanian, F.; Mitton, T.; ORCHESTRA: A Fault Injection Environment for Distributed Systems, Relatório Técnico, CSE-TR-318-96, University of Michigan, Ann Arbor-MI, 1996 (http:// www.eesc.umich.edu/techreports/cse96.html - 10 de janeiro, 1998).

[DAW96b] Dawson, S.; Jahanian, F.; Mitton, T.; Experiments on Sis Commercial TCP Implementations Using a Software Fault Injection Tool, Relatório Técnico, CSE-TR-298-96, University of Michigan, Ann Arbor-MI, 1996 (http:// www.eesc.umich.edu/techreports/cse96.html - 10 de janeiro, 1998).

[DEL93a] Delamaro, M.E.; Maldonado, J.C.; Uma Visão sobre a Aplicação da Análise de Mutantes, Notas do ICMSC, n. 133, ICMSC/USP, São Carlos, SP, março 1993.

[DEL93b] Delamaro, M.E.; Proteum - Um Ambiente de Teste Baseado na Análise de Mutantes, Dissertação de Mestrado, ICMSC/USP, São Carlos, SP, outubro 1993.

[DEL94] Delamaro, M.E.; Maldonado, J.C.; Proteum - Manual do Usuário - versão 1.I-C, Relatório Técnico do ICMSC, n. 23, ICMSC/USP, São Carlos, SP, outubro 1994.

[DEL96] Delamaro, M.E.; Maldonado, J.C.; Mathur, A.P.; Integration Testing Using Interface Mutation, ISSRE'96 - The Seventh International Symposium on Software Reliability Engineering, 1996. 
[DEL97a] Delamaro, M.E.; Maldonado, J.C.; Interface Mutation: An Approach for Integration Testing, Workshop do Projeto Validação e Teste de Sistemas de Operação, Águas de Lindóia - SP, janeiro 1997, pp. 177-189.

[DEL97b] Delamaro, M.E.; Mutação de Interface: Um Critério de Adequação Interprocedimental para o Teste de Integração, Tese de Doutorado, IFSC/USP, São Carlos, SP, junho, 1997.

[DEM78] DeMillo, R.A.; Software Testing and Evaluation, The Benjamim/ Commings Publishing Company, Inc, 1978.

[DEM94] DeMillo, R.A.; Li, T.; Mathur, A.P.; Architecture of Tamer: A Tool for Dependability Analysis of Distributed Fault-Tolerance Systems, Relatório Técnico, SERC-TR-158-P, Purdue University, W. Lafayette - IN, setembro 1994.

[DEM95] DeMillo, R.A.; Mathur, A.P.; A Grammar Based Fault Classification Scheme and its Application to the Classification of the Errors of TEX, novembro 1995.

[ECH92] Echtle, K.; Leu, M.; The EFA Fault Injector for Fault-Tolerant Distributed System Testing, IEEE Workshop on Fault Tolerant Parallel and Distributed Systems, Amherst, MA, USA, 1992.

[END75] Endres, A.; An Analysis of Errors and Their Causes in Systems Program, IEEE Transactions on Software Engineering, V. SE-1, N. 2, junho, 1975.

[FEL67] Feller, W.; An Introduction to Probability Theory and Its Applications, V.1, 3. Edição, John Wiley \& Sons, 1967.

[GEI92] Geist, R.; Offutt, J.; Harris, F.C.; Estimation and Enhancement of. Real-Time Software Reliability through Mutation Analysis, IEEE Trans. on Computer, V. 41, N. 5, maio 1992.

[GO075] Goodenough, J.B.; Gerhart, S.L.; Toward a Theory of Test Data Selection, IEEE Transactions of Software Engineering, V. SE-1, N. 2, junho 1975.

[GHO97] Ghosh, S.; Mathur, A.P.; Testing for Fault Tolerance, Relatório Técnico, SERC-TR-175-P, Purdue University, W. Lafayette-IN, setembro 1997.

[GRA97] Grady, R.B.; Successful Software Process Improvement, prentice Hall, 1997. 
[HEL91] Heller, D; Xview Programming Manual, O'Reilly \& Associates, Canadá, 1991.

[HOR92] Horgan, J.R.; Mathur, A.P.; Assessing Testing Tools in Research and Education, IEEE Software, V.9, N.3, maio 1992.

[IEE91] IEEE Software Engineering Standards Collection, Spring 1991, Ed. IEEE, NY, USA, 1991.

[KAN92] Kanawati, G.A.; Kanawati, N.A.; Abrahan, J.A.; FERRARI: A Tool for the Validation of System Dependability Properties, Proc. FTCS-22, Boston, MA, USA, 1992.

[KA093] Kao, W.; Iyer, R.K.; Tang, D.; FINE: A Fault Injection and Monitoring Environment for Tracing the Unix System Behavior under Faults, IEEE Trans. on Software Engineering, 19(11), 1993.

[KNU89] Knuth, The Errors of TEX, Software Practice and Experience, V. 19, N. 7, ju lho 1989 , pp.607-685.

[LAP92] Laprie, J.C.; Dependability: Basic Concepts and Terminology, Dependable Computing and Fault-Tolerant Systems Series, V.5, Spring-Verlag, 1992.

[LOV93] Lovric, T.; Echtle, K.; ProFI: Processor Fault Injection for Dependability Validation, IEEE Intl. Workshop on Fault and Error Injection for Dependability Validation of Computer Systems, Gotemburgo, Suécia, 1993.

[LUT90] Luts, M.; Testing Tools, IEEE Software, V.7, N.3, maio 1990.

[MAL89] Maldonado, J.C.; Chaim, M.L.; Jino, M.; Arquitetura de uma Ferramenta de Teste de Apoio ao Critério Potenciais Usos, Proc. XXII Congresso Nacional de Informática, São Paulo, SP, setembro 1989.

[MAL91] Maldonado, J.C.; Critérios Potenciais Usos: Uma Contribuição para o Teste Estrutural de Software, Tese de Doutorado, DCA/FEEC/UNICAMP, Campinas, SP, julho 1991.

[MAR93] Martins, E.; Validação Experimental da Tolerância a Falhas: A Técnica de Injeção de Falhas, V Simpósio de Computadores Tolerantes a Falhas, São José dos Campos, SP, outubro 1993. 
[MAR95a] Martins, E.; Integrando Injeção de Falhas e Testes Formais na Validação da Tolerância a Falhas, IX SBES - Simpósio Brasileiro de Engenharia de Software, PE, outubro 1995.

[MAR95b] Martins, E.; ATIFS: Um Ambiente de Teste baseado em Injeção de Falhas por Software, Relatório Técnico, DCC-95-24, dezembro 1995.

[MAT94] Mathur, A.P.; Wong, W.E.; An Empirical Comparison of Data Flow and Mutation-Based Test Adequacy Criteria, Software Testing, Verification and Reliability, V.4, 1994.

[MIL72] Mills, H.; On the Statistical Validation of Computer Programs, Relatório Técnico, FSC-72-6015, IBM Federal System Division, 1972.

[MYE79] Myers, G.; The Art of Software Testing, J. Wiley \& Sons, 1979.

[NAK98a] Nakagawa, E.Y.; Maldonado, J.C.; Estudo e Priorização da Aplicação dos Operadores de Mutação na Injeção de Defeitos, Relatório Técnico, USP/ICMC, São Carlos, 1998, (em preparação).

[NAK98b] Nakagawa, E.Y.; Maldonado, J.C.; Manual do Usuário da ITool v. I.0-C, Relatório Técnico, USP/ICMC, São Carlos, 1998, (em preparação).

[NIE93] Nielsen J.; Usability Engineering, Academic Press, Boston, 1993.

[OFF95] Offut, A.J.; et al.; An Experimental Evaluation of Data Flow and Mutation Testing, Software Practice and Experience, to appear 95.

[OST84] Ostrand, T.J.; Weyuker, E.J.; Colleting and Categorizing Software Error Data in an Industrial Environment, The Journal of Systems and Software, V. 4, 1984, pp. 289-300.

[OUS94] Ousterhout, J.K.; Tcl and the Tk Toolkit, Addison-Wesley Publishing Company, 1994.

[PFL98] Pfleeger, S.L.; Software Quality, Dr. Dobb's Journal, N. 283, março, 1998.

[PRE92] Pressman, R.B.; Software Engineering: a Practitioner's Approach, $3^{\text {a. }}$ Edition, McGraw-Hill, New York, US A, 1992.

[RAP85] Rapps, S.; Weyuker, E.J.; Data Flow Analysis Techniques for Test Data Selection, IEEE Trans. on Software Engineering, V. 11, abril 1985. 
[ROS93] Rosenberg, H.A.; Shin, K.G.; Software Fault Injection and its Applications in Distributed Systems, Proc. FTCS-23, Toulouse, France, 1993 (ftp://rtcl.eecs.umich.edu/outgoing/rosen/, 19 de outubro 1996).

[SEG88a] Segall, Z.; Vrsalovic, D.; Siewiorek, D.P.; Yaskin, D.; Kownacki, J.; Barton, J.; Dancey, R.; Robinson, A.; Lin, T.; FIAT - Fault Injection Based Automated Testing Environment, Proc. FTCS-18, Tokio, Japan, junho 1988.

[SEG88b] Segall, Z.; Barton, J.; Vrsalovic, D.; Siewiorek, D.P.; Dancey, R.; Robinson, A.; Fault Injection Based Automated Testing: Practice and Examples, Proc. VIII Digital Avionics System Conference, San Jose, USA, 1988.

[SHO75] Shooman, M.L.; Bolsky, M.; Types, Distribution and Test and Correction Times for Programming Errors, Proc. of the 1975 International Conference on Reliable Software, IEEE Computer Society Press, 1975.

[SOM96] Sommerville, I.; Software Engineering, 5. edição, Addison Wesley, 1996.

[SOM97] Somani, A.K.; Vaidya, N.H.; Understanding Fault Tolerance and Reliability, IEEE Computer, V. 30, N. 4, abril, 1997.

[SOU96] Souza, S.R.S.; Avalią̧ão do Custo e Eficácia do Critério Análise de Mutantes na Atividade de Teste de Software, Dissertação de Mestrado, ICMSC/USP, São Carlos, SP, 1996.

[VOA96] Voas, J.M.; McGraw, G.; Kassab, L.; Voas, L.; A Crystal Ball for Software Quality, Reliable Software Technologies Corporation, ftp://ftp.rstcorp.com/pub/papers/crystal.ps, Sterling, VA, USA, 19 de outubro de 1996.

[VOA97] Voas, J.; et al; Predicting How Badly "Good" Software Can Behave, IEEE Software, V.14, N.4, julho/agosto 1997.

[WAL97] Wallace, D.R.; Ippolito, L.M.; Hecht, H.; Error, Fault and Failure Data Collection and Analysis, Quality Week, São Francisco, EUA, maio 1997.

[WEL95] WeIch, B.B.; Practical Programming in Tcl and Tk, Prentice HaII, 1995.

[WON94a] Wong, W.E.; et al.; Mutation versus All-uses: An Empirical Evaluation of Cost, Strength, and Effectiveness, Software Quality and Productivity Theory, practice, education and training, Hong Kong, dezembro 1994. 
[WON94b] Wong, W.E.; et al.; Constrained Mutation in C Programs, VIII SBES Simpósio Brasileiro de Engenharia de Software, Curitiba, PR, 1994.

[WON94c] Wong, W.E.; London, S.; Mathur, A.; Effect of Test Set Minimization on the Fault Detection Effectiveness of the All-Uses Criterion, Technical Report SERC-TR-152-P, Software Engineering Research Center, Purdue University, abril 1994. 


\section{Apêndice A: Operadores de Mutação do Critério Análise de Mutantes}

Os operadores de mutação do critério Análise de Mutantes para o teste de unidade de programas escritos na linguagem $C$ são classificados em quatro classes: Mutação de Comandos (Statement Mutation), Mutação de Operadores (Operator Mutation), Mutação de Constantes (Constant Mutation) e Mutação de Variáveis (Variable Mutation), como listados ns Quadros 14, 15, 16 e 17, respectivamente.

Quadro 14 : Operadores da Classe Mutaçāo de Comandos

\begin{tabular}{|c|c|}
\hline 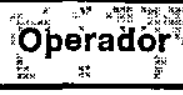 & 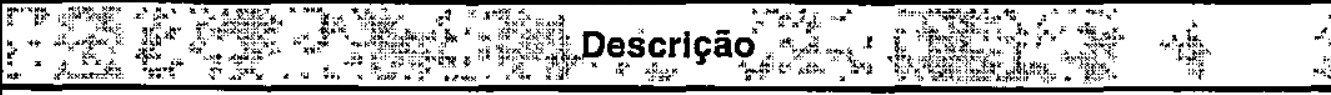 \\
\hline SBRC & roca o break pelo comando continue. \\
\hline SBRn & $\begin{array}{l}\text { Troca o comando break (ou continue) que localiza-se no n-ésimo nivel de } \\
\text { profundidade, pela função BREAK_OUT_TO_LEVEL_N (j), com } 2=j=n \text {, } \\
\text { desviando a seqüência de execuçāo para o j-ésimo laço aninhado. }\end{array}$ \\
\hline SCRB & Troca o continue pelo comando break. \\
\hline SCRn & $\begin{array}{llcccccc}\text { Similar ao SBRn, no entanto, } & \text { a troca } & \text { é } & \text { feita } & \text { pela } & \text { função } \\
\text { CONTINUE_OUT_TO_LEVEL_N }(j), \operatorname{com} & 2=j=n .\end{array}$ \\
\hline SDWD & Troca o comando do-while por while. \\
\hline SGLR & $\begin{array}{l}\text { Modela erros relacionados ao uso incorreto do rótulo do comando goto. Considere } \\
\text { goto } l, \ldots \text { goto } l n, n \text { distintos no programa em teste. O operador SGLR troca cada } \\
\text { rótulo } l i \text { do comando goto } l i \text { por }(n-l) \text { rótulos } l l, l 2, \ldots l i-l, l i+l, \ldots l n \text {. }\end{array}$ \\
\hline SMTC & $\begin{array}{l}\text { Introduz uma guarda antes do corpo do laço, false_after_n_inter }(n) \text { e juntamente com } \\
\text { o operador SMTT assegura que cada laço seja executado mais de uma vez e, este } \\
\text { tenha efeito na saída do programa. }\end{array}$ \\
\hline SMTT & $\begin{array}{l}\text { Introduz uma guarda antes do corpo do laço, trap_after_n_loop_inter }(n) \text { e } \\
\text { juntamente com o comando SMTC assegura que cada laço seja executado mais de } \\
\text { uma vez e, este tenha efeito na saída do programa. }\end{array}$ \\
\hline SMVB & ue indica fim de comandos compostos. \\
\hline SRSR & $\begin{array}{l}\text { Destinado a revelar erros na composição das funçôes. Tendo-se a seqüência de } \\
\text { execução dos comandos } C 1, C 2, C 3, \ldots C n, R \text {, onde } C \text { i é o i-ésimo comando executado } \\
\text { e } \mathrm{R} \text { é o comando return, esse operador revela erros com relação ao sufixo da } \\
\text { sequêência de execução que não afetam a saída do programa. }\end{array}$ \\
\hline SSDL & $\begin{array}{l}\text { Projetado para mostrar que cada comando tem um efeito na saída. Esse operador } \\
\text { apaga comandos, um de cada vez, gerando um mutante para cada comando apagado. }\end{array}$ \\
\hline SSWM & $\begin{array}{l}\text { Modela erros na formulação do comando switch. Em cada um dos ramos do comando } \\
\text { switch, é introduzida a função trap_on_case ( ) e ao executar essa função causa a } \\
\text { morte do mutante. }\end{array}$ \\
\hline STRI & $\begin{array}{l}\text { Analisa os ramos do comando if, gerando dois mutantes para cada if. A expressão } \\
\text { condicional } e \text { do if é substituída pelas funçōes trap_on_true }(e) \text { e trap_on_false }(e) \text {. }\end{array}$ \\
\hline STRP & $\begin{array}{l}\text { Destinado a revelar código nāo executado do programa em teste, trocando cada } \\
\text { comando pela funçāo trap_on_stat () e quando esse é executado o mutante é morto. }\end{array}$ \\
\hline & \\
\hline
\end{tabular}


Quadro 15: Operadores da Classe Mutą̧äo de Operadores

\begin{tabular}{|c|c|}
\hline Operador & Descrição \\
\hline OAAA & $\begin{array}{l}\text { Troca um operador aritmético com atribuição por um outro operador aritmético com } \\
\text { atribuição. }\end{array}$ \\
\hline$\overline{\mathrm{OAAN}}$ & Troca um operador aritmético por um outro aritmético. \\
\hline OABA & $\begin{array}{l}\text { Troca um operador aritmético com atribuição por um operador bit a bit com } \\
\text { atribuição. }\end{array}$ \\
\hline OABN & Troca um operador aritmético por um operador bit a bit. \\
\hline OAEA & Troca um operador aritmético com atribuição por um operador atribuição. \\
\hline OALN & Troca um operador aritmético por um operador lógico. \\
\hline OARN & Troca um operador aritmético por um operador relacional. \\
\hline OASA & $\begin{array}{l}\text { Troca um operador aritmético com atribuição por um operador deslocamento com } \\
\text { atribuição. }\end{array}$ \\
\hline OASN & Troca um operador aritmético por um operador de deslocamento. \\
\hline OBAA & $\begin{array}{l}\text { Troca um operador bit a bit com atribuição por um operador aritmético com } \\
\text { atribuição. }\end{array}$ \\
\hline OBAN & Troca um operador bit a bit por um operador aritmético. \\
\hline OBBA & $\begin{array}{l}\text { Troca um operador bit a bit com atribuição por um outro operador bit a bit com } \\
\text { atribuição. }\end{array}$ \\
\hline$\overline{\text { OBBN }}$ & Troca um operador bit a bit por um outro operador bit a bit. \\
\hline OBEA & Troca um operador bit a bit com atribuição por um operador atribuição. \\
\hline OBLN & Troca um operador bit a bit por um operador lógico. \\
\hline OBNG & $\begin{array}{l}\text { Modela erros relacionados ao sentido das expressões com operadores bit a bit, através } \\
\text { da inserção de um operador bit a bit de negação - }\end{array}$ \\
\hline OBRN & Troca um operador bit a bit por um operador relacional. \\
\hline OBSA & $\begin{array}{l}\text { Troca um operador bit a bit com atribuição por um operador de deslocamento com } \\
\text { atribuição. }\end{array}$ \\
\hline OBSN & Troca um operador bit a bit por um operador de deslocamento. \\
\hline OCNG & $\begin{array}{l}\text { Modela erros relacionados ao sentido das condições de controle de comandos } \\
\text { seletivos e interativos, excluindo o comando switch. }\end{array}$ \\
\hline OCOR & $\begin{array}{l}\text { Modela erros relacionados ao uso incorreto do operador cast e substitui cada } \\
\text { ocorrência do operador cast por outros tipos. }\end{array}$ \\
\hline OEAA & Troca um operador atribuição por um operador aritmético com atribuição. \\
\hline OEBA & Troca um operador atribuição por um operador bit a bit com atribuição. \\
\hline OESA & Troca um operador atribuição por um operador deslocamento com atribuição. \\
\hline Oido & Modela erros relacionados ao uso incorreto de $+\mathrm{e}--$. \\
\hline OIPM & $\begin{array}{l}\text { Modela erros relacionados a construção incorreta de expressões contendo os } \\
\text { operadores }++,-\cdots \text { e o operador de ponteiro }\left({ }^{*}\right) \text {. }\end{array}$ \\
\hline OLAN & Troca um operador lógico por um operador aritmético. \\
\hline OLBN & Troca um operador lógico por um operador bit a bit. \\
\hline OLLN & Troca um operador lógico por um outro operador lógico. \\
\hline OLNG & $\begin{array}{l}\text { Modela erros relacionados ao sentido das condições em comandos seletivos e } \\
\text { interativos. }\end{array}$ \\
\hline OLRN & Troca um operador lógico por um operador relacional. \\
\hline OLSN & Troca um operador lógico por um operador de deslocamento. \\
\hline ORAN & Troca um operador relacional por um operador aritmético. \\
\hline ORBN & Troca um operador relacional por um operador bit a bit. \\
\hline
\end{tabular}




\section{Continuaçāo da Quadro 3}

\begin{tabular}{|l|l|}
\hline ORLN & Troca um operador relacional por um operador lógico. \\
\hline ORRN & Troca um operador relacional por um outro relacional. \\
\hline ORSN & Troca um operador relacional por um operador de deslocamento. \\
\hline OSAA & $\begin{array}{l}\text { Troca um operador de deslocamento com atribuição por um operador aritmético com } \\
\text { atribuição. }\end{array}$ \\
\hline OSAN & Troca um operador de deslocamento por um operador aritmético. \\
\hline OSBA & $\begin{array}{l}\text { Troca um operador de deslocamento com atribuição por um operador bit a bit com } \\
\text { atribuição. }\end{array}$ \\
\hline OSBN & Troca um operador de deslocamento por um operador bit a bit. \\
\hline OSEA & Troca um operador de deslocamento com atribuição por um operador atribuiçāo. \\
\hline OSLN & Troca um operador de deslocamento por um logico. \\
\hline OSRN & Troca um operador de deslocamento por um relacional. \\
\hline OSSA & $\begin{array}{l}\text { Troca um operador de deslocamento com atribuição por um outro operador de } \\
\text { deslocamento com atribuiçāo. }\end{array}$ \\
\hline OSSN & Troca um operador de deslocamento por um outro operador de deslocamento \\
\hline
\end{tabular}

Quadro 16: Operadores da Classe Mutação de Constantes

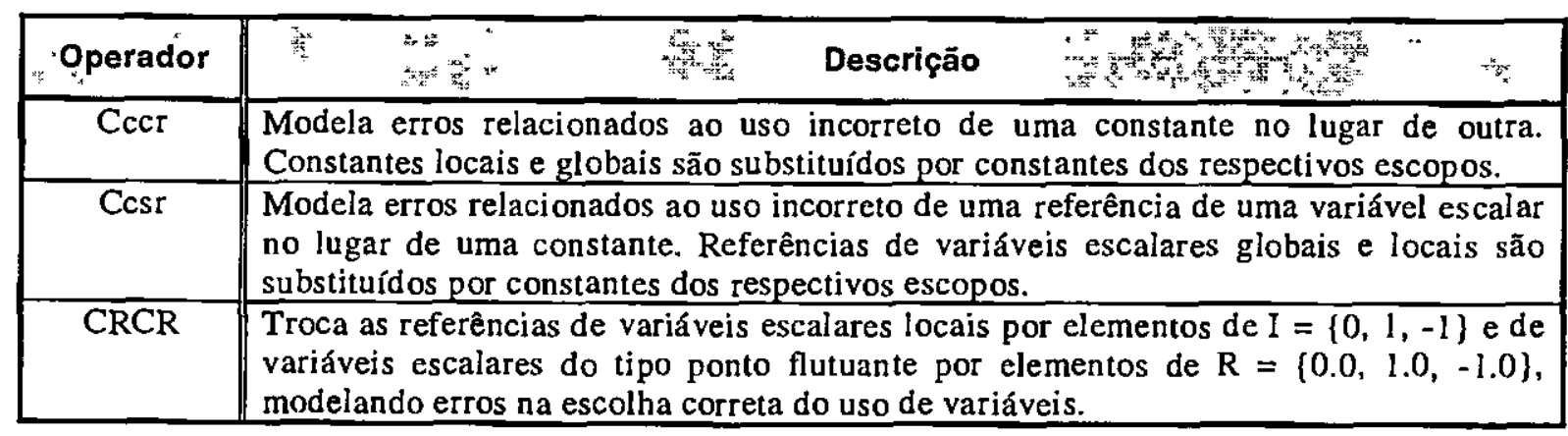

Quadro 17: Operadores da Classe Mutação de Variáveis

\begin{tabular}{|c||l|}
\hline Operador & \multicolumn{1}{|c|}{ Descrição } \\
\hline Varr & Modela erros relacionados ao uso incorreto de uma variável "array" no lugar de outra. \\
\hline VDTR & $\begin{array}{l}\text { Troca cada referência a uma variável escalar pelas funções trap_on_negative }(x), \\
\text { trap_on_positive }(x) \text { e trap_on_zero }(x) \text {, onde } x \text { pode ser uma variável integer, real e } \\
\text { double. }\end{array}$ \\
\hline Vprr & $\begin{array}{l}\text { Modela erros relacionados ao uso incorreto de variáveis do tipo ponteiro no lugar de } \\
\text { outra. }\end{array}$ \\
\hline VSCR & Modela erros relacionados ao uso incorreto de componentes de uma estrutura. \\
\hline Vsrr & Modela erros relacionados ao uso incorreto de uma variável escalar no lugar de outra. \\
\hline Vtrr & $\begin{array}{l}\text { Modela erros relacionados ao uso incorreto de variáveis do tipo estrutura no lugar de } \\
\text { outra. }\end{array}$ \\
\hline VTWD & $\begin{array}{l}\text { Modela erros relacionados ao valor de variáveis ou expressões, sendo útĩ para checar } \\
\text { valores limites para variáveis escalares, através da utilização das funções pred ( ) e } \\
\text { succ( (), que retorna o predecessor e o sucessor da variável escalar envolvida. }\end{array}$ \\
\hline
\end{tabular}




\section{Apêndice B: Operadores de Mutação do Critério Mutação de Interface}

Os operadores de mutação do critério Mutação de Interface para o teste de integração são classificados em duas classes ou grupos: Grupo 1 (realiza a mutação na função que está sendo chamada em uma conexão) e Grupo 2 (realiza mutação na função que realiza a chamada de outra função na conexão), sendo listados nos Quadros 18 e 19, respectivamente. Esses operadores utilizam-se dos conjuntos descritos abaixo, supondo-se que a Mutação de Interface está sendo aplicada entre as funções $f$ e $g$.

$C(g)$ : constantes utilizadas em $g$;

$E(g)$ : variáveis g lobais não utilizadas em $g$;

$G(g)$ : variáveis globais utilizadas em $g$;

$L(g)$ : variáveis declaradas no escopo de $g$, ou seja, variáveis locais;

$P(g)$ : parâmetros formais de $g$;

$R(g)$ : constantes requeridas contendo valores especiais, relevantes para alguns tipos primitivos de dados da linguagem $\mathrm{C}$ e operadores associados a esses tipos.

Quadro 18: Operadores de Mutaçāo de Interface - Grupo 1

\begin{tabular}{|c||l|}
\hline Operador & \multicolumn{1}{|c|}{ Desçição } \\
\hline CovAllEdg & Cobertura de todos os arcos. \\
\hline CovAllNod & Cobertura de todos os nós. \\
\hline DirVarAriNeg & Insere um operador aritmético de negação na variável de interface. \\
\hline DirVarBitNeg & Insere um operador bit a bit de negação na variável de interface. \\
\hline DirVarIncDec & $\begin{array}{l}\text { Insere/remove operador incremental (++) e decremental (--) na variável de } \\
\text { interface. }\end{array}$ \\
\hline DirVarLogNeg & Insere um operador lógico de negação na variável de interface. \\
\hline DirVarRepCon & Troca variável de interface por elementos de C. \\
\hline DirVarRepExt & Troca variável de interface por elementos de E. \\
\hline DirVarRepGlo & Troca variável de interface por elementos de G. \\
\hline DirVarRepLoc & Troca variável de interface por elementos de L. \\
\hline DirVarRepPar & Troca variável de interface por elementos de P. \\
\hline DirVarRepReq & Troca variável de interface por elementos de R. \\
\hline IndVarAriNeg & Insere operador aritmético de negacaão em variável que não é de interface. \\
\hline IndVarBitNeg & Insere operador bit a bit de negação em variável que não é de interface. \\
\hline IndVarIncDec & $\begin{array}{l}\text { Insere/remove operador incremental (t+) e decremental (--) em variável que é de } \\
\text { in terface. }\end{array}$ \\
\hline IndVarLogNeg & Insere operador lógico de negação em variável que não é de interface. \\
\hline IndVarRepCon & Troca variável que nāo é de interface por elementos de C. \\
\hline IndVarRepExt & Troca variável que não é de interface por elementos de E. \\
\hline IndVarRepGlo & Troca variável que nāo é de interface por elementos de G. \\
\hline IndVarRepLoc & Troca variável que não é de interface por elementos de L. \\
\hline IndVarRepPar & Troca variável que não é de interface por elementos de P. \\
\hline IndVarRepRea & Troca variável que não é de interface por elementos de R. \\
\hline RetStaDel & Apaga comando return. \\
\hline RetStaRep & Troca comando return. \\
\hline
\end{tabular}


Quadro 19: Operadores de Mutaçāo de Interface - Grupo 2

\begin{tabular}{|c|c|}
\hline Operapory & 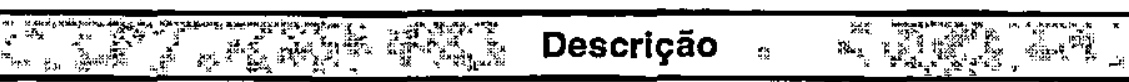 \\
\hline ArgAriNeg & Insere operador aritmético de negação em argumentos. \\
\hline ArgBitNeg & Insere operador bit a bit de negação em argumentos. \\
\hline ArgDel & Remove argumento. \\
\hline ArgIncDec & Incremento e decremento de argumentos. \\
\hline ArgLogNeg & Insere operador lógico de negaçāo em argumentos. \\
\hline ArgRepReq & Troca argumento por elementos de $\mathrm{R}$. \\
\hline ArgStcAli & Troca argumentos de tipos compativeis. \\
\hline ArgStcDif & Troca argumentos de tipos nāo compatíveis. \\
\hline FunCalDel & Remove chamada de função. \\
\hline
\end{tabular}




\section{Apêndice C: Um Exemplo Utilizando a Ferramenta}

Neste apêndice é mostrado um exemplo de uma sessão de teste utilizando o esquema de injeção de defeitos estabelecido e a ferramenta de injeção de defeitos de software denominada ITool.

O programa em avaliação é o identifier que tem a função de validar identificadores de programas escritos em uma linguagem variante do PASCAL, denominada Silly PASCAL. Um identificador válido deve começar com uma letra e conter apenas letras ou dígitos. Além disso, deve ter no mínimo um caractere e no máximo seis caracteres de comprimento. O código fonte desse programa é mostrado na Figura 29. Esse programa possui um total de 24 LOC (linhas de código), não incluindo comentários.

\section{C.1. Interface Gráfica}

Para utilizar a ferramenta ITool com interface gráfica, deve-se estar em um ambiente gráfico e chamar pelo comando itool em uma janela de comandos, por exemplo, o comdtool do Solaris. Esse comando executará a ferramenta. mostrando a janela que aparece na Figura 28. A partir dessa janela, pode-se utilizar todas as funcionalidades da ferramenta através do menu principal. Às op̧ões do menu ProgTest, FaultModel, TestCase e Inject - estão associados menus suspensos que disponibilizam conjunto de op̧ões.

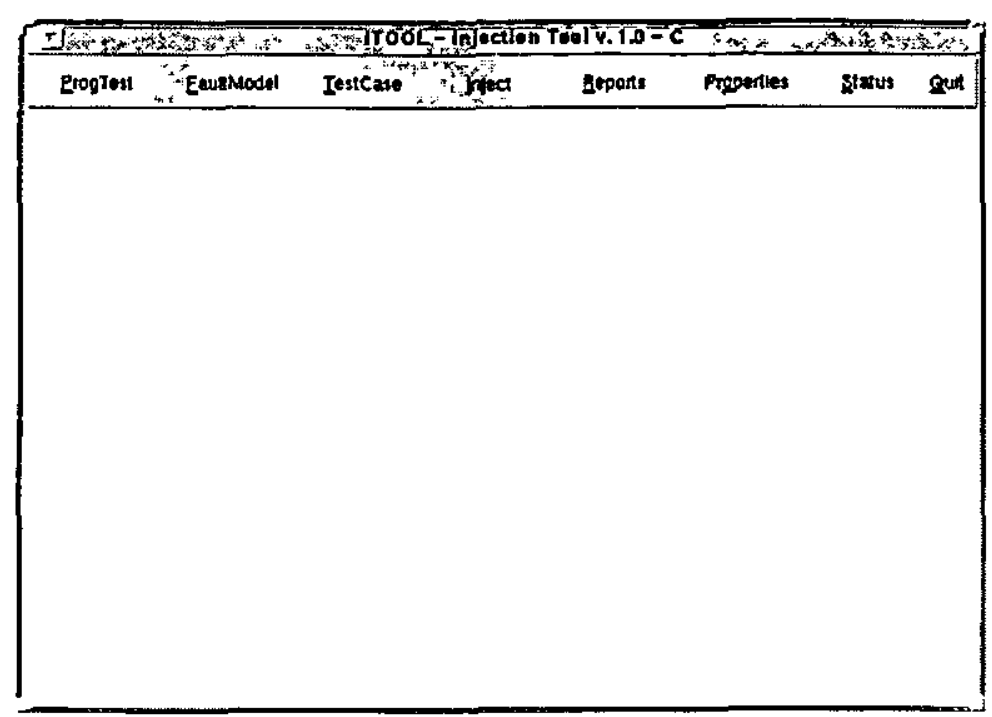

Figura 28: Janela Principal da ITool 


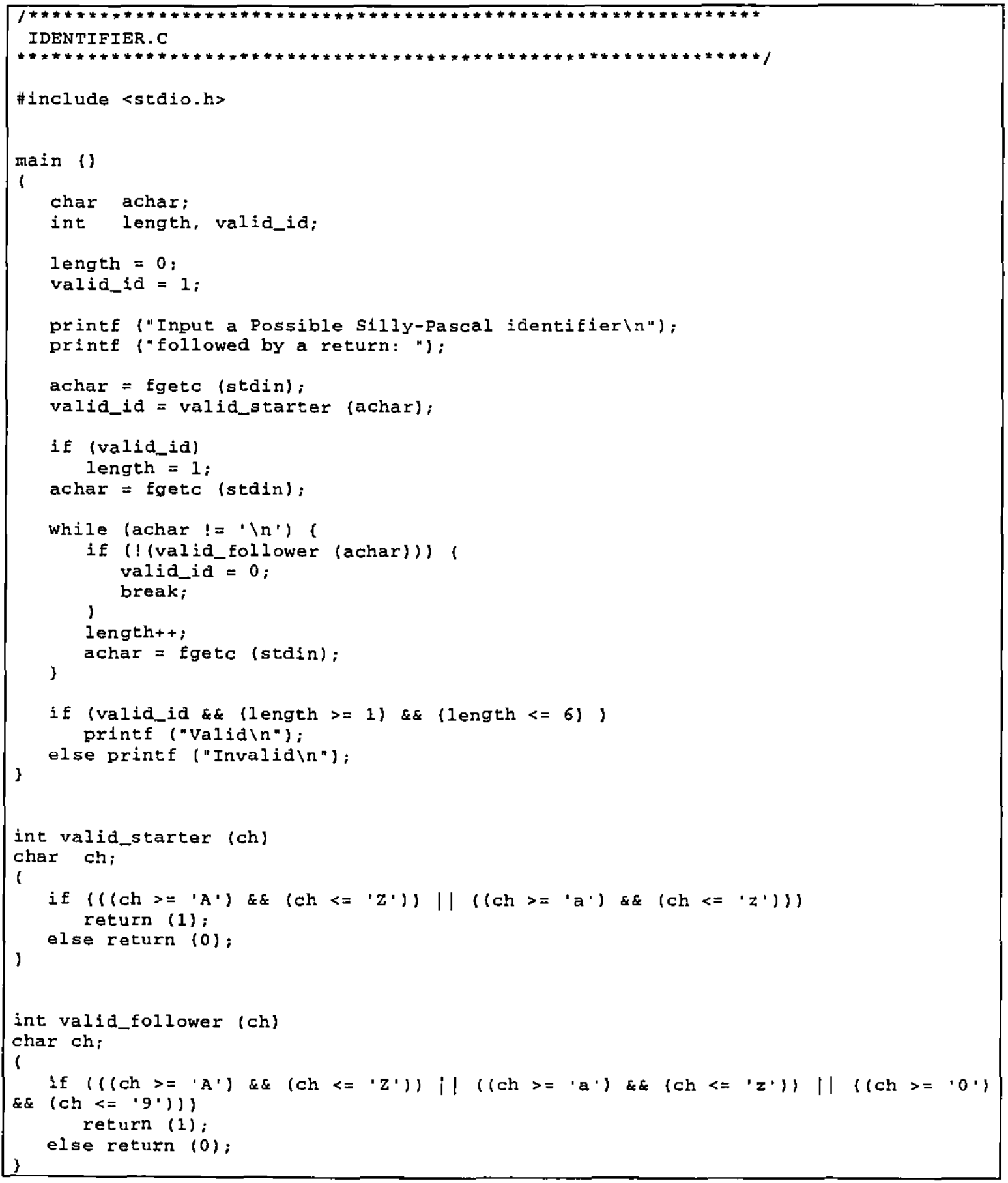

Figura 29 : Código Fonte do Programa Identifier

\section{C.1.1. Criando uma Sessão de Teste}

Para iniciar uma sessão de teste, deve-se criá-la selecionando a opção ProgTest no menu principal como mostrado na Figura 30, e em seguida, a opção $N e w$ do menu 
suspenso. Essa opção apresentará a janela mostrada na Figura 31 que permite ao usuário entrar com dados - Directory (nome do diretório de trabalho onde estão os arquivos fonte e executável e onde serão criados os arquivos de trabalho da ITool), Program Test Name (nome da sessão de teste), Source Program (nome do programa fonte), Executable Program (nome do programa executável) e Compilation Command (comando de compilação utilizado para compilar o programa fonte, criando-se o programa executável) — para a criação da sessão de teste.

Para esse exemplo, o nome da sessão de teste é Identifier. O nome do arquivo fonte é identifier.c (para a ferramenta não é necessário fornecer a extensão .c) e o nome do executável é identifier. Nesse caso, está sendo utilizado o compilador gcc disponível no Solaris para compilar o fonte e criar o executável, mas poderia ser utilizado qualquer outro compilador. Assim, o comando de compilação é gcc identifier. $c-o$ identifier.

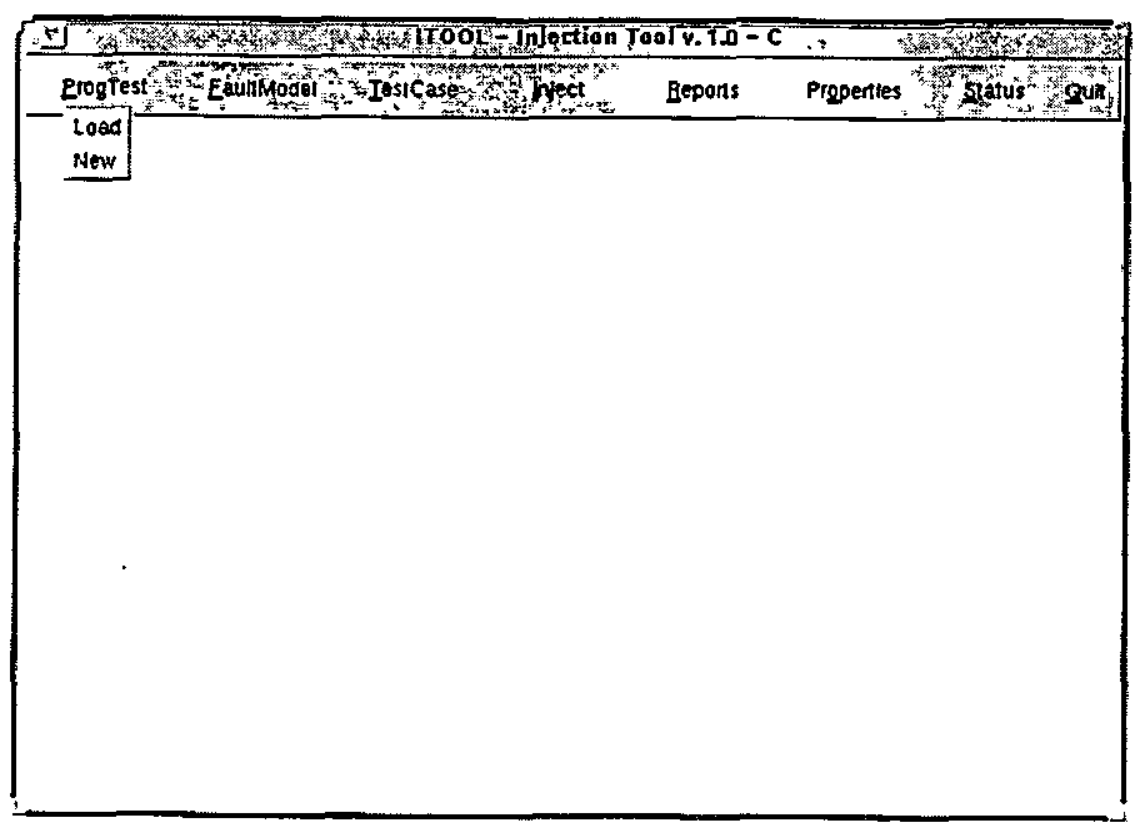

Figura 30: Opçāo para Manipular Sessão de Teste 


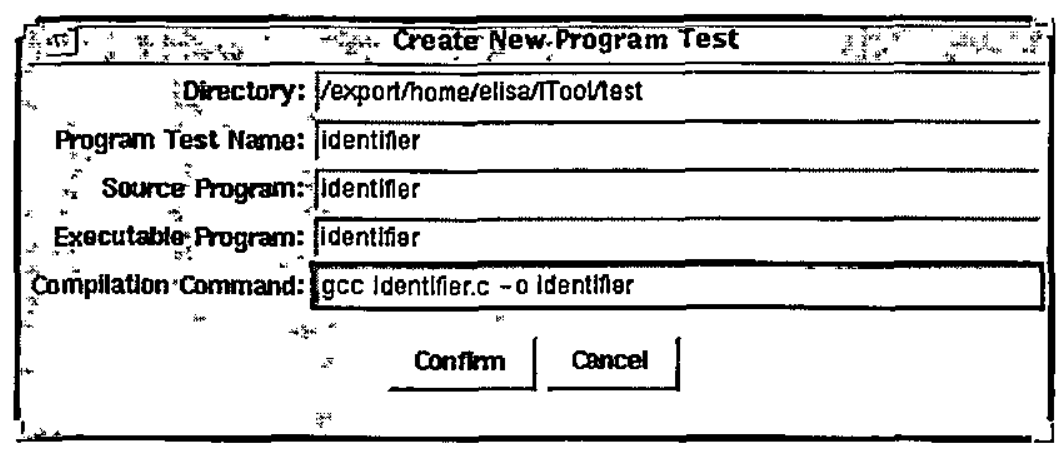

Figura 31: Criando uma Sessäo de Teste

Durante a criação da sessão de teste são gerados todos os defeitos; por default, são gerados $10 \%$ de defeitos para cada operador; isto significa que, para cada operador de mutação, ao invés de gerar todos os defeitos (ou mutantes, no contexto do critério Análise de Mutantes), isto é $100 \%$, somente $10 \%$ serão gerados. Outras porcentagens podem ser utilizadas, definindo outros valores na janela Properties, que pode ser chamada diretamente do menu principal.

Para esse exemplo, foram gerados um total de 926 defeitos, gerando-se $10 \%$ dos defeitos de cada operador. Essa geração é transparente ao usuário e é uma atividade que requer mais tempo de processamento se comparado com outras atividades executadas pela ferramenta.

\section{C.1.2. Manipulando um Modelo de Defeitos}

O próximo passo é a seleção de um modelo de defeitos para essa sessão de teste. Selecionando-se a opção FaultModel é mostrado um menu suspenso, como pode ser observado na Figura 32.

A opção Select desse menu permite chamar a janela mostrada na Figura 33, através do qual se pode selecionar um arquivo contendo o modelo de defeitos a ser utilizado na avaliação. Deve-se entrar com o nome do diretório onde se encontra o arquivo de modelos de defeitos - no caso, /export/home/elisa/ITool/tool/bin/models - e o nome do arquivo contendo o modelo de defeitos - modell.mdl. 


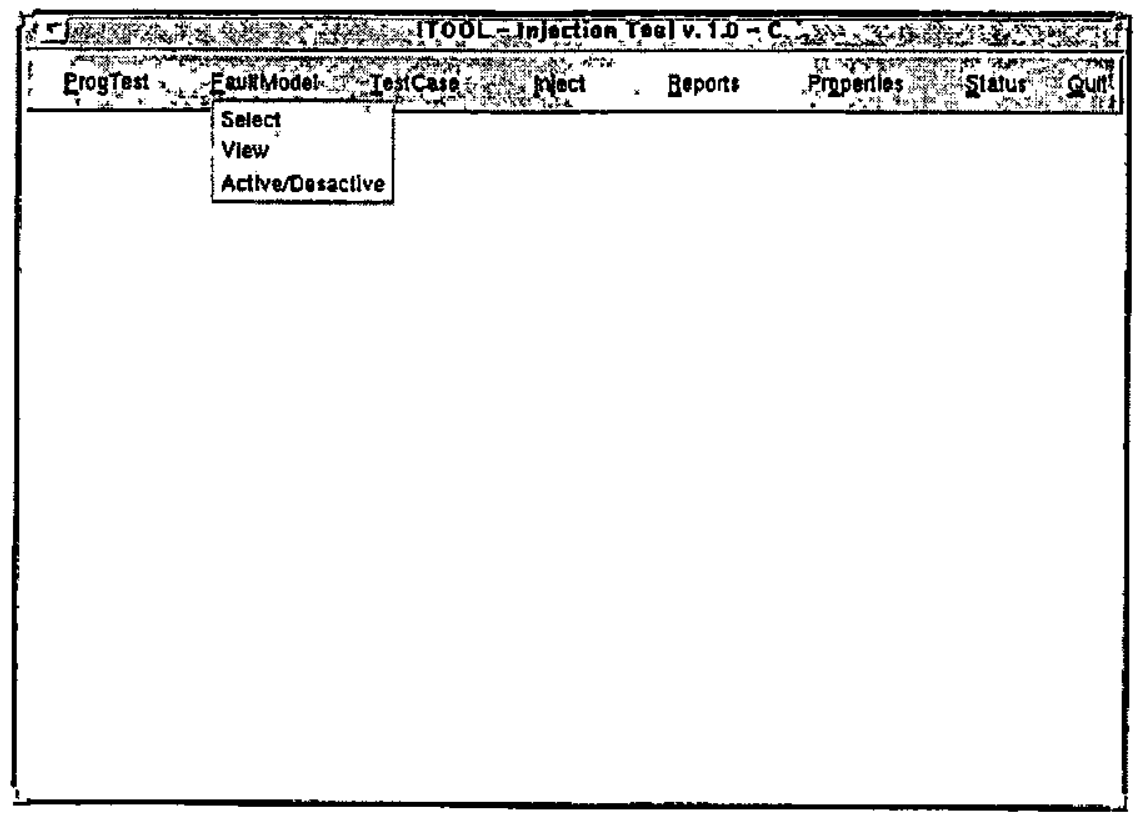

Figura 32: Op̧āo para Manipular Modelos de Defeitos

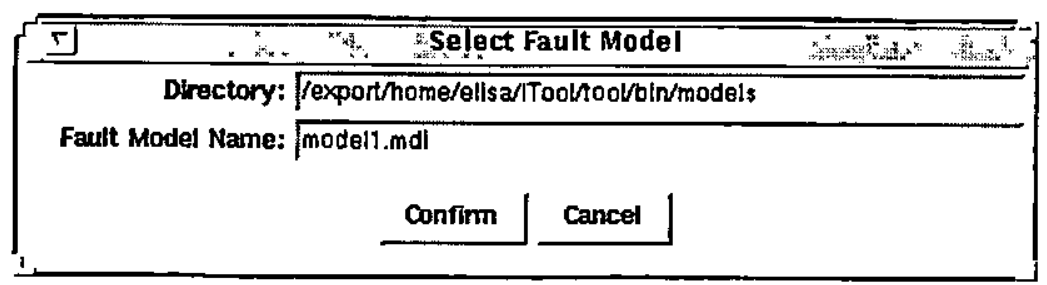

Figura 33: Selecionando um Modelo de Defeitos

Após a seleção de um modelo de defeitos, pode-se visualizá-la através da opção View do menu de modelo de defeitos que permite chamar a janela mostrada na Figura 34.

Desejando-se modificar o estado de ativação das classes e dos operadores, isto é, selecionar classes e operadores a serem utilizados na seleção de um conjunto a partir do qual serão sorteados defeitos a serem injetados, a opção Active/Deactive disponibiliza uma janela denominada Active/Deactive Class que permite realizar essa tarefa.

Está associado a cada classe um conjunto de operadores de acordo com o mode lo de defeitos selecionado e, desejando-se não injetar defeitos gerados por um determinado operador, pode-se desabilitar esse operador. A janela que permite realizar essa tarefa - Active/Deactive Operator - pode ser chamada através do botão $\perp_{\mathrm{da}}$ 
janela Active/ Deactive Class. Cada classe possui um botão que chama a janela com os operadores relacionados. A Figura 35 mostra os operadores relacionados à classe SIEF (Simple Incorrect Entity Fault).

Para esse exemplo, as classes MPEF (Misplaced Entity Fault) e SPEF (Spurius Entity Fault) estão desabilitadas e as classes MSEF (Missing Entity Fault) e SIEF (Simple Incorrect Entity Fault) estão habilitadas. Para cada classe, alguns operadores foram habilitados para gerar os defeitos a serem injetados.

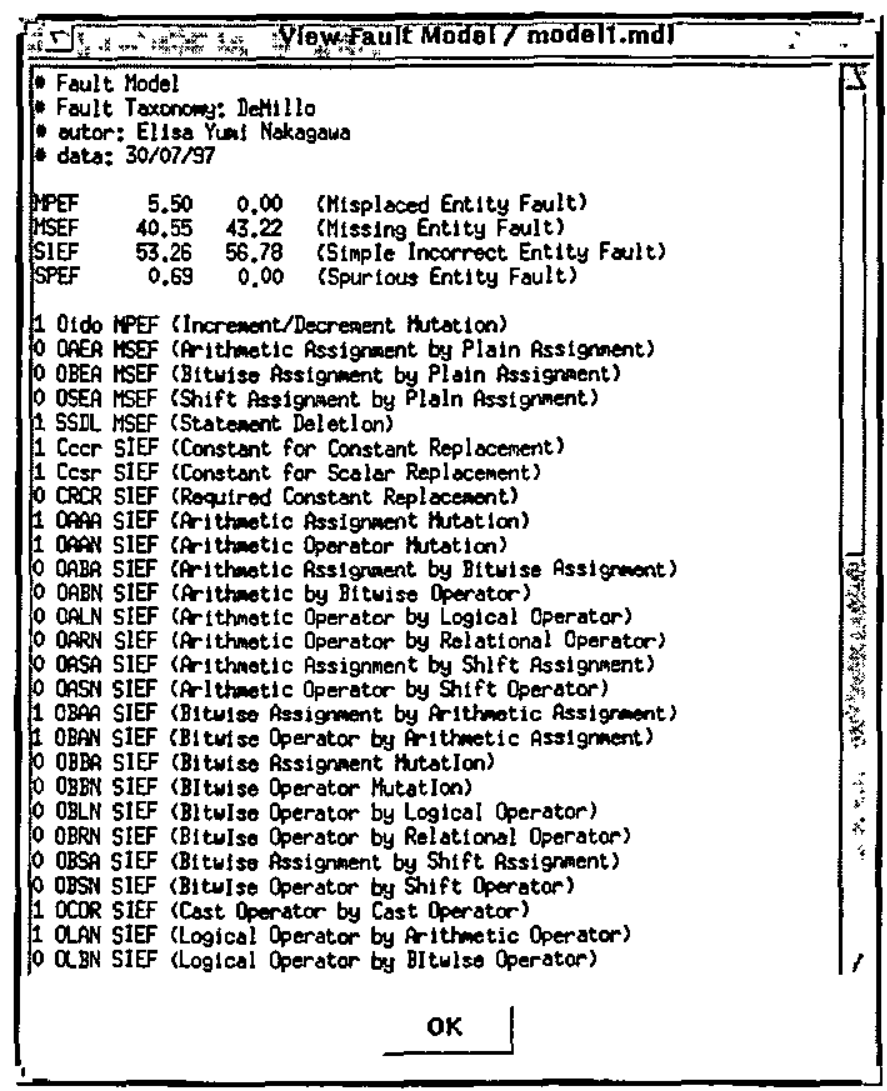

Figura 34: Visualizando um Modelo de Defeitos 


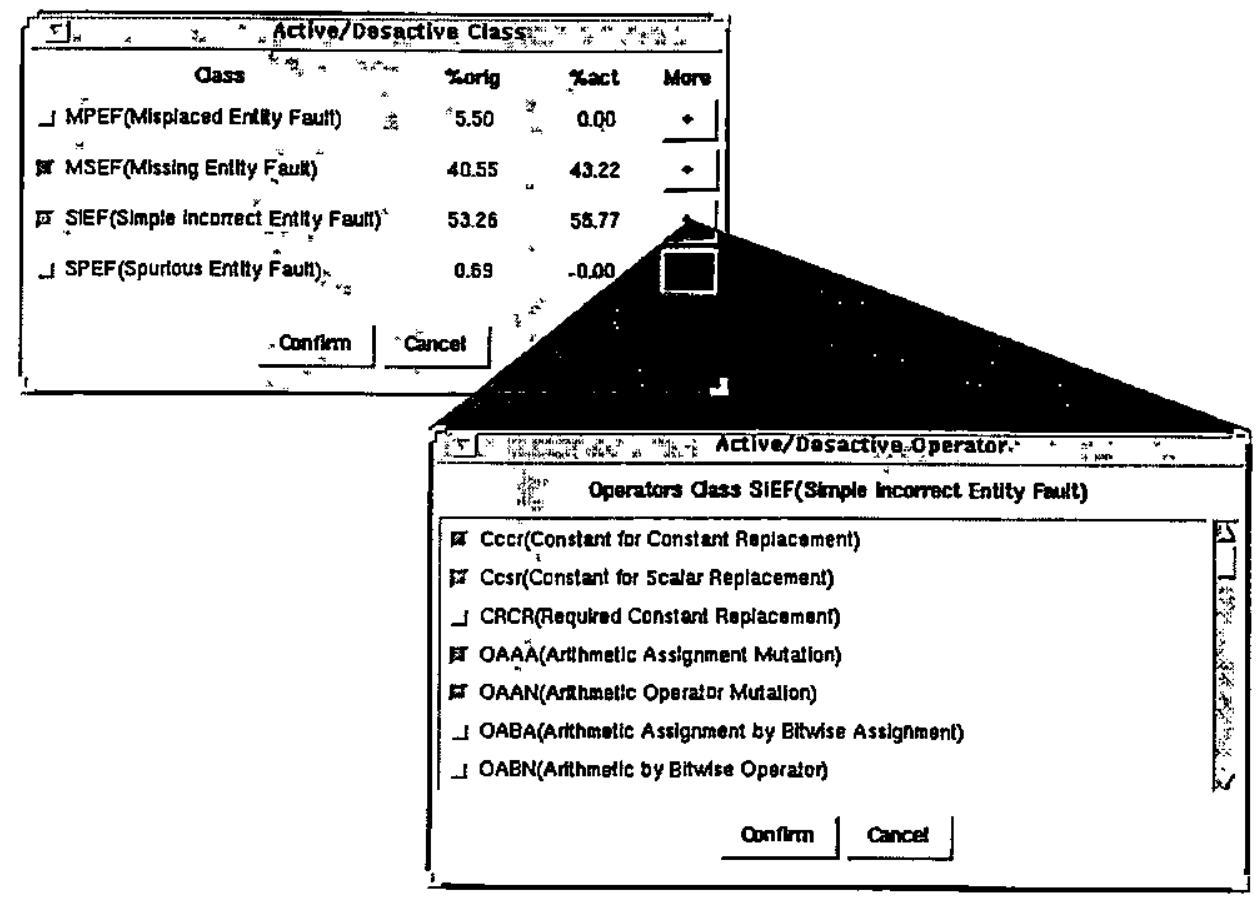

Figura 35: Ativando/Desativando Classes de Defeitos e Operadores de Mutação

\section{C.1.3. Adicionando Casos de Teste}

Agora que o programa possui os defeitos injetados, necessita-se de um conjunto de casos de teste que podem ser manipulados através da opção TestCase do menu principal. Nessa opção está vinculado um menu com diversas opções como visto na Figura 36. 


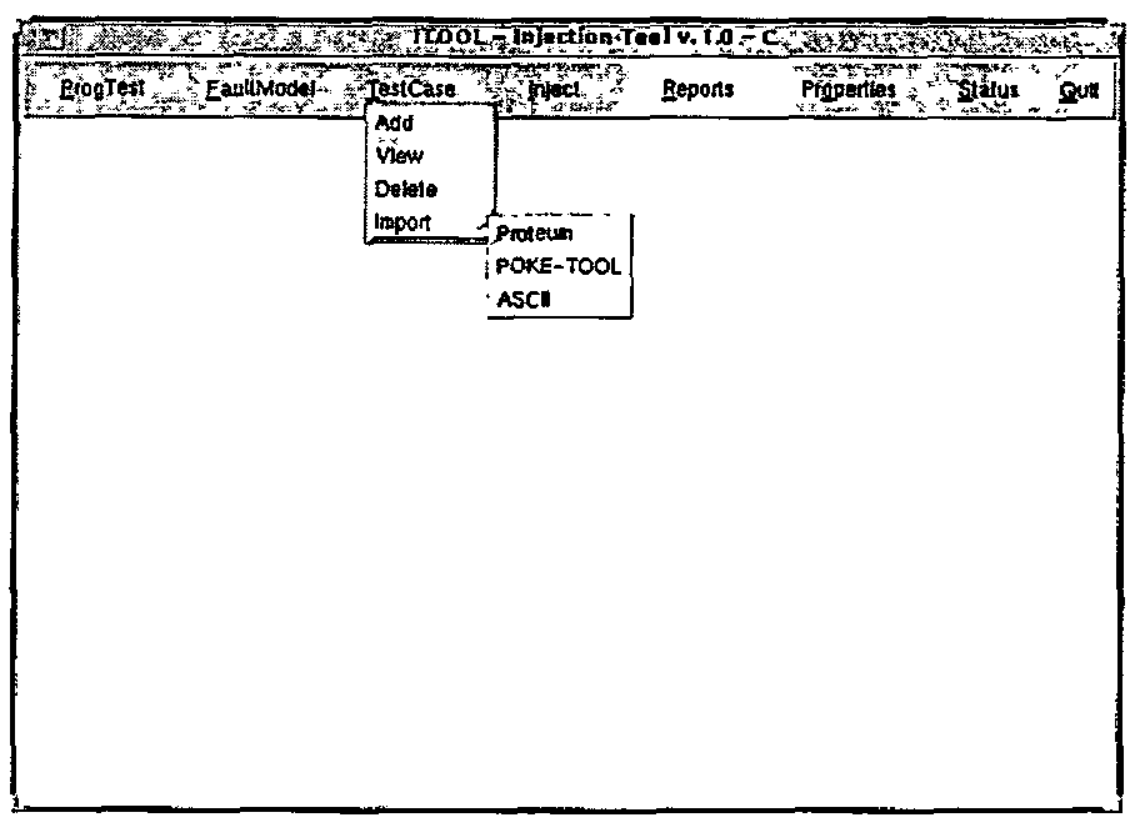

Figura 36: Op̧̧ão para Manipular Casos de Teste

Para entrar com casos de teste na ferramenta, pode-se adicioná-los um a um ou importar de sessões de teste de outras ferramentas - Proteum e POKE-TOOL - ou de arquivos ASCII.

Ao selecionar a opção $A d d$ no menu de casos de teste, será disponibilizada uma janela para a entrada de parâmetros, como mostrada na Figura 37, se o programa em avaliação necessita de parâmetros na linha de comando quando é executado; em seguida, entra-se com dados de teste na janela de comandos (cmdtool do Solaris, por exemplo, como mostrada na Figura 38) de onde foi chamada a ITool. Nessa janela pode-se interagir com o programa identifier, como se fosse uma execução normal. A entrada do programa identifier é uma sequiência de caracteres, ou seja, o nome de um identificador que se deseja validar. O resultado da execução do identifier é uma mensagem de que o identificador é válido ou inválido.

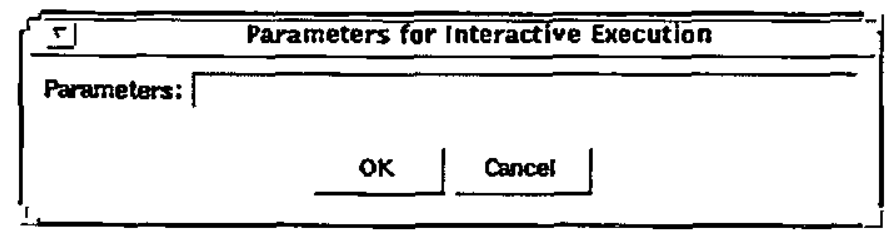

Figura 37: Parametro para Inserção de Casos de Teste 


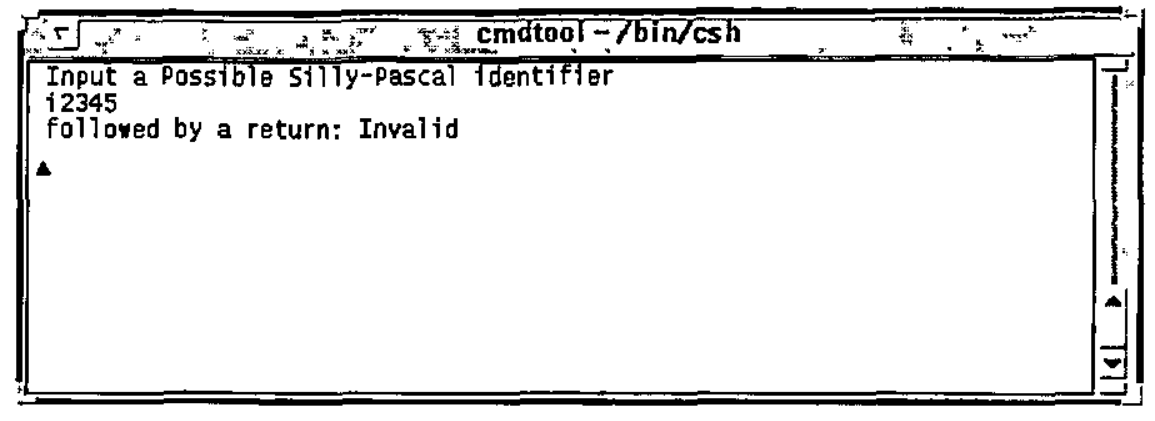

Figura 38: Entrando com Dados para o Programa

Os casos de teste podem ser visualizados ao selecionar a opção View do menu de casos de teste que chama a janela que aparece na Figura 39. Nessa janela, além das entradas e saídas do programa identifier, são fornecidos o tempo de execução em centésimo de segundos, o código de retorno e os parâmetros.

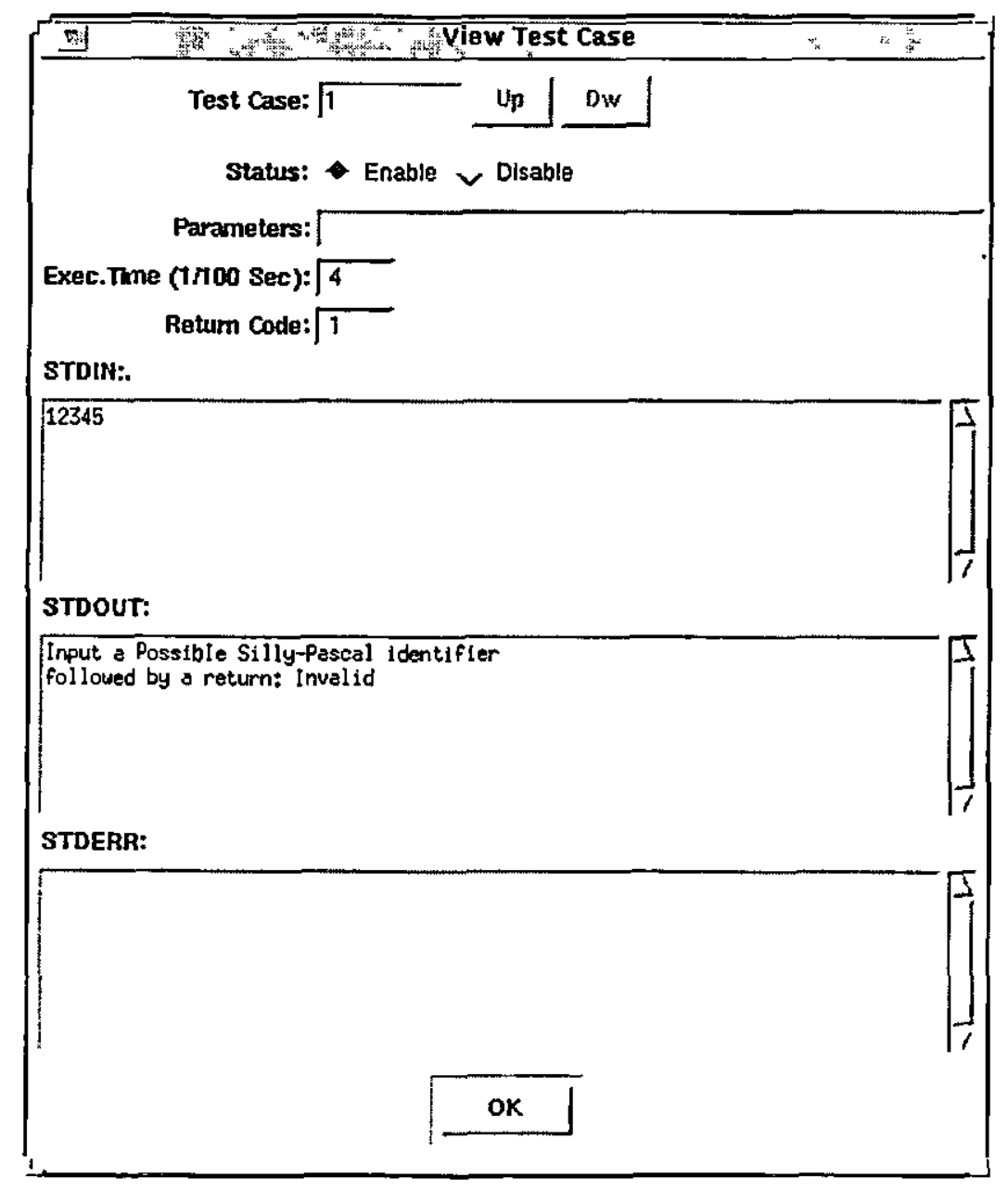

Figura 39: Visualizando Casos de Teste 
Pode-se assim, adicionar mais casos de teste, ou então, passar ao passo seguinte que é o de injetar defeitos no programa em avaliação.

\section{C.1.4. Injetando Defeitos}

A manipulação dos defeitos injetados pode ser feita através da opção Inject do menu principal que apresenta um menu suspenso como mostrado na Figura 40. Manipular significa injetar defeitos, visualizar, avaliar e ativar/desativar defeitos injetados, além de localizar defeitos reais.

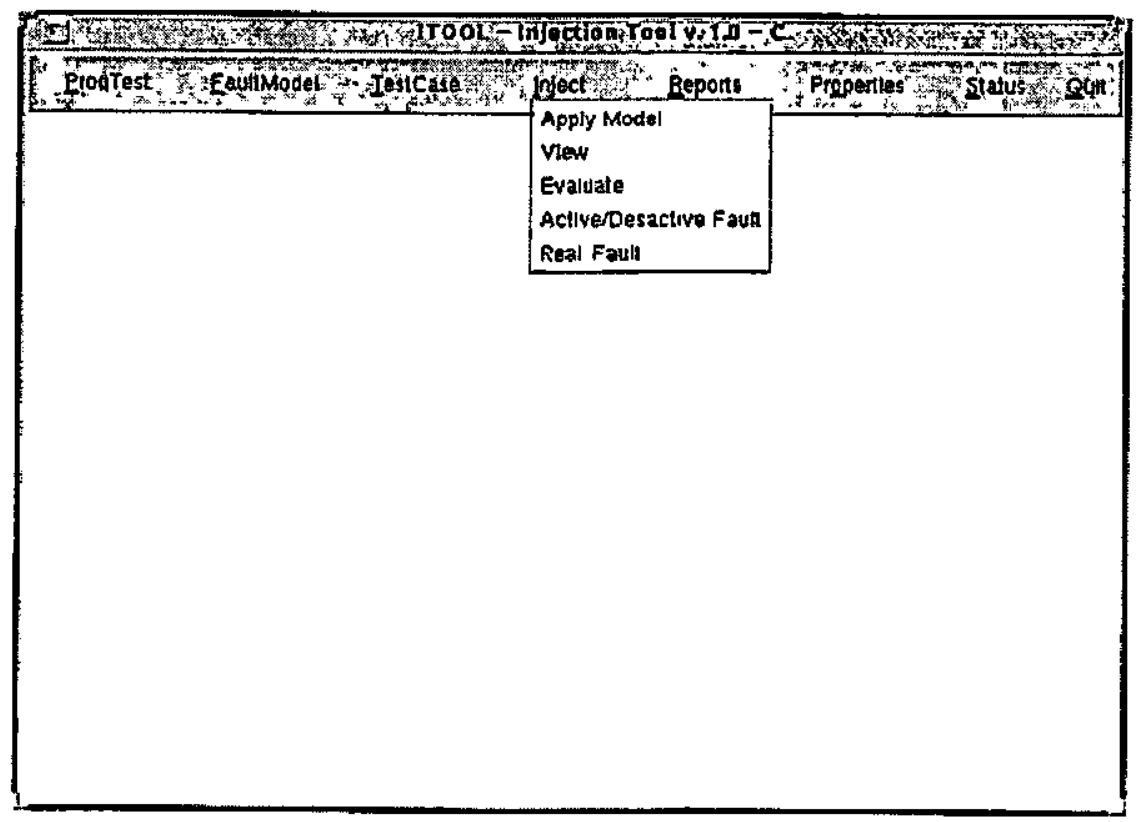

Figura 40: Op̧āo para Manipular o Programa com Defeitos Injetados

A injeção de defeitos é baseada no modelo de defeitos selecionado anteriormente. O número de defeitos a injetar e a classe são definidos por esse modelo, juntamente com o Faults/KLOC (número de defeitos a cada 1.000 linhas de código) fornecido pelo usuário. Para esse exemplo, foram selecionadas todas as funções (Blocks) para serem avaliadas, mas pode-se selecionar uma função ou um conjunto de funções para avaliação. Esses dados são entrados na janela Apply Fault Model, mostrado na Figura 41, chamada através da opção Apply Model do menu de defeitos injetados. 


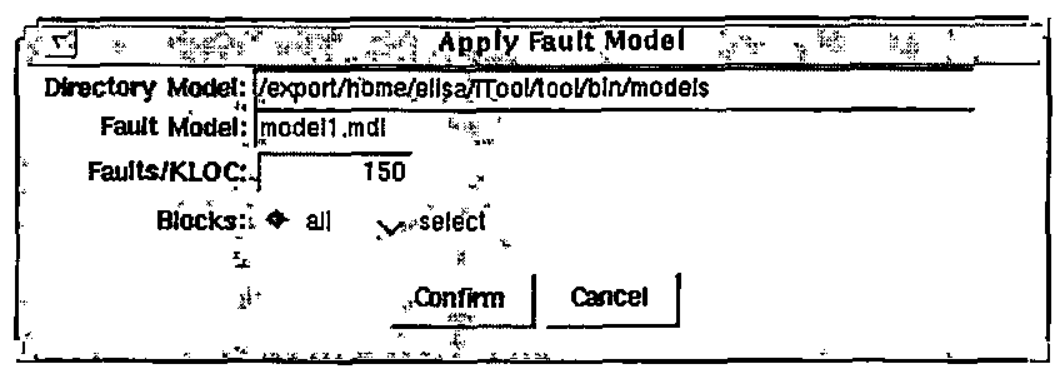

Figura 41: Aplicando o Modelo de Defeitos

O Quadro 20 mostra o total de defeitos gerados para cada uma das quatro classes, a porcentagem relativa e o número de defeitos selecionados e o número de defeitos a injetar. O identifier possui $24 \mathrm{LOC}$; assim, tendo-se 150 defeitos a cada 1.000 linhas de código, serão injetados 3 defeitos.

Quadro 20: Defeitos Gerados e Selecionados de Cada Classe

\begin{tabular}{|c|c|c|c|c|}
\hline Classe & \# de Defeitos & \% Relativa & $\begin{array}{c}\text { \# de Defeitos } \\
\text { Selecionados }\end{array}$ & $\begin{array}{c}\text { \# de Defeitos } \\
\text { a Injetar }\end{array}$ \\
\hline Entidade Mal Empregada & 1 & 0,00 & 0 & 0 \\
\hline Falta de Entidade & 29 & 43,22 & 29 & 1 \\
\hline Entidade Simples Incorreta & 695 & 56,78 & 38 & 2 \\
\hline Entidade Espúria & 201 & 0,00 & 0 & 0 \\
\hline Total & 926 & 100,00 & 67 & 3 \\
\hline
\end{tabular}

Na Figura 42 é apresentado o arquivo Identifier.FLT que armazena os defeitos que foram injetados. 


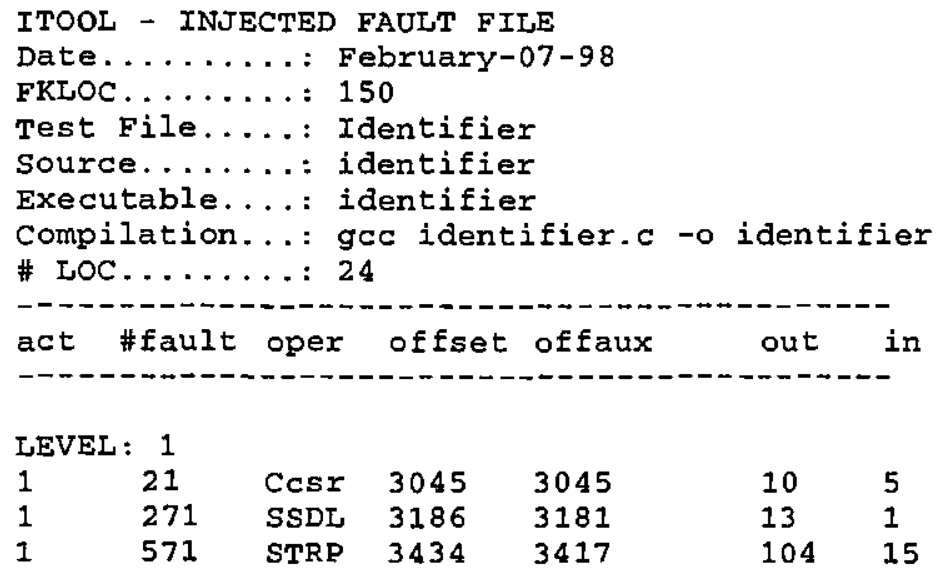

Figura 42: Arquivo Identifier.FLT que Armazena os Defeitos Injetados

O próximo passo é a execução do programa com os defeitos injetados e verificar o comportamento do programa para cada caso de teste.

A janela mostrada na Figura 43 permite selecionar um intervalo de casos de teste para ser utilizada na execução do programa. Essa janela pode ser chamada através da opção Evaluate do menu que manipula o programa com defeitos injetados. Ao confirmar (botão Confirm), imediatamente, é iniciada a execução do programa com cada caso de teste, como mostrado na Figura 44. Pode-se também interromper a execução através do botão Cancel contido nessa janela.

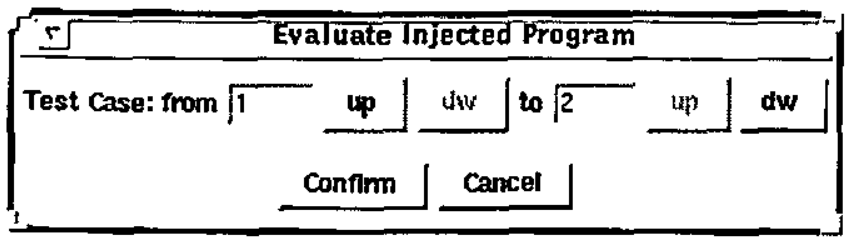

Figura 43: Selecionado Casos de Teste a Serem Utilizados

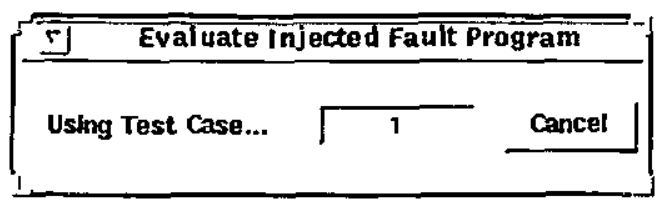

Figura 44: Executando Programa com Defeitos Injetados 
Utilizando a ITool à luz do critério Semeadura de Defeitos, pode-se ativar e desativar defeitos injetados e nesse processo, o usuário tem a possibilidade de identificar defeitos reais. A ativação/desativação de defeitos injetados pode ser feita através da janela Active/Deactive Fault, como mostrada na Figura 45 e chamada através da opção Active/Deactive Fault do menu suspenso associado à opção Inject.

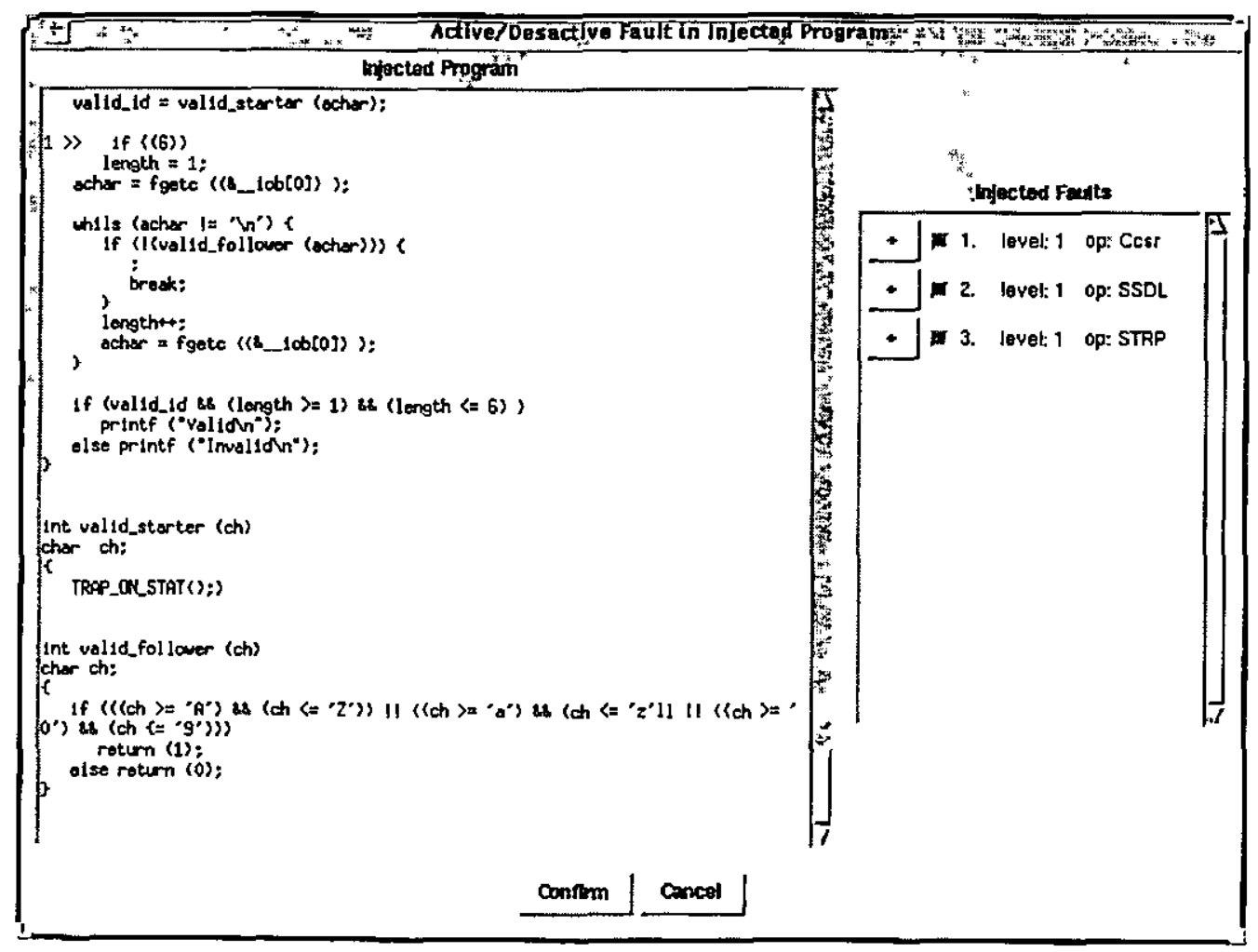

Figura 45: Ativação/Desativação de Defeitos Injetados

Ao localizar um defeito real, isto é, contido no programa original, o usuário pode editar o programa através da opção Real Fault do menu suspenso associado à opção Inject. Essa opção disponibilizará um editor de texto como mostrado na Figura 46. 


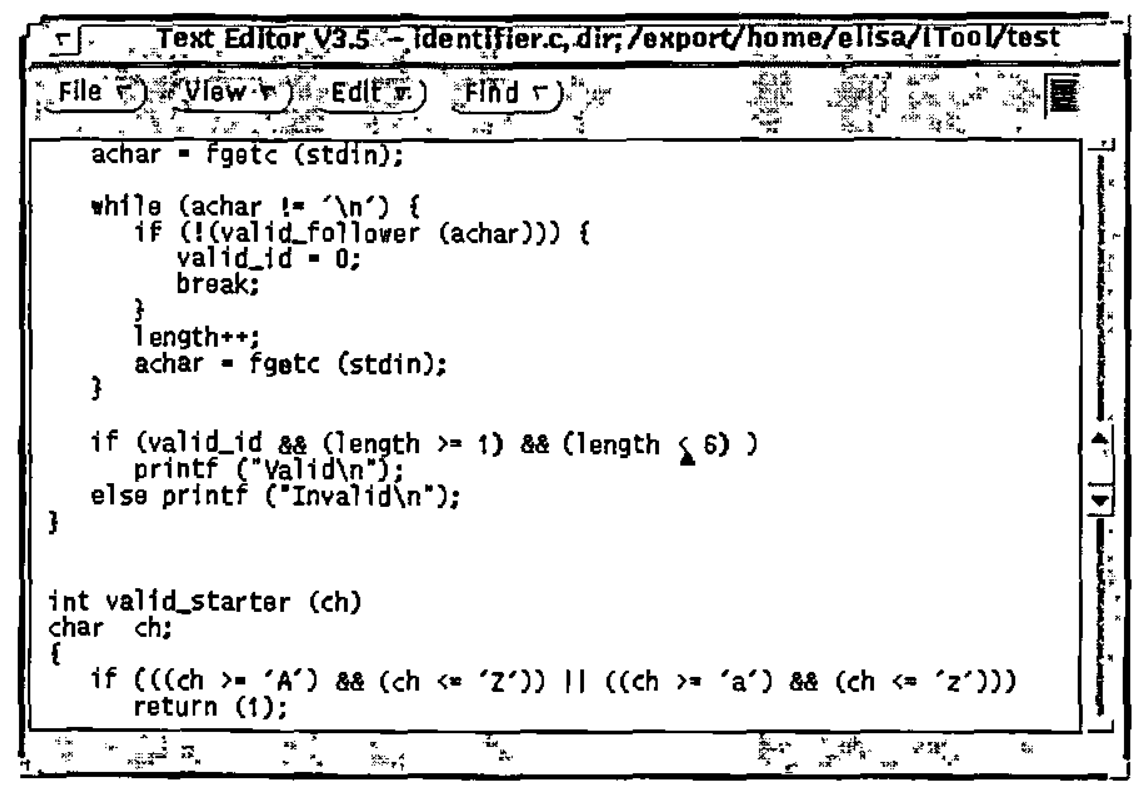

Figura 46: Eliminando um Defeito Real

\section{C.1.5. Visualizando Resultados}

Em qualquer fase do teste, pode-se acompanhar o andamento do teste ao acionar o botão Status no menu na janela principal. Uma janela como a mostrada na Figura 47 é exibida na qual é apresentado um sumário da situação do teste.

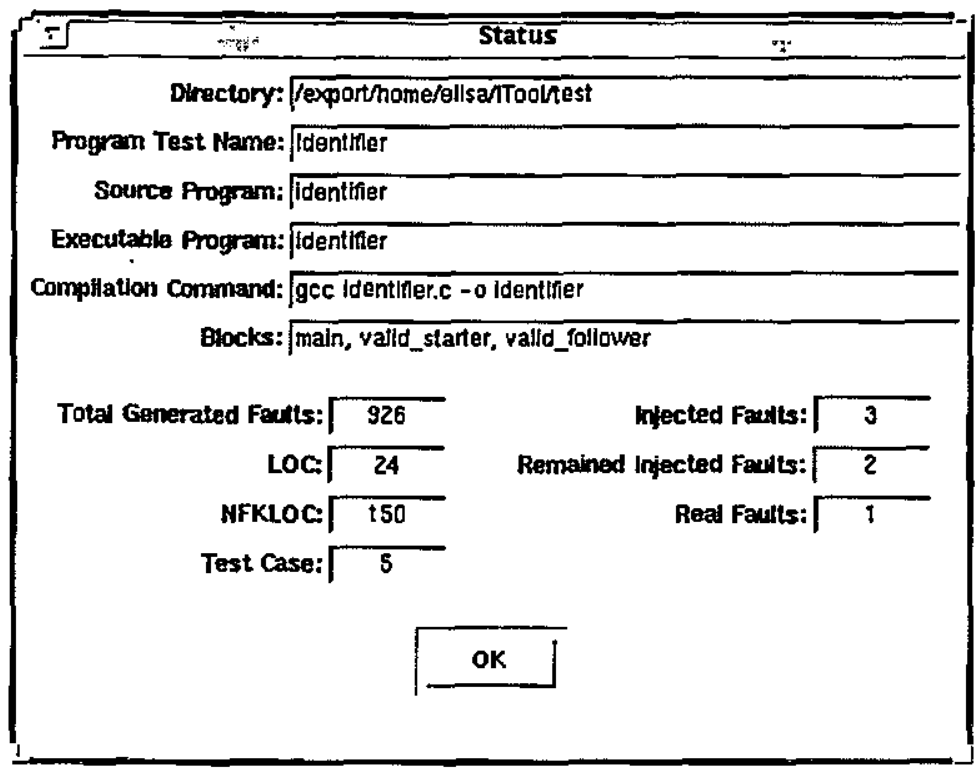

Figura 47: Visualizando Andamento do Teste 
Com essa informações, a ferramenta dá subsídios para a aplicação da ferramenta no contexto do critério Semeadura de Defeitos para estimar o número de defeitos remanescentes no software.

Se desejar continuar a avaliação, pode-se adicionar mais casos de teste, injetar defeitos utilizando outros modelos de defeitos, executar o programa e se possível localizar outros defeitos reais no programa.

Para sair da ferramenta ITool, terminado a execução de uma sessão de teste, ou então, em qualquer fase do andamento do teste, pressiona-se o botão Quit no menu da janela principal. A sessão de teste pode ser retomada, no estado em que foi interrompida, através da opção Load no menu ProgTest da janela principal.

\section{C.2. Módulos Funcionais}

Esta ferramenta também pode ser utilizada através de acesso direto aos módulos executáveis independentes via shell scripts.

A sequiência que foi mostrada acima para este exemplo, pode ser executada através de chamada dos seguintes módulos com os respectivos parâmetros mostrados a seguir.

\section{C.2.1. Criando uma Sessão de Teste}

Para criar uma nova sessão de teste, utiliza-se a sequiência de comandos mostrada abaixo. O módulo pteste cria arquivos com as informações gerais da sessão de teste, o módulo li gera a linguagem intermediária, o módulo li2nli acrescenta informaçðes na linguagem intermediária e cria o grafo do fluxo de controle do programa, o opmuta gera os defeitos utilizando-se os operadores de mutação e o fault manipula esses defeitos. Nessa fase, o tcase é utilizado para criar a base de dados de casos de teste.

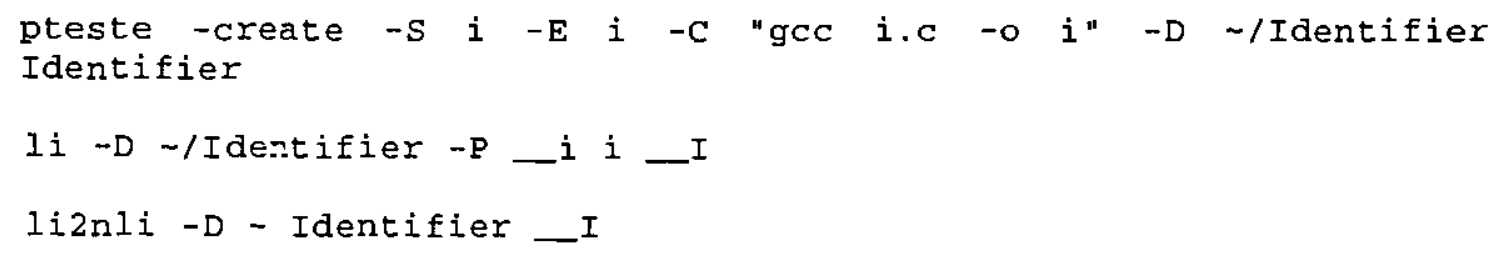




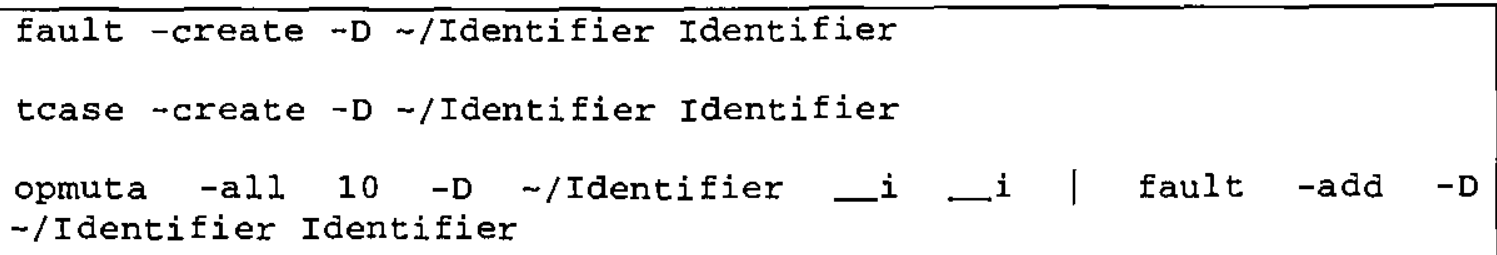

\section{C.2.2. Manipulando um Modelo de Defeitos}

Quando uma sessão de teste é manipulada através de chamadas aos módulos funcionais executáveis, a ativação/desativação de classes de defeitos e de operadores de mutação deve ser realizada através da edição do arquivo de modelo de defeitos Identifier.FLT - utilizando-se um editor de texto, como o texteditor, disponível no ambiente Solaris. O formato do arquivo do modelo de defeitos é brevemente apresentado na Seção 4.4.1.2. Formato do Arquivo do Modelo de Defeitos.

\section{C.2.3. Adicionando Casos de Teste}

A adição de casos de teste é possível através da utilização do módulo tcase e os parâmetros mostrados abaixo. Esse módulo executará o programa identifier, como mostrado na Figura 38, e armazenará as entradas e saídas na base de dados de casos de teste.

tcase -add $-D \sim /$ Identifier Identifier

\section{C.2.4. Injetando Defeitos}

A injeção dos defeitos é realizada através do programa inject e os parâmetros mostrados abaixo. Nessa tarefa, é necessário também fornecer o número de defeitos por linhas de código que se deseja injetar e o modelo de defeitos a ser utilizado.

inject -build -D $\sim /$ Identifier -MD \$ITOOLHOME/models $-M$ model.mdl $\rightarrow$ n 150 Identifier 
$O$ arquivo Identifier.FLT armazena os defeitos que foram injetados. Através desse arquivo é possível controlar a ativação/desativação dos defeitos, servindo como entrada para a reconstrução do programa com defeitos. Assim, após a edição do arquivo que armazena os defeitos injetados, a reconstrução do programa injetado é realizada pelo módulo inject e os parâmetros mostrados abaixo.

inject -rebuild $-\mathrm{D}-/$ Identifier $-E$ Identifier

A execução do programa com defeitos injetados utilizando os casos de teste pode ser realizada através do módulo inject com os parâmetros mostrados abaixo; este módulo permite selecionar os casos de teste que se deseja utilizar.

inject -exec $-\mathrm{f} 1$-t 2 -D $\sim$ /Identifier Identifier

\section{C.2.5. Visualizando Resultados}

Um relatório pode ser gerado através do comando abaixo utilizando o módulo report, o que permite acompanhar o andamento do teste.

report $-\mathrm{D} \sim /$ Identifier Identifier

Esses módulos possuem diversos outros parâmetros, que podem ser consultados no "Manual do Usuário da ITool - v. 1.0-C" [NAK98b]. 


\section{Apêndice D: Defeitos do Programa Space}

Neste apêndice são listados e descritos cada um dos 33 defeitos encontrados no programa Space pelos seus desenvolvedores.

\section{Defeito 1:}

Comando contendo defeito:

$$
\text { curr ptr }=\& p 1 \text {; }
$$

Correção:

$$
\text { * curr_ptr = p1; }
$$

\section{Defeito 2:}

Comando contendo defeito:

$$
\text { curr_ptr = \&pl; }
$$

Correçäo:

$$
\text { * curr_ptr }=\mathrm{p} 1 \text {; }
$$

\section{Defeito 3:}

Comando contendo defeito:

$$
\text { curr_ptr = tp; }
$$

Correção:

*curr_ptr $=* t p ;$

\section{Defeito 4:}

Comando contendo defeito: $\mathrm{pp} 2=$ curr_ptr;

Correção:

$$
{ }^{*} \mathrm{pp} 2={ }^{*} \text { curr_ptr; }
$$

\section{Defeito 5:}

Comando contendo defeito:

Correção:

$$
\mathrm{pp} 2=\text { curr_ptr; }
$$

${ }^{*} \mathrm{pp} 2={ }^{*} \mathrm{curr}$ _ptr;

\section{Defeito 6:}

Comando contendo defeito:

Correção:

$$
t p=\text { curr_ptr; }
$$

$$
{ }^{*} t p={ }^{*} \text { curr_ptri }
$$

\section{Defeito 7:}

Comando contendo defeito:

$$
\begin{aligned}
& a=\left(\left(p 1 \_e t+p 2 \_e t-2 * e\right) /(2 * x 1 * x 1)\right) ; \\
& c=\left(\left\{a^{*} \times 1 * \times 1+e-p 1 \text { et }\right) / \times 1\right) \text {; } \\
& b=\left(\left(q 1 \text { et }+q 2 \_e t-2^{*} e\right) /\left(2^{*} y 1^{*} y 1\right)\right) ; \\
& a=\left(\left(b^{*} y 1^{*} y 1+e-q 1_{\text {_et }}\right) / y 1\right) \text {; }
\end{aligned}
$$


Correção:

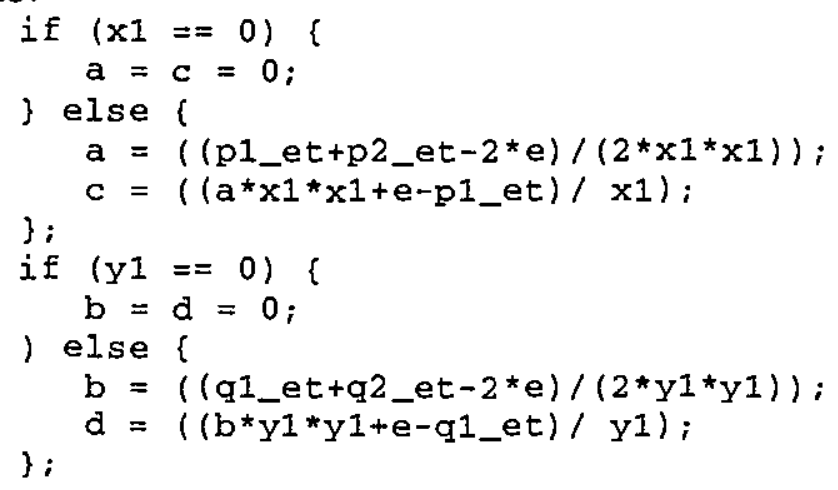

\section{Defeito 8:}

Comando contendo defeito:

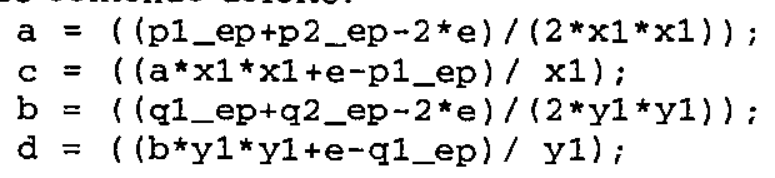

Correção:

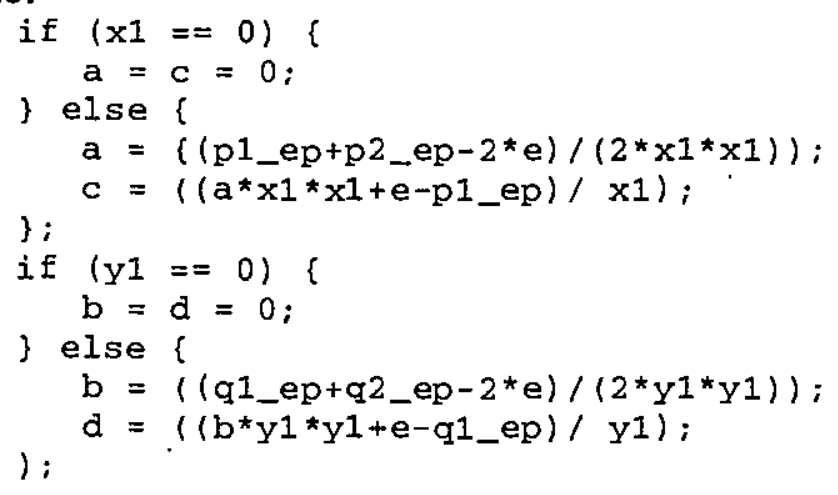

\section{Defeito 9:}

Comando contendo defeito:

$$
\begin{aligned}
& x=p^{*} \text { pstep }+q^{*} \text { qstep }{ }^{*} \cos (\text { angle); } \\
& y=q^{*} \text { qstep }{ }^{*} \sin (\text { angle }) ;
\end{aligned}
$$

Correção:

$$
\begin{aligned}
& y=q^{*} \text { qstep }{ }^{\star} d \sin (\text { angle }) ; \\
& x=p^{*} \text { pstep }+q^{\star} \text { qstep }{ }^{\star} \text { dcos (angle); }
\end{aligned}
$$

\section{Defeito 10:}

Comando contendo defeito:

Correção:

$$
\begin{aligned}
& x=P[i]^{*} \text { pstep }+Q[i]^{*} \text { qstep*cos (angle); } \\
& y=Q[i]^{*} \text { qstep*sin(angle); }
\end{aligned}
$$

$$
\begin{aligned}
& x=P[i]^{*} \text { pstep }+Q[i]^{*} \text { qstep*dcos (angle); } \\
& y=Q[i]^{*} \text { qstep*dsin(angle); }
\end{aligned}
$$




\section{Defeito 11:}

Comando contendo defeito:

$$
\begin{aligned}
& x=p^{*} \text { pstep }+q^{*} \text { qstep }{ }^{*} \cos (\text { angle) } \\
& y=q^{*} \text { qstep }{ }^{*} \sin (\text { angle }) ;
\end{aligned}
$$

Correção:

$$
\begin{aligned}
& x=p^{*} \text { pstep }+q^{*} \text { qstep*dcos (angle); } \\
& y=q^{*} \text { qstep*dsin (angle) }
\end{aligned}
$$

\section{Defeito 12:}

Comando contendo defeito:

Correção:

$$
\begin{aligned}
& X E=((X D-X C) * \cos (p h i))-((Y D-Y C) * \sin (p h i))+X C ; \\
& Y E=((X D-X C) * \sin (p h i))+((Y D-Y C) * \cos (p h i))+Y C ;
\end{aligned}
$$

$$
\begin{aligned}
& X E=((X D-X C) * d \cos (p h i))-((Y D-Y C) * d \sin (p h i))+X C ; \\
& Y E=((X D-X C) * d \sin (p h i))+((Y D-Y C) * d \cos (p h i))+Y C ;
\end{aligned}
$$

\section{Defeito 13:}

Comando contendo defeito:

$$
\text { qstep }=2 \text { * radius } * 2 * \cos (\text { angle) } ;
$$

Correção:

$$
\text { qstep }=2 \text { * radius *2* dcos (angle); }
$$

Comando contendo defeito:

Correção:

$$
\text { angle }=\operatorname{atan}\left(\left(2^{*} \text { qdim }\right) /(\text { pdim })\right) ;
$$

$$
\text { angle }=\operatorname{datan}((2 * q d i m) /(\operatorname{pdim})) \text {; }
$$

Comando contendo defeito:

Correção:

$$
\text { pstep }=\text { pdim; qstep }=(\text { qdim }) /(\sin (\text { angle })) \text {; }
$$

$$
\text { pstep }=\text { pdim; qstep }=(\text { qdim }) /(\text { dsin }(\text { angle })) ;
$$

Comando contendo defeito:

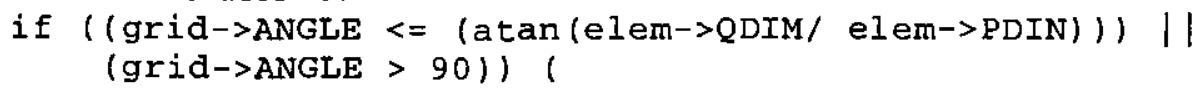

Correçäo:

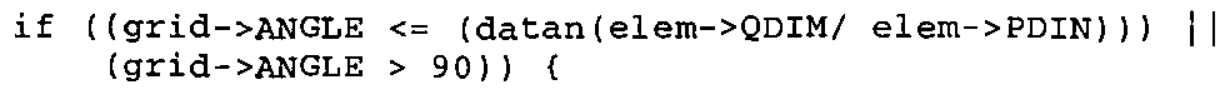

\section{Defeito 14:}

Comando contendo defeito:

GetKeyword (Keywords [88], curr_ptr);

Correção:

$$
\text { error }=(\text { GetKeyword (Keywords }[88] \text {, curr_ptr)); }
$$

\section{Defeito 15:}

Comando contendo defeito:

GetKeyword (Keywords[88], curr_ptr); Correção: 
error $=($ Getkeyword (Keywords $[88]$, curr_ptr) $)$;

\section{Defeito 16:}

Comando contendo defeito:

Correção:

$$
\text { (gnode_ptr->GEOMPORT_PTR) }->\text { PPA }+=\text { phase; }
$$

(gnode_ptr->GEOMPORT_PTR) $->$ PPA = phase $;$

Comando contendo defeito, se defeito 27 está presente:

(group_ptr $->E L E M \_P T R$ ) $\rightarrow$ PORT_PTR $->$ PPA $=$

Correção:

$$
\text { (geomnode_app_ptr->GEOMPORT_PTR) ->PPA; }
$$

$$
\begin{aligned}
& \text { (group_ptr->ELEM_PTR) }->\text { PORT_PTR }->\text { PPA }+= \\
& \text { (geomnode_app_ptr } \rightarrow>\text { GEOMPORT_PTR) } \rightarrow>\text { PPA; }
\end{aligned}
$$

Comando contendo defeito, se defeito 27 não está presente:

(geomnode_app_ptr->GEOMPORT_PTR) $\rightarrow$ PPA $=$

Correção:

$$
\text { (group_ptr->ELEM_PTR) } \rightarrow \text { PORT_PTR } \rightarrow \text { PPA ; }
$$

$$
\begin{aligned}
& \text { (geomnode_app_ptr->GEOMPORT_PTR) }->\text { PPA }+= \\
& \text { (group_ptr->ELEM_PTR) }->\text { PORT_PTR }->\text { PPA; }
\end{aligned}
$$

\section{Defeito 17:}

Correção (inclusão do comando):

$$
\text { port_ptr->OMIT_POL }=1 \text {; }
$$

\section{Defeito 18:}

Comando contendo defeito:

Correção:

$$
\text { app_ptr->PSEA }+=\text { phi; }
$$

$$
\text { app_ptr->PHEA }+=\text { phi; }
$$

\section{Defeito 19:}

Correção (eliminação do trecho de comandos):

$$
\begin{aligned}
& \text { if ( } \text { (group_ptr->ELEM_PTR) }>\text { POLARIZATION } !=0 \text { ) } \\
& \text { return } 0 \text {; }
\end{aligned}
$$

\section{Defeito 20:}

Comando contendo defeito:

Correção:

$$
\text { can = angle_step; }
$$

$$
\text { can += angle_step; }
$$

\section{Defeito 21:}

Comando contendo defeito:

$\mathrm{cph}=$ phase_step;

Correção:

$$
\text { cph += phase_step: }
$$




\section{Defeito 22:}

Correção (inclusão dos comandos):

OBS: o bloco de comando do ramo else, indicado por “..." abaixo, é parte do programa original, com o defeito.

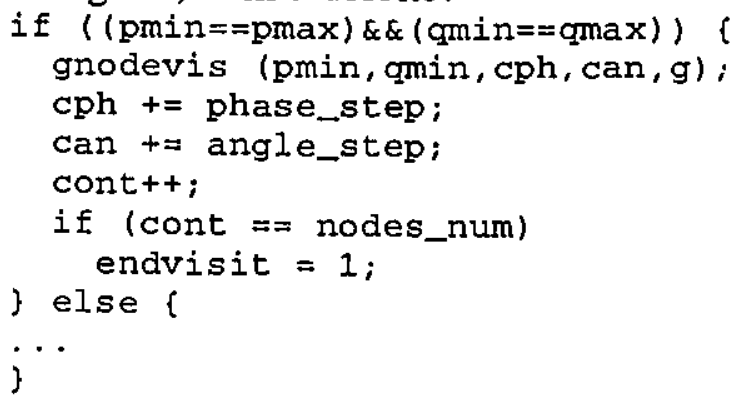

\section{Defeito 23:}

Comando contendo defeito:

Correção:

while (app_ptr $\rightarrow$ NEXT $!=(($ void*) 0$))$ (

while (app_ptr $\left.!=\left(\left(\operatorname{voi} d^{\star}\right) 0\right)\right)($

\section{Defeito 24:}

Correção (inclusão do trecho de comandos):

OBS: os blocos de comandos do ramo else, indicado por “..." abaixo, são partes do programa original, com o defeito.

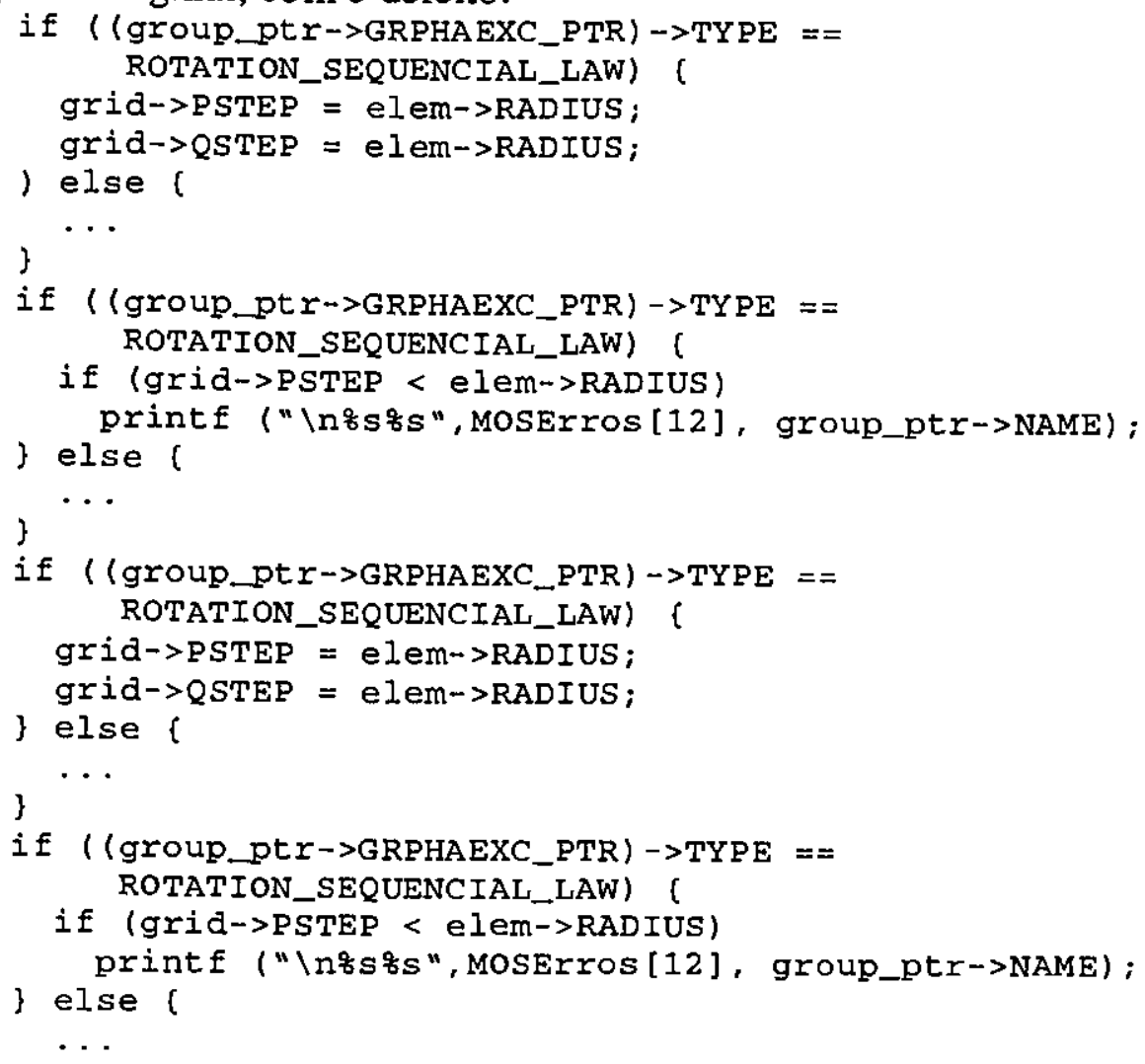


Defeito 25:

\}

Comando contendo defeito:

Correção:

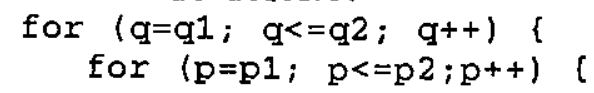

\section{Defeito 26:}

Comando contendo defeito:

Correção:

$$
\text { ultimo_ptr }=(\text { (void } *) \text { ) ; }
$$

ultimo_ptr->NEXT $=(($ void $*) 0)$;

\section{Defeito 27:}

Comando contendo defeito, se defeito 16 está presente:

(group_ptr->ELEM_PTR) $\rightarrow$ PORT_PTR $>$ PSH $=$

(geomnode_app_ptr->GEOMPORT_PTR) $\rightarrow$ PSH ;

(group_ptr->ELEM_PTR) $\rightarrow>$ PORT_PTR $\rightarrow$ PSC $=$

(geomnode_app_ptr $\rightarrow$ GEOMPORT_PTR) $>>$ PSC ;

(group_ptr->ELEM_PTR) $\rightarrow$ PORT_PTR $>$ PPA $=$

Correção:

(geomnode_app_ptr->GEOMPORT_PTR) ->PPA ;

$$
\begin{aligned}
& \text { (geomnode_app_ptr } \rightarrow>\text { GEOMPORT_PTR) }->\text { PSH }= \\
& \text { (group_ptr->ELEM_PTR) ->PORT_PTR->PSH ; } \\
& \text { (geomnode_app_ptr }->\text { GEOMPORT_PTR) }->\text { PSC }= \\
& \text { (group_ptr->ELEM_PTR) ->PORT_PTR->PSC; } \\
& \text { (group_ptr->ELEM_PTR) } \rightarrow>\text { PORT_PTR->PPA; }
\end{aligned}
$$

Comando contendo defeito, se defeito 16 está presente:

(group_ptr->ELEM_PTR) $>$ PORT_PTR->PSH = (geomnode_app_ptr->GEOMPORT_PTR) $>$ PSH ;

(group_ptr->ELEM_PTR) $->$ PORT_PTR->PSC = (geomnode_app_ptr $->$ GEOMPORT_PTR) $->$ PSC ;

(group_ptr $\rightarrow$ ELEM_PTR) $\rightarrow>$ PORT_PTR $\rightarrow$ PPA $=$

Correção:

(geomnode_app_ptr $\rightarrow$ GEOMPORT_PTR) $>>$ PPA ;

$$
\begin{gathered}
\text { (geomnode_app_ptr->GEOMPORT_PTR) ->PSH = } \\
\text { (group_ptr->ELEM_PTR) ->PORT_PTR->PSH; } \\
\text { (geomnode_app_ptr->GEOMPORT_PTR) ->PSC = } \\
\text { (group_ptr->ELEM_PTR) ->PORT_PTR->PSC; } \\
\text { (geomnode_app_ptr->GEOMPORT_PTR) ->PRA = } \\
\text { (group_ptr->ELEM_PTR) ->PORT_PTR->PPA; }
\end{gathered}
$$

\section{Defeito 28:}

Comando contendo defeito:

app_ptraddrem_ptr;

Correção:

$$
\text { *app_ptr=*adarem_ptr; }
$$




\section{Defeito 29:}

Comando contendo defeito:

$$
\begin{array}{ll}
\text { strcpy (Keywords [84], "P1_ET"); } \\
\text { strcpy (Keywords [85], "P2_ET"); } \\
\text { strcpy (Keywords [86], "Q1_ET"); } \\
\text { strcpy (Keywords [87], "O2_ET"); }
\end{array}
$$

Correção:

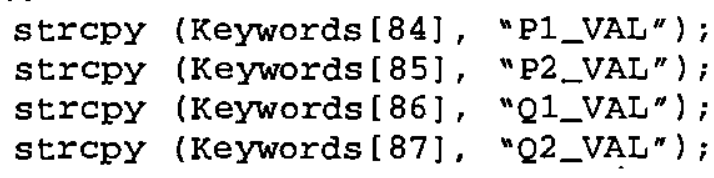

Comando contendo defeito:

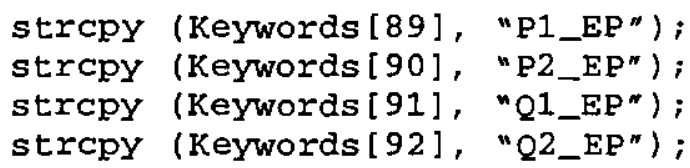

Correção:

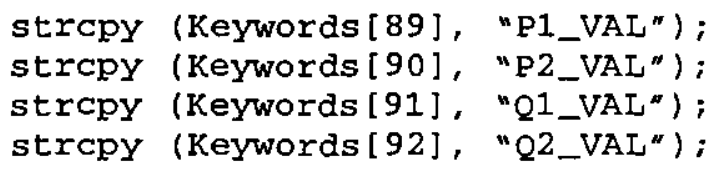

Defeito 30:

Comando contendo defeito: addrem_ptr $=(($ void $*)$ 0);

Correção:

$$
\text { *addrem_ptr }=((\text { void *) } 0) \text {; }
$$

\section{Defeito 31:}

Comando contendo defeito:

$$
\text { if (error } !=0 \text { ) ( }
$$

Correção:

$$
\text { if (error }==17)(
$$

\section{Defeito 32:}

Correção (consiste na troca de posição do comando abaixo):

$$
g^{->P H A S E} \text { UNIT }=0 \text {; }
$$

\section{Defeito 33:}

Comando contendo defeito:

Correção:

$$
\text { gnode_ptr->PHEA = angle; }
$$

$$
\text { gnode_ptr->PHEA }+=\text { angle; }
$$

